\author{
Universidade de São Paulo \\ Instituto de Astronomia, Geofísica e Ciências Atmosféricas
}

Departamento de Ciências Atmosféricas

Gláuber Camponogara

\title{
Extremos de precipitação diária em Belém, Pará, e estrutura vertical da atmosfera
}



Gláuber Camponogara

\section{Extremos de precipitação diária em Belém, Pará, e estrutura vertical da atmosfera}

Dissertação apresentada ao Departamento de Ciências Atmosféricas do Instituto de Astronomia, Geofísica e Ciências Atmosféricas da Universidade de São Paulo como requisito parcial para obtenção do título de Mestre em Ciências.

Versão corrigida. O original encontra-se disponível na unidade.

Área de Concentração: Meteorologia

Orientadora: Prof ${ }^{\mathrm{a}}$. Dr ${ }^{\mathrm{a}}$. Maria Assunção Faus da Silva Dias

São Paulo 

À minha família, alicerce de tudo que sou. 



\section{AGRADECIMENTOS}

À minha orientadora, Profa ${ }^{a}$ Dr ${ }^{a}$. Maria Assunção Faus da Silva Dias, pelo apoio intelectual no projeto de pesquisa.

Aos meu pais, Luiz e Ivani Camponogara, e meus irmãos, Ândrei e Douglas Camponogara, por todo apoio, carinho e dedicação ao longo da minha vida.

À minha namorada e grande mulher, Carol, por toda a ajuda, atenção e companheirismo durante o mestrado.

Aos membros da banca do Exame de Qualificação do mestrado, Profs. Drs. Augusto José Pereira Filho e Rita Yuri Ynoue, pelas sugestões e críticas construtivas para o desenvolvimento deste trabalho.

Ao Laboratório MASTER (IAG/USP), em especial ao Bruno e ao Jean, por todo suporte com o modelo BRAMS, desde a instalação ao ajuste ideal, e pela disponibilidade dos dados.

Aos Profs. Drs. Adilson Wagner Gandu, Edmilson Dias de Freitas e Ricardo de Camargo (IAG/USP) e ao Dr. Ricardo Hallak (IAG/USP) pelas preciosas dicas e sugestões com relação ao BRAMS.

Ao Prof. Dr. Carlos Frederico Mendonça Raupp pelas valiosas sugestões na análise espacial dos dados.

Aos colegas Cris, Helber e Bruce pela contribuição com as análises sinóticas.

Aos colegas, Jônatan e Carlos, pelas dicas e sugestões com relação ao software R.

Ao meu grande amigo, Rafael, pelo apoio e companhia desde o início da graduação.

Aos meus amigos pela parceria nos trabalhos referentes às disciplinas do mestrado e pelo contínuo apoio após o término das mesmas.

Ao IAG/USP (Instituto de Astronomia, Geofísica e Ciências Atmosféricas da Universidade de São Paulo) pela oportunidade de realização do curso de mestrado.

À Coordenação de Aperfeiçoamento de Pessoal de Nível Superior (CAPES), pelo apoio financeiro durante o desenvolvimento projeto de pesquisa. 

"Para os crentes, Deus está no princípio das coisas. Para os cientistas, no final de toda a reflexão." 



\section{RESUMO}

CAMPONOGARA, G. Extremos de precipitação diária em Belém, Pará, e estrutura vertical da atmosfera. 2012. 90 f. Dissertação (Mestrado em Meteorologia) Instituto de Astronomia, Geofísica e Ciências Atmosféricas, Universidade de São Paulo, São Paulo, 2012.

Diversas atividades ligadas ao gerenciamento de recursos hídricos necessitam da previsão de acumulados diários de chuva extremos. Entretanto, grande parte dos modelos utilizados operacionalmente apresentam uma tendência a subestimar os extremos de precipitação mesmo com apenas 24 horas de antecedência. Existem diversas razões para esse tipo de erro de previsão tais como, limitações nas parametrizações de convecção para modelos com resolução de dezenas de quilômetros e a não inclusão do efeito de aerossóis como núcleos de condensação de gotas de nuvens nos modelos de grande escala. Dentro desse contexto, este trabalho tem como objetivo analisar situações de eventos extremos de precipitação na região de Belém, Pará, onde o regime de precipitação é modulado, principalmente, pela brisa marítima, linhas de instabilidade, distúrbios ondulatório de leste, zona de convergência intertropical, alta da Bolívia e Vórtices Ciclônicos de Altos Níveis (VCAN). A abordagem será de identificação de perfis verticais cinemáticos e termodinâmicos típicos de eventos extremos de precipitação diária em Belém, Pará. Para esse fim, escolheuse fazer uma análise de dados de radiossondagem e precipitação utilizando as Funções Ortogonais Empíricas (EOF - Empirical Orthogonal Functions) combinadas e verificar como o Brazilian developments on the Regional Atmospheric Modeling System (BRAMS) simula características básicas de chuva acumulada diária. A variância explicada das EOF calculadas a partir do conjunto de variáveis acumulado diário de precipitação (acpcp), temperatura $(t)$, razão de mistura de vapor d'água $\left(r_{v}\right)$, vento zonal $(u)$ e vento meridional $(v)$ e acpcp, $u$ e $v$ apresentaram valores de variância explicada baixos em relação as EOF calculadas a partir de acpcp e $u$ somente. A terceira $\operatorname{EOF}\left(e_{3}\right)$ foi a que melhor identificou os extremos chuvosos em relação a primeira e segunda. Observou-se padrões sinóticos favoráveis à convecção para os dias relativos à acumulados de chuva acima da média e menos favoráveis para os dias relativos à acumulados de chuva abaixo da média. Nos dias que apresentaram os maiores acumulados de chuva identificados por $e_{3}$ verificou-se a presença da Alta da Bolívia e de um VCAN sobre o Oceano Atlântico influenciando a região de estudo. Observou-se um caso de uma linha de instabilidade que adentrou o continente associada a um jato de baixos níveis e outro caso de uma perturbação de latitudes médias, ambos os casos ocasionaram acumulados de chuva acima da média. A previsão de 24 horas do BRAMS apresentou máximos e mínimos de anomalias de acpcp coincidentes com os dados observados. Os dias relativos à acumulados de chuva acima da média apresentaram correntes ascendentes e descendentes mais intensas que os dias relativos à acumulados de chuva abaixo da média. Observou-se máximos de correntes ascendentes associados a formação de novas células convectivas.

Palavras-chave: trópicos, precipitação, EOF, BRAMS, perfis verticais cinemáticos. 



\begin{abstract}
CAMPONOGARA, G. Extreme daily rainfall in Belém, Pará, and vertical structure of atmosphere. São Paulo: Institute of Astronomy, Geophysics and Atmospheric Sciences, University of São Paulo, 2012, 90 p. Masters Dissertation in Meteorology.

Several activities related to water management need the forecasting of cumulative daily rainfall extreme. However, most of the models used operacionaly tend to underestimate the extreme rainfall even with 24 hours of advance. There are several reasons for this type of forecast error such as, limitations in convection parametrizations for models with resolution of tens of kilometers and not inclusion of the effect of aerosols as cloud condensation nuclei for cloud droplets in large-scale models. Withing this context, this study aims to analyze situations of extreme precipitation events in the region of Belém, Pará, where the rainfall regime is modulated mainly by sea breeze, squall lines, easterly wave disturbances, intertropical convergence zone, Bolivian high and cyclonic vortices of high levels (VCAN). The approach will be to identify kinematic and thermodynamics vertical profiles typical of extreme daily rainfall events in Belém, Pará. To this end, it was chosen to analyze sounding and rainfall data using the combined Empirical Orthogonal Functions (EOF) and verify how the Brazilian developments on the Regional Atmospheric Modeling System (BRAMS) simulates the basic features of daily accumulated rainfall. The explained variance of EOF calculated from the set of variables accumulated daily precipitation $\left(\right.$ acpcp), temperature $(t)$, mixing ratio of water vapor $\left(r_{v}\right)$, zonal wind $(u)$ e meridional wind $(v)$ and acpcp, $u$ and $v$ showed low values of explained variance in relation to the EOF calculated from acpcp and $u$ only. The third EOF $\left(e_{3}\right)$ was the best in the identification of extreme rainfall compared to first and second. Observed synoptic patterns are favorable to convection on days with accumulated rainfall above average and less favorable on days for accumulated rainfall below average. In the days that had the highest accumulated rainfall identified by $e_{3}$, it was verified that the presence of the Bolivian high and a VCAN on the Atlantic Ocean influence the study region. A case of squall line that entered the continent associated with a low level jet and other case of disturbance of midlatitudes, resulted in accumulated rainfall above average. The BRAMS 24h-simulation presented maximum and minimum aсрсp anomalies coincident with the observed data. The days on the accumulated rainfall above average showed more intense updrafts and downdrafts that the days on the accumulated rainfall below average. Observed maximum updrafts associated with the formation of new convective cells.
\end{abstract}

Keywords: tropics, rainfall, EOF, BRAMS, kinematic vertical profiles. 



\section{LISTA DE FIGURAS}

1 Dados de comparação de viés (Previsão/Observação) para a previsão com 24 horas de antecedência para diversos modelos operacionais (http:// avaliacaodemodelos.cptec.inpe.br/obs/qpf/phps/index.php). . . . . 27

2 Normal climatológica da (a) umidade relativa e temperatura média e da (b) precipitação para Belém. Fonte: Instituto Nacional de Meteorologia INMET . . . . . . . . . . . . . . . . . . . . . . 28

3 Esquema de como ocorre a formação de um ciclone subtropical a $200 \mathrm{hPa}$ sobre o Atlântico Sul (KOUSKY; GAN, 1981) . . . . . . . . . . . . . . . . 34

4 Grades aninhadas e centradas em Belém, utilizadas nas simulações com o BRAMS . . . . . . . . . . . . . . . . . . . . . 41

5 Perfil vertical dos três primeiros autovetores do vento zonal de cada período do ano. . . . . . . . . . . . . . . . . . . . . . . . 48

6 Série dos coeficientes de expansão de $e_{1}$ para os dias que o TRMM registrou chuva em cada período do ano. . . . . . . . . . . . . . . . . . . . . 49

7 Série dos coeficientes de expansão de $e_{2}$ para os dias que o TRMM registrou chuva em cada período do ano. . . . . . . . . . . . . . . . . 50

8 Série dos coeficientes de expansão de $e_{3}$ para os dias que o TRMM registrou chuva em cada período do ano. . . . . . . . . . . . . . . . . . 51

9 Perfil vertical dos três primeiros autovetores do vento zonal de cada período do ano para a série dos coeficientes de expansão negativos. . . . . . . . . . . 53

10 Histogramas de frequência do acumulado diário de chuva para $[C]_{+10 \%}$. . . 55

11 Histogramas de frequência do acumulado diário de chuva para $[C]_{-10 \%}$. . . 56

12 Histogramas bidimensionais de frequência do vento zonal $(\mathrm{m} / \mathrm{s})$ para $[C]_{+10 \%}^{e_{3}}$ em (a) JAS, (b) OND, (c) JFM e (d) AMJ. . . . . . . . . . . . . . . 57

13 Histogramas bidimensionais de frequência do vento zonal $(\mathrm{m} / \mathrm{s})$ para $[C]_{-10 \%}^{e_{3}}$ em (a) JAS, (b) OND, (c) JFM e (d) AMJ. . . . . . . . . . . . . . . . . 58 
14 Histogramas de frequência de CAPE para $[C]_{+10 \%}^{e_{3}} \ldots \ldots \ldots \ldots$

15 Histogramas de frequência de CAPE para $[C]_{-10 \%}^{e_{3}} \ldots \ldots \ldots \ldots$. . . . . . 61

16 Histogramas de frequência de CINE para $[C]_{+10 \%}^{e_{3}} \ldots \ldots \ldots$. . . . . . . 62

17 Histogramas de frequência de CINE para $[C]_{-10 \%}^{e_{3}} \ldots \ldots \ldots . \ldots . \ldots 6$

18 Histogramas de frequência de CISZ para $[C]_{+10 \%}^{e_{3}}$. . . . . . . . . . . 64

19 Histogramas de frequência de CISZ para $[C]_{-10 \%}^{e_{3}} \ldots \ldots \ldots . \ldots . \ldots 6$

20 Campos de linhas de corrente e divergência do vento (sombreado) em $10^{-6}$ $\mathrm{s}^{-1}$ para 16/01/2004 às 12 UTC em (a) 1000, (b) 500 e (c) 200 hPa. . . . . 69

21 Imagens do satélite GOES 12 realçadas no canal do infravermelho para 16/01/2004 para os horários das (a) 17:45, (b) 19:45, (c) 20:45 e (d) 21:45 UTC. . . . . . . . . . . . . . . . . . 70

22 Campos de linhas de corrente e divergência do vento (sombreado) em $10^{-6}$ $\mathrm{s}^{-1}$ para 09/04/2009 às 12 UTC em (a) 1000, (b) 500 e (c) $200 \mathrm{hPa}$. . . . . 72

23 Imagens do satélite GOES 12 realçadas no canal do infravermelho para 09/04/2009 para os horários das (a) 18:45, (b) 19:45, (c) 20:45, (d) 22:45 e (e) $23: 45$ UTC . . . . . . . . . . . . . . . . . . . . . . . . 73

24 Hodógrafa de Belém para o dia 09/04/2009 às 12 UTC. . . . . . . . . . . . 74

25 Campos de linhas de corrente e divergência do vento (sombreado) em $10^{-6}$ $\mathrm{s}^{-1}$ para 22/08/2007 às 12 UTC em (a) 1000, (b) 700 e (c) $200 \mathrm{hPa}$. . . . 75

26 Imagens do satélite GOES 12 realçadas no canal do infravermelho a partir de 22/08/2007 para os horários das (a) 19:45, (b) 20:45, (c) 01:45, (d) 03:45, (e) $06: 45$ e (f) 14:45 UTC . . . . . . . . . . . . . . . . . . . . 76

27 Perfil vertical do vento zonal (m/s) para o dia 22/08/2007 às 12 UTC. . . . 77

28 Campos de linhas de corrente e divergência do vento (sombreado) em $10^{-6}$ $\mathrm{s}^{-1}$ a parir de 04/12/2009 às (a) 12 e (b) 00 UTC em 850 hPa e às (c) 12 e (d) 00 UTC em $200 \mathrm{hPa} \ldots \ldots \ldots$. . . . . . . . . . . . . . 78

29 Imagens do satélite GOES 12 realçadas no canal do infravermelho a partir de 04/12/2009 para os horários das (a) 11:45, (b) 17:45, (c) 23:45, (d) 03:45 UTC. . . . . . . . . . . . . . . . . . . . 79 
30 Campos de linhas de corrente e divergência do vento (sombreado) em $10^{-6}$ $\mathrm{s}^{-1}$ para 04/01/2005 às 12 UTC em (a) 1000, (b) 500 e (c) 200 hPa. . . . . 81

31 Imagens do satélite GOES 12 realçadas no canal do infravermelho para 04/01/2005 para os horários das (a) 18:45, (b) 19:45, (c) 20:45 e (d) 21:45 UTC. . . . . . . . . . . . . . . . . . . . . 82

32 Campos de linhas de corrente e divergência do vento (sombreado) em $10^{-6}$ $\mathrm{s}^{-1}$ para 01/06/2007 às 12 UTC em (a) 1000 e (b) $200 \mathrm{hPa}$. . . . . . . . . 83

33 Imagens do satélite GOES 12 realçadas no canal do infravermelho para 01/06/2007 para os horários das (a) 15:45, (b) 16:45, (c) 20:45 e (d) 23:45 UTC. . . . . . . . . . . . . . . . . . . . 84

34 Campos de linhas de corrente e divergência do vento (sombreado) em $10^{-6}$ $\mathrm{s}^{-1}$ a partir de 16/08/2007 às (a) 12 e (b) 00 UTC em 1000 hPa e às (c) 12 e (d) 00 UTC em 500 hPa. . . . . . . . . . . . . . . 86

35 Imagens do satélite GOES 12 realçadas no canal do infravermelho para 17/08/2007 para os horários das (a) 04:15 e (b) 07:15 UTC. . . . . . . . . 87

36 Campos de linhas de corrente e divergência do vento (sombreado) em $10^{-6}$ $\mathrm{s}^{-1}$ para 03/10/2007 às $12 \mathrm{UTC}$ em (a) 1000, (b) 500 e (c) $200 \mathrm{hPa}$. . . . 88

37 Imagens do satélite GOES 12 realçadas no canal do infravermelho para 03/10/2007 para os horários das (a) 15:45, (b) 16:45, (c) 20:45 e (d) 23:45 UTC.

38 Acumulado de chuva total da grade 4 para os dias em que o coeficiente de expansão é máximo (a) positivo e (b) negativo.

39 Acumulado diário de precipitação observado e simulado normalizados para os casos identificados por $e_{3} \ldots \ldots \ldots$. . . . . . . . . . . . . . . . 91

40 Velocidade vertical positiva máxima a 1992,4 m da grade 4 para os dias em que o coeficiente de expansão é máximo (a) positivo e (b) negativo. . . . . . 92

41 Velocidade vertical negativa máxima a 535,6 m da grade 4 para os dias em que o coeficiente de expansão é máximo (a) positivo e (b) negativo. . . . . 93 
42 Somatório das razões de mistura de água líquida e gelo de nuvem totais da grade 4 em cada nível vertical e passo de tempo para os dias em que o coeficiente de expansão é máximo positivo em (a) JAS, (b) OND, (c) JFM e $(\mathrm{d})$ AMJ. . . . . . . . . . . . . . . . . . . . . . . . . . . 94

43 Somatório das razões de mistura de água líquida e gelo de nuvem totais da grade 4 em cada nível vertical e passo de tempo para os dias em que o coeficiente de expansão é máximo negativo em (a) JAS, (b) OND, (c) JFM

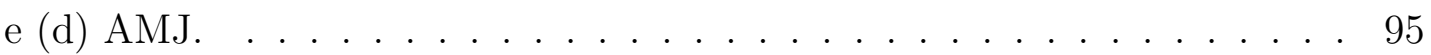




\section{LISTA DE TABELAS}

1 Principais opções utilizadas na inicialização do BRAMS. . . . . . . . . . . 42

2 Principais opções utilizadas na inicialização do BRAMS para cada grade. . 43

3 Quantis de 95\% dos acumulados diários de chuva para cada período do ano em Belém. . . . . . . . . . . . . . . . . . . . . 45

4 Variação explicada para os três primeiros autovalores e seus somatórios para cada matriz de dados gerada. . . . . . . . . . . . . . . . . . . . . . 46

5 Três primeiros autovetores da precipitação para cada período do ano. . . . 46

6 Três primeiros autovetores da precipitação de cada período do ano para a série de coeficientes de expansão negativos. . . . . . . . . . . . . . . . . . 52

$7 \quad$ Acumulado de chuva total de cada período do ano para $[C]_{+10 \%} \ldots \ldots$. . . . 54

8 Acumulado de chuva total de cada período do ano para $[C]_{-10 \%} \ldots \ldots$. . . . 54

9 Frequência de eventos com CISZ entre $-1 \times 10^{-3} \mathrm{~s}^{-1}$ e $1 \times 10^{-3} \mathrm{~s}^{-1}$ para $[C]_{+10 \%}^{e_{3}}$ e $[C]_{-10 \%}^{e_{3}}$ em cada período de dados. . . . . . . . . . . . . . 66

10 Frequência de eventos com CISZ positivo para $[C]_{+10 \%}^{e_{3}}$ em cada período de dados. . . . . . . . . . . . . . . . . . 66

11 Frequência de eventos com CISZ positivo para $[C]_{-10 \%}^{e_{3}}$ em cada período de dados. . . . . . . . . . . . . . . . . . 66

12 Acumulado diário de chuva de cada período do ano para os dias com coeficiente de expansão máximo. . . . . . . . . . . . . . . . . . . . . . . 68

13 Acumulado diário de chuva de cada período do ano para os dias com coeficiente de expansão mínimo ou máximo negativo. . . . . . . . . . . . . . . 68 



\section{LISTA DE ABREVIATURAS E SIGLAS}

\begin{tabular}{|c|c|c|}
\hline $\mathrm{AB}$ & - & Alta da Bolívia \\
\hline AMJ & - & Abril, Maio e Junho \\
\hline BRAMS & - & Brazilian developments on the Regionl Atmospheric Modeling System \\
\hline CAPE & - & Convective Available Ponticial Energy \\
\hline CATT & - & Coupled Aerosol and Tracer Transport model \\
\hline $\mathrm{CCN}$ & - & Cloud Condensation Nuclei \\
\hline CINE & - & Convective Inhibition Energy) \\
\hline CISL & - & Computional and Information Systems Laboratory \\
\hline CISZ & - & Cisalhamento do vento zonal entre os níveis de 500 e $1000 \mathrm{hPa}$ \\
\hline CPTEC & - & Centro de Previsão do Tempo e Estudos Climáticos \\
\hline DOL & - & Distúrbio Ondulatório de Leste \\
\hline ECMWF & - & European Centre for Medium-Range Weather Forecasts \\
\hline EOF & - & Empirical Orthogonal Functions \\
\hline FINEP & - & Financiadora de Estudos e Projetos \\
\hline GFS & - & Global Forecast System \\
\hline GOES & - & Geostationary Operational Environmental Satellite \\
\hline INMET & - & Instituto Nacional de Meteorologia \\
\hline INPE & - & Instituto Nacional de Pesquisas Espaciais \\
\hline JAS & - & Julho, Agosto e Setembro \\
\hline JFM & - & Janeiro, Fevereiro e Março \\
\hline LAPACK & - & Linear Algebra PACKage \\
\hline LEAF & - & Land Ecosystem-Atmosphere Feedback \\
\hline LIA & - & Linhas de instabilidade que adentram a Amazônia \\
\hline LIC & - & Linhas de instabilidade costeiras \\
\hline LST & - & Local Standard Time \\
\hline MASTER & - & laboratório de Meteorologia Aplicada a Sistemas de Tempo Regionais \\
\hline NCAR & - & National Center for Atmospheric Research \\
\hline NCEP & - & National Centers for Environmental Prediction \\
\hline NCL & - & Nível de Condensação por Levantamento \\
\hline
\end{tabular}


NDVI - Normalized Difference Vegetation Index

NNE $\quad-\quad$ Norte do Nordeste do Brasil

OND - Outubro, Novembro e Dezembro

RAMS - Regional Atmospheric Modeling System

SPM - Simple Photochemical Module

TEB - Town Energy Budget

TRMM - Tropical Rainfall Measurement Mission Project

TSM - Temperatura da superfície do mar

UTC - Coordinated Universal Time

VCAN - Vórtice Ciclônico de Altos Níveis

ZCAS - Zona de Convergência do Atlântico Sul

ZCIT - Zona de Convergência Intertropical 


\section{LISTA DE SÍMBOLOS}

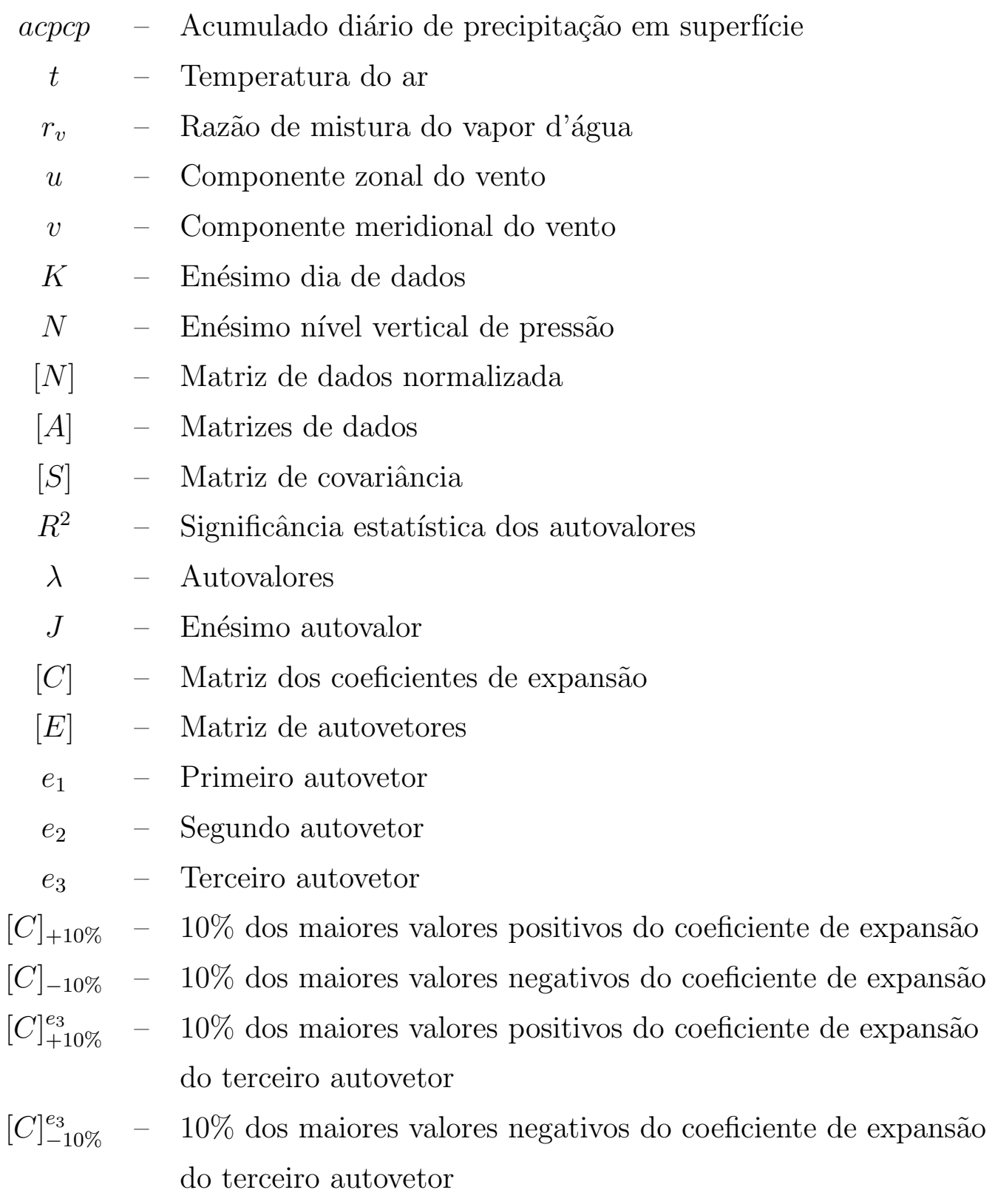





\section{SUMÁRIO}

1 Introdução $\quad 27$

1.1 Motivação . . . . . . . . . . . . . . . . . . 27

1.2 Climatologia . . . . . . . . . . . . . . . . . . . . 28

1.2.1 Brisa marítima e linhas de instabilidade . . . . . . . . . . . 29

1.2.2 Zona de Convergência Intertropical e Distúrbios Ondulatórios de Leste . . . . . . . . . . . . . . . . . . . . 30

1.2.3 Alta da Bolívia e Vórtice Ciclônico de Altos Níveis . . . . . . . . 32

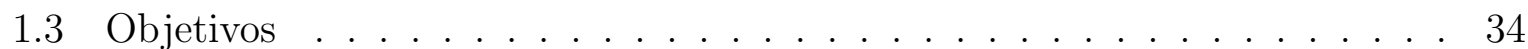

2 Metodologia e dados $\quad 35$

2.1 Funções Ortogonais Empíricas combinadas . . . . . . . . . . . . . . 35

2.2 Dados . . . . . . . . . . . . . . . . . . . . . 37

2.3 O modelo BRAMS . . . . . . . . . . . . . . . . . . . 38

2.4 Simulações numéricas . . . . . . . . . . . . . . . . . . . . . . . . 40

3 Resultados e discussões $\quad 45$

3.1 Análise das EOF combinadas . . . . . . . . . . . . . . . . . 45

3.2 Análise sinótica . . . . . . . . . . . . . . . . . . . . . . . . 68

3.2 .116 de janeiro de $2004 \ldots \ldots \ldots$. . . . . . . . . . . . . . 68

3.2 .29 de abril de $2009 \ldots \ldots \ldots . \ldots . \ldots . \ldots . \ldots 71$

3.2 .322 de agosto de $2007 \ldots \ldots \ldots \ldots$. . . . . . . . . . . . 74

3.2.4 4 de dezembro de $2009 \ldots \ldots$. . . . . . . . . . . . . . . 77

3.2 .54 de janeiro de $2005 \ldots \ldots \ldots \ldots$. . . . . . . . . . . . . 80 
3.2 .61 de junho de $2007 \ldots \ldots$. . . . . . . . . . . . . . . 83

3.2 .716 de agosto de $2007 \ldots \ldots \ldots \ldots$

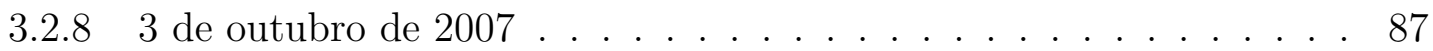

3.3 Análise das simulações numéricas . . . . . . . . . . . . . . . . . . . . . 90

3.3.1 Total de precipitação . . . . . . . . . . . . . . . . . . . . 90

3.3 .2 Movimento vertical . . . . . . . . . . . . . . . . . . 91

3.3.3 Razão de mistura de água líquida e gelo de nuvem . . . . . . . . . . 93

4 Sumário e conclusões $\quad 97$

$\begin{array}{ll}\text { Referências Bibliográficas } & 101\end{array}$ 


\section{INTRODUÇÃO}

\subsection{Motivação}

A previsão da ocorrência de extremos de acumulados diários de precipitação é de grande importância para diversas atividades ligadas ao gerenciamento de recursos hídricos. No entanto, a maioria dos modelos utilizados operacionalmente tende a subestimar os valores extremos de precipitação mesmo com apenas 24 horas de antecedência, conforme pode ser visto na Figura 1.
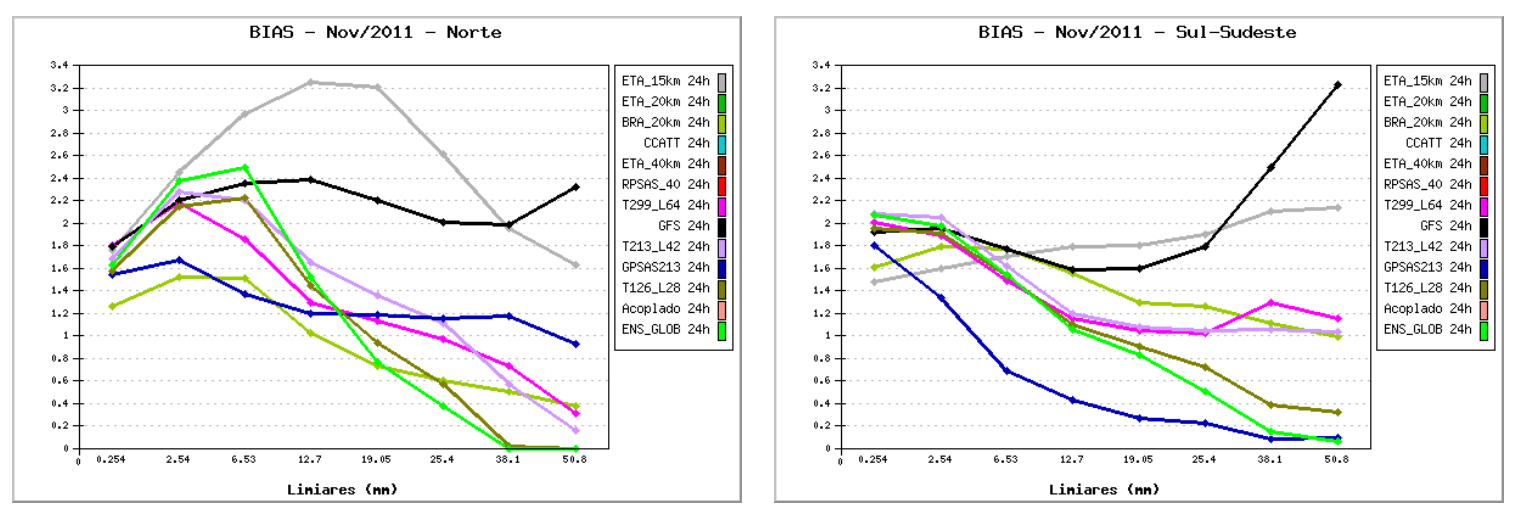

Figura 1: Dados de comparação de viés (Previsão/Observação) para a previsão com 24 horas de antecedência para diversos modelos operacionais (http://avaliacaodemodelos.cptec.inpe. $\mathrm{br} / \mathrm{obs} / \mathrm{qpf} / \mathrm{phps} /$ index.php).

As razões para esse tipo de erro de previsão são várias. Existem limitações nas parametrizações de convecção para modelos com resolução da ordem de dezenas de quilômetros que explicam boa parte do problema. Randall et al. (2003) fazem uma análise dessa questão que tem motivado muitas pesquisas ao longo de mais de três décadas sem ter avançado conforme seria desejável. Os autores sugerem que a solução está no uso de modelos com $2 \mathrm{~km}$ de resolução simulando explicitamente as nuvens e parametrizando os processos microfísicos.

No caso da inclusão dos processos microfísicos há ainda um efeito que os modelos de grande escala não costumam incluir que é o efeito dos aerossóis como fonte de Núcleos de 
Condensação de Gotas de Nuvens (Cloud Condensation Nuclei-CCN). Conforme Koren et al. (2008) e Martins et al. (2009), entre outros, a inclusão dos efeitos de concentração e distribuição de tamanhos de CCN pode alterar significativamente as taxas de precipitação associadas a nuvens profundas. Freitas et al. (2009) e Longo et al. (2006) introduzem o efeito radiativo dos aerossóis no modelo BRAMS com resolução de dezenas de quilômetros e mostram que mesmo indiretamente esse processo afeta a precipitação pelo efeito de redução dos fluxos turbulentos na camada limite planetária.

Finalmente, existem situações atmosféricas com condições de temperatura, umidade e velocidade e direção do vento cujos perfis verticais são particularmente favoráveis a desenvolvimentos convectivos com altas taxas de precipitação ou grandes acumulados diários de precipitação. Naegelin e McCrone (2006) fazem uma revisão sobre esses aspectos, com uma discussão da complexidade envolvida.

\subsection{Climatologia}

A cidade de Belém está localizada na região nordeste do estado do Pará, e devido a sua proximidade com o equador e o Oceano Atlântico, apresenta altos valores de temperatura e umidade com pouca variação ao longo do ano (Figura 2a). Belém possui uma estação seca e uma chuvosa bem definidas, nas quais o período mais chuvoso começa em dezembro e termina em maio (Figura $2 b$ ).

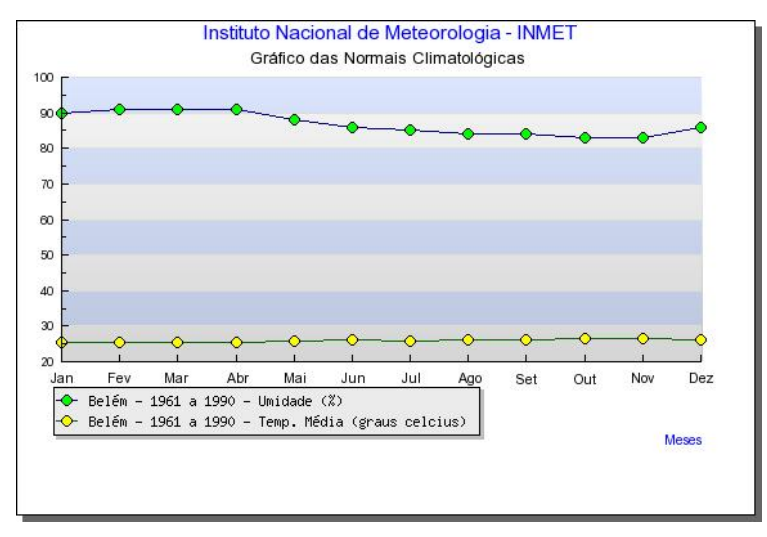

(a)

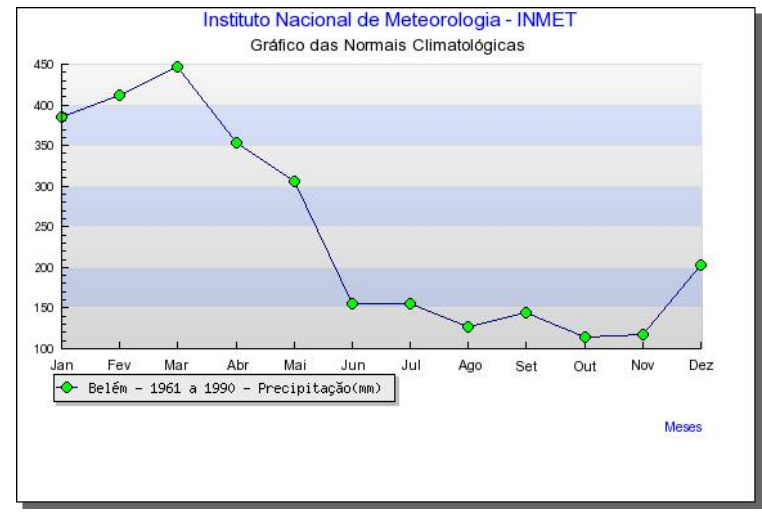

(b)

Figura 2: Normal climatológica da (a) umidade relativa e temperatura média e da (b) precipitação para Belém. Fonte: Instituto Nacional de Meteorologia - INMET.

Kousky e Molion (1985) explicam que conforme a Alta Subtropical do Atlântico se enfraquece e se move em direção ao norte durante a estação de inverno, as regiões sul e leste da Amazônia sofrem uma estação seca, evidenciada por dados de precipitação de 
estações individuais e por estimativas de satélite. E quando há ausência de fenômenos atmosféricos forçantes de grande escala, as células convectivas iniciam seu desenvolvimento logo durante a manhã. Essas células sofrem um processo de seleção, onde as maiores crescem e eventualmente formam aglomerados ou linhas, enquanto que as menores acabam sendo suprimidas.

Machado et al. (2004) fizeram uma descrição da variabilidade diurna e sazonal da cobertura de nuvem total e convectiva sobre a Amazônia e suas relações com a termodinâmica da atmosfera e os tipos de vegetação. Estes autores encontraram um maior número de eventos de chuva durante toda a tarde com o máximo no início da tarde em Belém, havendo uma contribuição pequena com um pico de eventos de chuva às 20 LST. Contudo, durante a estação seca, Belém tem um número significativo de eventos de chuva com picos às 19 e 20 LST.

Machado et al. (2004) observaram que Belém apresenta um maior número de tempestades no fim da estação seca e durante a transição de estação seca para chuvosa, o que coincide com período de intensa atividade de linhas de instabilidade. Isso pode ser explicado pelo fato de que o CAPE (Convective Available Ponticial Energy) máximo ocorre durante a transição entre a estação seca e a úmida e no início da estação úmida.

As chuvas em Belém são moduladas por fenômenos que vão desde a mesoescala brisa marítima e linhas de instabilidade - a grande escala - Distúrbio Ondulatório de Leste (DOL), Zona de Convergência Intertropical (ZCIT), Alta da Bolívia (AB) e Vórtices Ciclônicos de Altos Níveis (VCAN).

\subsubsection{Brisa marítima e linhas de instabilidade}

A brisa marítima surge devido ao contraste térmico entre oceano e continente. Como o oceano possui uma capacidade térmica maior, aquece e resfria mais lentamente que o continente. Dessa forma, surgem gradientes de temperatura e densidade, gerando uma circulação chamada de brisa. Durante a noite essa circulação acontece do continente para o oceano em baixos níveis (brisa terrestre), no período diurno ocorre o oposto, indo do oceano para o continente (brisa marítima). Quando a brisa marítima adentra o continente experimenta uma superfície mais rugosa, o que causa uma desaceleração da mesma e, portanto contribui para convergência próxima à costa (KOUSKY, 1980).

Machado et al. (2004) verificaram que a brisa marítima domina a atividade convectiva em Belém, contribuindo com a forte variação diurna de nuvens convectivas na região. 
Kousky (1980) sugere, com base em dados observacionais, que as linhas de instabilidade formadas na costa nordeste do Brasil podem ser originadas pela brisa marítima.

Garstang et al. (1994) descrevem a estrutura, dinâmica e ciclo de vida das linhas de instabilidade que formam-se na costa nordeste da América do Sul e adentram o continente. Neste trabalho consta que as linhas de instabilidade são sistemas lineares descontínuos de aglomerados de nuvens, formam-se na costa nordeste da América do Sul no meio da tarde e deslocam-se, normalmente, no sentido nordeste-sudoeste induzidos pela brisa marítima, com uma velocidade média de 50 a $60 \mathrm{~km} / \mathrm{h}$. Possuem, geralmente, comprimento de 1000 a 3000 km e largura de 100 a 200 km. Algumas linhas dissipam-se próximo à costa (Linhas de Instabilidade Costeiras - LIC), outras adentram a Floresta Amazônica (Linhas de Instabilidade que adentram a Amazônia - LIA). Alcântara et al. (2011), sob o ponto de vista observacional, mostraram que as LIA estão intimamente ligadas à espessura e intensidade dos jatos de baixos níveis. Tanto as LIC como as LIA podem ocorrer durante todo o ano, mas sua maior frequência ocorre entre os meses de abril e agosto (COHEN, 1989).

Garstang et al. (1994) classificam as LIA em seis estágios referentes ao seu ciclo de vida: gênesis (formação das primeiras células convectivas), intensificação (aglomerados de nuvens crescem e organizam-se em forma de linha), maturação (o sistema alcança seu tamanho máximo), enfraquecimento (a linha de instabilidade enfraquece e diminui sua velocidade), regeneração (ocorre durante o período de máximo aquecimento diurno) e dissipação.

Cohen et al. (1995) relatam que a propagação das linhas de instabilidade é resultado de um sistema complexo onde ocorrem interações entre escalas que variam da grande escala, para mesoescala e a escala de nuvem. A grande escala está associada aos distúrbios ondulatórios de leste e às fontes de calor localizadas no oeste da Amazônia, a mesoescala envolve os fenômenos de brisa marítima e a escala de nuvem está relacionada com a manutenção das linhas no seu ciclo de vida.

\subsubsection{Zona de Convergência Intertropical e Distúrbios Ondulatórios de Leste}

A ZCIT é um dos mais importantes sistemas moduladores da precipitação no Norte e norte do Nordeste do Brasil e está localizada climatologicamente sobre o ramo ascendente da célula de Hadley. Hastenrath e Lamb (1977) a definem como um sistema que possui em sua estrutura as seguintes características: baixa pressão em superfície, temperatura da superfície do mar máxima, confluência dos ventos alísios de norte e sul, convergência 
máxima de massa e cobertura máxima de nuvens convectivas. Seu comportamento possui um papel importante na estação chuvosa do norte do Nordeste do Brasil (NNE).

Uvo e Nobre (1989) fizeram um estudo, baseado em observações, sobre a influência da ZCIT na precipitação da região NNE. Nesse trabalho, inferiram que a qualidade da estação chuvosa na região semi-árida está intimamente ligada ao tempo de permanência da ZCIT mais ao sul, ou seja, em anos mais secos esse sistema fica mais ao sul de fevereiro até março, e nos anos chuvosos, até maio. Quando a ZCIT começa a deslocar-se para norte entre o final de abril e o início de maio, observam-se, normalmente, chuvas mais abundantes nas regiões supracitadas. Enquanto que se a ZCIT começar a migrar para norte entre o final de fevereiro e início de março, normalmente um déficit de chuva é observado na região NNE.

Souza e Cavalcanti (2009) analisaram as relações entre características do Atlântico nos extratrópicos e a Zona de Convergência Intertropical. Observaram que o dipolo da Temperatura da Superfície do Mar (TSM) propicia condições para desenvolvimento de intensa convecção na ZCIT em abril. Um aquecimento anômalo no Atlântico Tropical Sul e um resfriamento no Atlântico Tropical Norte induzem a ZCIT a posicionar-se mais a sul, enquanto que o oposto induz a mesma a posicionar-se mais ao norte. Como a TSM influencia diretamente as altas subtropicais, a intensidade e a posição das mesmas também afetam a ZCIT.

Além da ZCIT, existem os DOL que, segundo Coutinho e Fisch (2007), são sistemas de grande importância nos regimes de chuva para o nordeste brasileiro e podem ser caracterizados por alterações significativas nos ventos meridionais. Deslocam-se juntamente com os ventos alísios para oeste no Atlântico Tropical, onde tais características podem ser observadas nos campos de vento e pressão (ALVES et al., 1999).

Em um estudo de avaliação do modelo operacional European Centre for MediumRange Weather Forecasts (ECMWF) sobre a África e o Atlântico Tropical, Reed et al. (1988), de agosto a setembro de 1985, identificaram 20 DOL. Esses sistemas sinóticos possuíam comprimentos de onda variando entre 2000 e $3000 \mathrm{~km}$, velocidade de fase de $6^{\circ}$ a $7^{\circ}$ de longitude/dia e período de 3 a 5 dias.

Espinoza (1996) estudou as características dos distúrbios ondulatórios de leste no Atlântico Tropical. Verificou uma maior predominância e intensidade desses distúrbios no Hemisfério Norte durante o verão boreal e no Hemisfério Sul durante o verão austral. Esses sistemas apresentaram determinadas características de acordo com a sazonalidade. Para o verão (dezembro, janeiro e fevereiro) o comprimento de onda encontrado foi en- 
torno de 6000 a $7000 \mathrm{~km}$ e velocidade de fase de 10 a $14 \mathrm{~m} / \mathrm{s}$, no outono (março, abril e maio) o comprimento encontrado varia entre 5000 a $6000 \mathrm{~km}$ e velocidade de fase de 10 a $13 \mathrm{~m} / \mathrm{s}$, no inverno (junho, julho e agosto) o comprimento vai de 3500 a $4000 \mathrm{~km}$ e velocidade de 10 a $13 \mathrm{~m} / \mathrm{s}$ e na primavera (setembro, outubro e novembro) o comprimento fica entre 4000 e $5000 \mathrm{~km}$ e velocidade entre 9 e 15 m/s. Espinoza (1996) também percebeu que os DOL possuíam inclinação horizontal orientada no sentido sudeste/noroeste e uma leve inclinação para leste nas estações de verão e primavera, enquanto que para as outras estações esses distúrbios tinham inclinação horizontal sentido sudoeste/nordeste e inclinação vertical para leste de 1000 a $700 \mathrm{hPa}$ e para oeste de 700 a $500 \mathrm{hPa}$.

A precipitação gerada pelos DOL tende a ser mais esparsa a oeste do cavado (próxima ao seu eixo), mais intensa e frequente sobre o eixo e de moderada a forte a leste do eixo do cavado (COUTINHO; FISCH, 2007). Além disso, os DOL podem intensificar perturbações convectivas como, por exemplo, as linhas de instabilidade, favorecendo sua propagação continente adentro (BARBOSA, 2005).

\subsubsection{Alta da Bolívia e Vórtice Ciclônico de Altos Níveis}

A Alta da Bolívia é basicamente um anticiclone em altos níveis (KOUSKY; KAGANO, 1981). Está associada à convergência em baixos níveis gerada pelo forte aquecimento diurno em superfície, que leva à formação de nuvens estando associada à liberação de calor sensível e latente (MOLION, 1987). Localiza-se a oeste da fonte de calor devido a dispersão de ondas (SILVA DIAS et al., 1983). Possui uma variação sazonal, tanto em intensidade quanto em posição, a qual está diretamente relacionada à distribuição espacial e temporal da precipitação na região amazônica (KOUSKY; KAGANO, 1981).

Virji (1981), analisando o movimento das nuvens através de dados geostacionários, averiguou que o anticiclone é associado a um campo de divergência em altos níveis e Kreuels et al. (1975) mostraram que esse vórtice continha um núcleo quente em médios níveis e uma camada fria entre 200 e 100 hPa. A camada de ar quente está associada a subsidência compensatória aos movimentos convectivos ascendentes enquanto que a camada de ar frio está associada ao esparramento da bigorna e seu resfriamento adiabático devido ao movimento ascendente e a evaporação dos cristais de gelo (LENTERS; COOK, 1997).

Lenters e Cook (1997) exploraram os mecanismos responsáveis pela circulação na alta troposfera sobre a América da Sul durante verão austral. Constataram que a circulação observada no verão da América do Sul está ligada ao aquecimento por liberação de calor 
latente (condensação) e que a $\mathrm{AB}$ é uma resposta à ação conjunta da precipitação na Amazônia, Andes central e ZCAS (Zona de Convergência do Atlântico Sul). Embora o posicionamento da $\mathrm{AB}$ sobre o Altiplano seja devido à precipitação amazônica a nordeste do sistema, sua intensidade é mais influenciada pela precipitação nos Andes central. O aquecimento por condensação gerado pelas ZCAS, embora fraco, favorece o alongamento do vórtice para sudeste.

Através de simulações numéricas com GCM, Lenters e Cook (1997) verificaram que os Andes possue um efeito secundário na $\mathrm{AB}$, pois evidenciaram a presença da mesma na ausência dos Andes. Embora tenha efeito secundário, a topografia contribui para a precipitação nos Andes central fortalecendo, de forma indireta, o vórtice anticiclônico de altos níveis.

Quanto à climatologia dos VCAN, Ramírez et al. (1999) observaram um grande número de vórtices na estação de verão, na qual janeiro foi o mês que mais destacouse, sendo identificados 30 vórtices entre os anos de 1980 a 1989. Já na estação de inverno, nos meses de julho e agosto, não encontraram nenhum sistema.

No estudo feito por Ramírez et al. (1999) consta que, normalmente, a gênesis dos vórtices que ocorrem sobre o Atlântico Tropical Sul acontece nos altos níveis, permanecendo confinados entre a média e a alta troposfera durante todo seu ciclo de vida. Além disso, possuem uma inclinação para leste com a altura e a atividade convectiva é mais intensa na direção de deslocamento do ciclone, geralmente à oeste.

Mishra et al. (2007) inferiram que a instabilidade barotrópica gerada pelo cisalhamento do vento zonal pode contribuir para a formação dos VCAN frequentemente observados próximos ao Nordeste brasileiro. Mishra et al. (2007) também sugeriram um cenário favorável à gênesis e desenvolvimento desse sistema: instabilidade barotrópica, a qual pode disparar a formação do vórtice, e um forte cisalhamento zonal com a latitude entre a Alta da Bolívia e o Cavado do Nordeste, responsável, provavelmente, pela intensificação e deslocamento do ciclone.

Os vórtices ciclônicos de altos níveis que influenciam a costa nordeste do Brasil também podem formar-se pela atuação de sistemas frontais. Conforme ilustrado de forma esquemática na Figura 3, a forte advecção quente em baixos e médios níveis, antecessora à frente fria, provoca uma amplificação da crista em médios níveis e consequentemente uma intensificação do cavado a sua vanguarda com o deslocamento do sistema frontal. Essa intensificação do cavado faz com que o mesmo, em altos níveis, assuma uma circulação ciclônica fechada. 


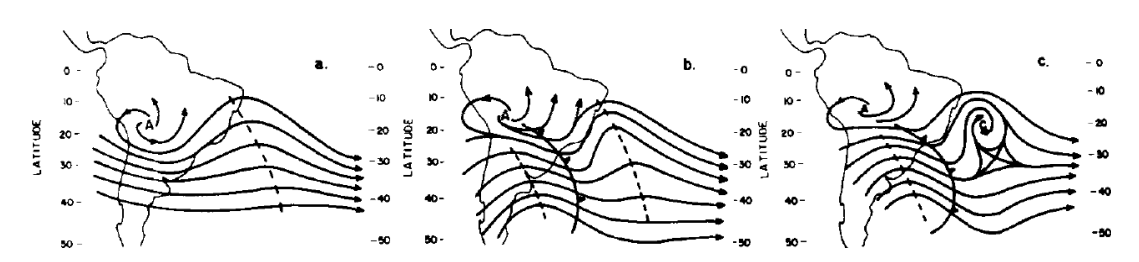

Figura 3: Esquema de como ocorre a formação de um ciclone subtropical a $200 \mathrm{hPa}$ sobre o Atlântico Sul (KOUSKY; GAN, 1981).

Segundo Kousky e Gan (1981), os vórtices ciclônicos possuem um núcleo frio apesar de haver aquecimento por compressão adiabática $\left(1\right.$ a $3{ }^{\circ} \mathrm{C}$ por dia) ocasionada pela convergência em altos níveis. Isso ocorre porque o resfriamento radiativo compensa esse aquecimento no centro do ciclone e, ao mesmo tempo, a intensa liberação de calor latente gerada pela atividade convectiva em sua periferia faz com que exista um gradiente de temperatura que aponte para fora do vórtice. Normalmente, em um VCAN estacionário, a convecção distribui-se de forma homogênea em sua periferia, entretanto, se o mesmo mover-se para oeste, ocorre uma intensificação da vorticidade relativa a oeste e consequentemente uma aumento da convecção nessa região.

\subsection{Objetivos}

O objetivo do presente trabalho é de identificar perfis verticais cinemáticos e termodinâmicos que tipicamente estão associados a extremos de precipitação diária na região de Belém, Pará. Para atingir esse objetivo optou-se por fazer uma análise de séries de precipitação e dados de radiossondagens através da técnica de Funções Ortogonais Empíricas (EOF - Empirical Orthogonal Functions) combinadas e verificar a atual capacidade de modelar as características básicas de chuva acumulada diária através do Brazilian developments on the Regional Atmospheric Modeling System (BRAMS). 


\section{METODOLOGIA E DADOS}

\subsection{Funções Ortogonais Empíricas combinadas}

Com base na metodologia contida em Marcelino (1985) e Wilks (2006) foram calculadas as EOF combinadas a partir da precipitação acumulada diária obtida a partir do produto TRMM-3B42 e perfis verticais termodinâmicos e cinemáticos obtidos pela radiossondagem operacional de Belém, Pará, compreendendo o período do dia 3 de julho de 1998 a 16 de novembro de 2010. Esse procedimento tem como intuito identificar perfis verticais tipicamente associados a extremos de precipitação diária. Para o cálculo do acumulado diário de chuva, a partir do TRMM, foi realizada uma extrapolação dos dados, multiplicando-se as horas disponíveis por três e, então, somando-se as taxas horárias de chuva a partir das 12 UTC.

Montaram-se três matrizes de dados distintas. Uma contendo as variáveis acumulado diário de precipitação em superfície $(\operatorname{acpcp}[\mathrm{mm} / \mathrm{dia}])$, temperatura do $\operatorname{ar}\left(t\left[{ }^{\circ} C\right]\right)$, razão de mistura vapor d'água $\left(r_{v}[\mathrm{~g} / \mathrm{kg}]\right)$, vento zonal $(u[\mathrm{~m} / \mathrm{s}])$ e vento meridional $(v[\mathrm{~m} / \mathrm{s}])$ para os níveis de pressão correspondentes a 1000, 850, 700, 500, 400, 300 e 200 hPa, como segue logo abaixo:

$$
[X]=\left[\begin{array}{ccccccccccccc}
\operatorname{acpcp}_{2} & t_{11} & \cdots & t_{1 N} & r_{v 11} & \cdots & r_{v 1 N} & u_{11} & \cdots & u_{1 N} & v_{11} & \cdots & v_{1 N} \\
\operatorname{acpcp}_{3} & t_{21} & \cdots & t_{2 N} & r_{v 21} & \cdots & r_{v 2 N} & u_{21} & \cdots & u_{2 N} & v_{21} & \cdots & v_{2 N} \\
\vdots & \vdots & \cdots & \vdots & \vdots & \cdots & \vdots & \vdots & \cdots & \vdots & \vdots & \cdots & \vdots \\
\operatorname{acpcp}_{K+1} & t_{K 1} & \cdots & t_{K N} & r_{v K 1} & \cdots & r_{v K N} & u_{K 1} & \cdots & u_{K N} & v_{K 1} & \cdots & v_{K N}
\end{array}\right]
$$

Outra, sem as variáveis $t$ e $r_{v}$ : 


$$
[Y]=\left[\begin{array}{ccccccc}
\operatorname{acpcp}_{2} & u_{11} & \cdots & u_{1 N} & v_{11} & \cdots & v_{1 N} \\
\operatorname{acpcp}_{3} & u_{21} & \cdots & u_{2 N} & v_{21} & \cdots & v_{2 N} \\
\vdots & \vdots & \cdots & \vdots & \vdots & \cdots & \vdots \\
\operatorname{acpcp}_{K+1} & u_{K 1} & \cdots & u_{K N} & v_{K 1} & \cdots & v_{K N}
\end{array}\right]
$$

E a última com, apenas, as variáveis acpcp e $u$ :

$$
[Z]=\left[\begin{array}{cccc}
\operatorname{acpcp}_{2} & u_{11} & \cdots & u_{1 N} \\
a c p c p_{3} & u_{21} & \cdots & u_{2 N} \\
\vdots & \vdots & \cdots & \vdots \\
\operatorname{acpcp}_{K+1} & u_{K 1} & \cdots & u_{K N}
\end{array}\right]
$$

Onde $K$ é o enésimo dia de dados e $N$ é o enésimo nível vertical de pressão.

As matrizes foram montadas para quatro períodos distintos: JFM (Janeiro, Fevereiro e Março), AMJ (Abril, Maio e Junho), JAS (Julho, Agosto e Setembro) e OND (Outubro, Novembro e Dezembro) referentes aos 12 anos de dados. Em seguida realizou-se a normalização dos dados para garantir que todas as variáveis tenham a mesma ordem de grandeza. Essa normalização foi feita da seguinte forma:

- Determinou-se a média e o desvio padrão para cada variável em cada nível vertical;

- Obteve-se a matriz normalizada $([N])$ subtraindo cada variável em cada nível vertical pela sua média e dividindo pelo respectivo desvio padrão.

Determinou-se também a matriz de covariância com os dados normalizados como segue logo abaixo:

$$
[S]=\frac{1}{n-1}[N]^{T}[N]
$$

Finalmente, com a matriz covariância, realizou-se a estimativa das EOF combinadas utilizando a função eigen() do software R (http://www.r-project.org) que, por padrão, utiliza as rotinas LAPACK (DSYEVR, DGEEV, ZHEEV). O LAPACK (Linear Algebra PACKage) é uma extensa biblioteca de álgebra linear escrita em fortran, a qual contém rotinas para diversos problemas relacionados a matrizes.

A fim de saber quanto de significância estatística possui cada autovalor, foi computada a porcentagem da variação explicada: 


$$
R_{j}^{2}=\frac{\lambda_{j}}{\sum_{j=1}^{J} \lambda_{j}} \times 100 \%
$$

Onde $\lambda_{j}$ representa os autovalores e $J$ o enésimo autovalor.

Determinaram-se os coeficientes de expansão (componentes ortogonais de tempo) que estão associados aos autovetores através da seguinte equação matemática:

$$
[C]=[N][E]
$$

Onde $[C]$ é a matriz dos coeficientes de expansão e $[E]$ é a matriz com os autovetores.

Os coeficientes de expansão são importantes por descrever a evolução temporal dos autovetores. Optou-se por utilizar somente os três primeiros autovetores $\left(e_{1}, e_{2}\right.$ e $\left.e_{3}\right)$, pois os demais apresentaram apenas uma pequena contribuição para a variância total.

Com o propósito de realizar uma análise mais objetiva e refinada dos autovetores, selecionaram-se $10 \%$ dos casos da série temporal dos autovetores para os maiores valores positivos $\left([C]_{+10 \%}\right)$ e negativos $\left([C]_{-10 \%}\right)$, separadamente. A partir desses casos selecionados, foram feitos histogramas para a precipitação, vento zonal, CAPE, CINE (Convective Inhibition Energy) e CISZ (cisalhamento do vento zonal entre os níveis de 1000 e 700 $\mathrm{hPa})$.

Através dos coeficientes de expansão, foram escolhidos dois dias para JFM, AMJ, JAS e OND, um no qual o coeficiente é máximo (máximo positivo) e outro no qual o mesmo é mínimo (máximo negativo) para o autovetor ou para os autovetores que melhor identificaram os extremos chuvosos. Então, foi realizada uma análise sinótica e simulações numéricas para melhor entender os padrões identificados pela ou pelas EOF.

\subsection{Dados}

Com a finalidade de calcular as EOF, foram utilizados dados de radiossondagem (12 UTC) da rede operacional de ar superior e precipitação (mm/3h) do TRMM-3B42 (Tropical Rainfall Measurement Mission Project) com resolução temporal de 3 horas e espacial de $0,25^{\circ} \times 0,25^{\circ}$. Para a análise sinótica dos dias de tempestade identificados por autovetores, adquiriram-se dados de reanálise do NCEP/NCAR (National Center for Environmental Prediction do National Center for Atmospheric Research) e imagens de satélite do GOES (Geostationary Operational Environmental Satellite) versão 12 realçadas 
no canal do infravermelho. As sondagens foram obtidas dos arquivos do Departamento de Ciências Atmosféricas da Universidade de Wyoming pelo endereço http://weather . uwyo.edu/upperair/sounding.html. Os dados do TRMM - 3B42 (http://trmm.gsfc . nasa.gov/3b42.html) e do GOES 12 foram fornecidos pelo laboratório de Meteorologia Aplicada a Sistemas de Tempo Regionais (MASTER).

Fez-se uso das análises do Global Forecast System (GFS) como condição inicial e de fronteira lateral para o BRAMS. Esses dados foram obtidos do Computional and Information Systems Laboratory (CISL) pertencente ao NCAR pelo link http://dss.ucar. edu/datasets/ds335.0/matrix.html, possuem 26 níveis na vertical, 4 horários diários (00, 06, 12, 18 UTC) e resolução horizontal de $0,5^{\circ} \times 0,5^{\circ}$. Para os períodos anteriores a 01/11/2006, devido a indisponibilidade de dados, utilizaram-se os mesmos dados de análise porém com resolução de $1^{\circ} \mathrm{x} 1^{\circ}$. Os dados de tipo de vegetação (Normalized Difference Vegetation Index - NDVI), umidade do solo, temperatura da superfície do mar média semanal, topografia, tipos de solo e uso do solo, utilizados para alimentar o modelo, foram obtidos do Centro de Previsão do Tempo e Estudos Climáticos do Instituto Nacional de Pesquisas Espaciais (CPTEC/INPE) pelo endereço eletrônico http://brams.cptec.inpe.br.

\subsection{O modelo BRAMS}

O Regional Atmospheric Modeling System (RAMS), do qual o BRAMS foi originado (FREITAS et al., 2009), foi desenvolvido pela Universidade do Estado do Colorado, sendo uma junção de vários modelos (PIELKE et al., 1992). Segundo Cotton et al. (2003), o modelo surgiu de uma fusão entre o CSU (modelo de nuvem e mesoescala) descrito por Tripoli e Cotton (1982), uma versão hidrostática do modelo de nuvem publicada em Tremback (1990), e o modelo de brisa marítima (MAHRER; PIELKE, 1977).

Pielke et al. (1992) relatam que o RAMS é um modelo que funciona de forma hidrostática e não-hidrostática, é equipado com múltiplas grades aninhadas (fixas ou móveis) e pode simular desde grandes vórtices turbulentos a sistemas convectivos de mesoescala e forçantes mecânicos e térmicos desses sistemas. Com a evolução dos computadores, o RAMS passou a utilizar equações apenas na forma não-hidrostática (COTTON et al., 2003).

De acordo com Cotton et al. (2003), o modelo possui um conjunto de opções físicas que podem ser alteradas de acordo com o tipo de estudo. Permite configurar resoluções de 
grade da ordem de menos de um metro a centenas de quilômetros. O RAMS possibilita o aninhamento de múltiplas grades, no qual as malhas finas podem ser usadas para resolver fenômenos de pequena escala como escoamentos em terrenos muito acidentados, enquanto que as malhas mais grossas podem tanto alimentar a grade mais refinada quanto simular sistemas atmosféricos de grande escala.

Entre as opções de parametrização de radiação solar existe o esquema de Chen e Cotton (1987) para onda longa e curta, utilizado nas simulações apresentadas neste trabalho. Esse esquema parametriza os fluxos radiativos levando em conta o conteúdo de água líquida, temperatura de nuvem, fração de cobertura de nuvem e ângulo zenital do sol. Kuo (1983) fez alguns testes com essa parametrização de radiação e obteve resultados satisfatórios na representação dos fluxos radiativos, embora esse esquema não leve em conta o gelo contido na nuvem.

Freitas et al. (2009) explicam que o projeto BRAMS começou através do patrocínio da agência brasileira de financiamento FINEP (Financiadora de Estudos e Projetos) durante 2002 e 2003. O objetivo do projeto era incluir melhorias no software, mantendo sua flexibilidade. Atualmente, um grupo do CPTEC é responsável pelo suporte e por incorporar no modelo as contribuições das pesquisas produzidas dentro centros de pesquisa e universidades. Desta forma, foram acrescentadas no modelo várias melhorias, tanto na representação da convecção de Cumulus profundos e rasos, como na inicialização de umidade do solo e no esquema de superfície para os trópicos. O BRAMS é um software livre e está disponível em http://brams.cptec.inpe.br.

A parametrização de convecção profunda utilizada nas simulações do presente estudo foi o esquema de Grell. A descrição matemática dessa parametrização é feita em Grell (1993). Cohen (2002) explica que esse esquema convectivo determina a chuva, supondo que a coluna atmosférica é estabilizada pela convecção à mesma taxa que o escoamento de grande escala a desestabiliza (equilíbrio quase-estático). Esse esquema considera, dentro da nuvem, apenas uma única corrente ascendente sem entranhamento, a qual desentranha apenas no topo da nuvem, e uma corrente descendente que surge no nível que contém menor energia estática úmida (isto é, o nível de menor temperatura potencial equivalente) e desentranha em uma camada de profundidade específica acima do solo.

O BRAMS possui em seu código um esquema de convecção rasa do tipo fluxo de massa proposto por Souza (1999). O esquema de Souza (1999) baseia-se na ideia de que se a atmosfera é forçada pelo fluxo de energia em superfície, um fluxo de massa é necessário para que a mesma possa restabelecer o equilíbrio radiativo-convectivo local. 
Souza e Silva (2003) realizaram testes da parametrização de convecção rasa no modelo RAMS, a fim de verificar o impacto ocasionado pelo esquema no modelo. Repararam que a estrutura vertical de temperatura e umidade foi significativamente alterada ao longo da integração do modelo. A parametrização captou de forma satisfatória o ciclo diurno da convecção rasa. Além disso, Souza e Silva (2003) perceberam uma tendência de aumento da quantidade de precipitação convectiva acumulada devido à implementação do esquema convectivo.

O modelo Land Ecosystem-Atmosphere Feedback version 2 (LEAF-2), descrito por Walko et al. (2000), possibilita ao BRAMS enxergar múltiplos solos em uma mesma célula de grade. O LEAF-2 é um modelo prognóstico que visa representar as características de superfície que incluem vegetação, solo, lagos, oceanos e cobertura de neve, e suas interações com a coluna atmosfera sobrejacente. Atualmente, na versão mais atual do BRAMS, versão 4.2, vem incluso o submodelo LEAF-3, versão posterior ao LEAF-2. O LEAF-3, ao contrário do seu antecessor, permite a inclusão de dados de NDVI para calcular a razão simples, fração da radiação fotossinteticamente ativa, folhas verdes, índice de área de folhas verdes, índice total de área e altura do dossel, como consta em Walko e Tremback (2005).

Além disso, nos últimos anos foram acoplados no BRAMS o Coupled Aerosol and Tracer Transport model (CATT), Town Energy Budget (TEB) e Simple Photochemical Module (SPM), que funcionam online. O CATT foi desenvolvido para o estudo de emissão, deposição e transporte de gases e aerossóis associados a queima de biomassa na América do Sul (FREITAS et al., 2009). O TEB permite a representação do balanço de energia em áreas urbanas (FREITAS et al., 2006). O SPM simula reações químicas na atmosfera (FREITAS et al., 2005).

\subsection{Simulações numéricas}

As simulações foram realizadas para um período de 24 horas para os dias identificados pela série temporal das EOF. Preferencialmente, optou-se por utilizar dados de análise do GFS de 0,5x0,5 graus de resolução como condição de entrada e de fronteira do modelo. Para as rodadas com esses dados, fez-se o uso de três grades aninhadas (grade 2, 3 e 4) como consta na Figura 4. Entretanto, os mesmos estão disponíveis apenas com essa resolução desde o final do ano de 2006, como citado anteriormente na seção de dados. Sendo assim, para os anos anteriores, utilizaram-se dados do GFS com resolução de 1x1 grau e, consequentemente, nas rodadas que os consideraram como condição inicial, foram 
aplicadas quatro grades aninhadas (Figura 4).

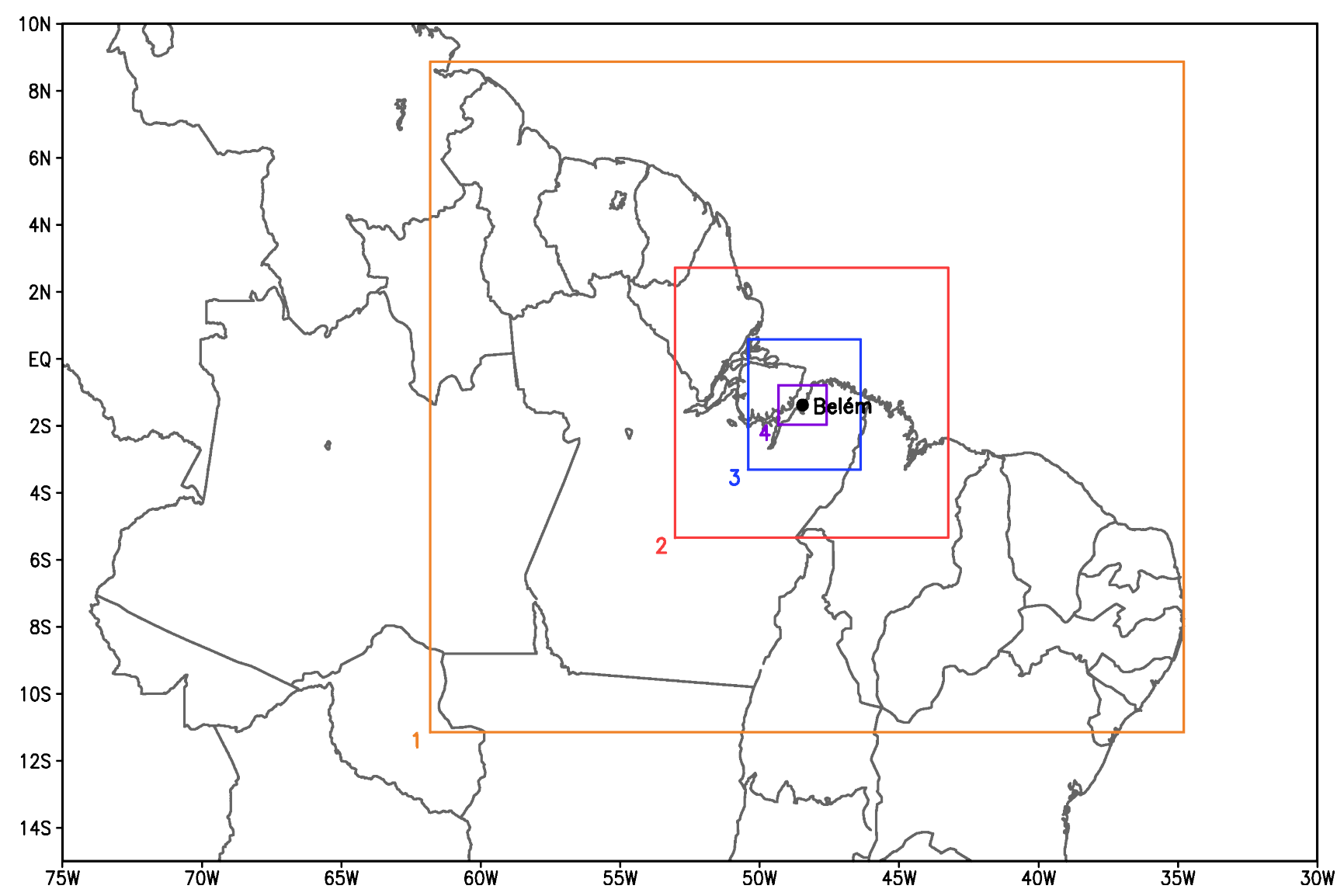

Figura 4: Grades aninhadas e centradas em Belém, utilizadas nas simulações com o BRAMS.

Quanto à área das grades utilizadas na simulação, a grade 1 possui 2880x2112 km, a grade 2 possui 1056x864 km, a grade 3 possui 440x424 km e a grade 4 possui 190x130 km. Na Tabela 1 estão as principais opções utilizadas no modelo e na Tabela 2 estão as principais opções utilizadas de forma individual para cada grade. 
Tabela 1: Principais opções utilizadas na inicialização do BRAMS.

\begin{tabular}{lc}
\hline Opções & \\
\hline Níveis verticais & 36 \\
Espaçamento vertical no primeiro nível & $100 \mathrm{~m}$ \\
Razão do incremento na vertical & $1,1 \mathrm{~m}$ \\
Espaçamento vertical máximo & $1000 \mathrm{~m}$ \\
Altura no topo do modelo & $14335 \mathrm{~m}$ \\
Passo de tempo com quatro grades & $80 \mathrm{~s}$ \\
Passo de tempo com três grades & $20 \mathrm{~s}$ \\
Número de pontos na fronteira lateral onde é aplicado o nudging & 5 \\
Escala de tempo de nudging na fronteira lateral & $3600 \mathrm{~s}$ \\
Escala de tempo de nudging no centro do domínio & $64800 \mathrm{~s}$ \\
Escala de tempo de nudging no topo do domínio & $10800 \mathrm{~s}$ \\
Parametrização de onda curta & Chen e Cotton (1987) \\
Parametrização de onda longa & Chen e Cotton (1987) \\
\hline
\end{tabular}




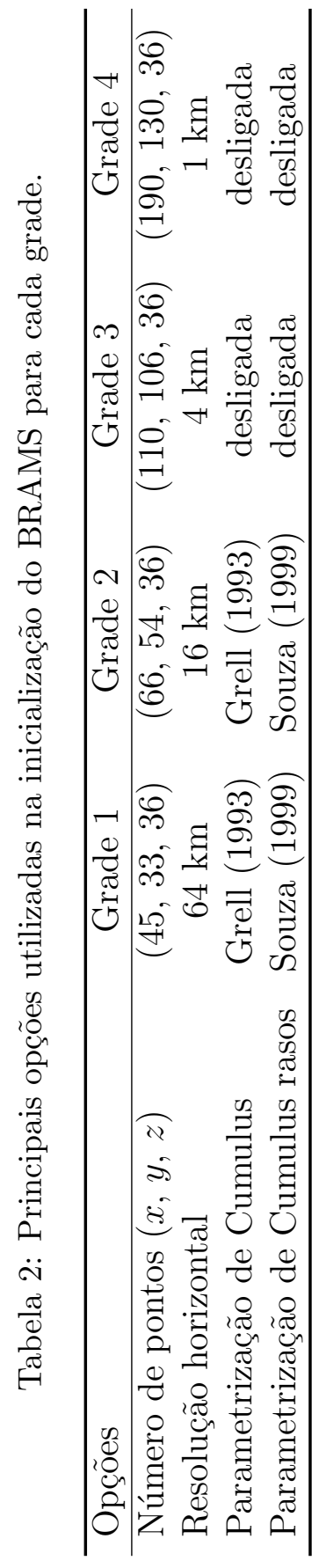




\section{RESULTADOS E DISCUSSÕES}

\subsection{Análise das EOF combinadas}

A técnica estatística de quantis permite identificar extremos chuvosos a partir de uma série de dados para uma determinada região. Para esse fim, utiliza-se o quantil de $95 \%$, cujo valor de chuva correspondente implica que existe a probabilidade de $5 \%$ da série chuva ser maior que esse valor para o período de dados em questão (XAVIER et al., 2002).

A Tabela 3 mostra quantis de $95 \%$ dos acumulados diários de chuva para cada período do ano em Belém. Observa-se uma tendência a maiores acumulados diários para JFM com 53,5 mm, seguido por AMJ com 47,9 mm, ou seja, há a probabilidade de $5 \%$ de ocorrerem chuvas acima de 53,5 mm para JFM e de 47,9 mm para o AMJ.

Tabela 3: Quantis de 95\% dos acumulados diários de chuva para cada período do ano em Belém.

\begin{tabular}{cccc}
\hline JFM & AMJ & JAS & OND \\
\hline $53,5 \mathrm{~mm}$ & $47,9 \mathrm{~mm}$ & $45,8 \mathrm{~mm}$ & $36,1 \mathrm{~mm}$ \\
\hline
\end{tabular}

A variação explicada pelos três primeiros autovalores para cada matriz de dados é mostrada na Tabela 4 . Nota-se que as matrizes $[Z]$ apresentaram maiores valores em porcentagem, ou seja, as EOF resultantes de $[Z]$ explicam juntas a maior parte da variância dos dados, sendo a matriz referente a AMJ $\left([Z]_{2}\right)$, com $73 \%$ de variância explicada $\left(R_{1}^{2}+R_{2}^{2}+R_{3}^{2}\right)$, a que melhor explicou a variabilidade dos dados. As matrizes $[X]$ são as que possuem menor significância estatística, provavelmente devido ao fato de que a temperatura e a umidade não apresentam grandes variações no decorrer do ano. Já a matriz $[Y]$, sem $t$ e $r_{v}$, apresentou um resultado melhor em relação a $[X]$, entretanto, inferior a $[Z]$, pois o vento meridional, provavelmente, apresenta uma pequena contribuição para o vento total (ACEITUNO, 1987; ALCÂNTARA et al., 2011). 
Tabela 4: Variação explicada para os três primeiros autovalores e seus somatórios para cada matriz de dados gerada.

\begin{tabular}{ccccccc}
\hline Matrizes & Variáveis & Período & $R_{1}^{2}(\%)$ & $R_{2}^{2}(\%)$ & $R_{3}^{2}(\%)$ & $R_{1}^{2}+R_{2}^{2}+R_{3}^{2}$ \\
\hline$[X]_{1}$ & acpcp, $t, r_{v}, u$ e $v$ & JFM & 14,19 & 9,82 & 8,73 & 32,74 \\
{$[X]_{2}$} & acpcp, $t, r_{v}, u$ e $v$ & AMJ & 15,67 & 12,79 & 8,31 & 36,77 \\
{$[X]_{3}$} & acpcp, $,, r_{v}, u$ e $v$ & JAS & 10,54 & 8,07 & 7,57 & 26,18 \\
{$[X]_{4}$} & acpcp, $t, r_{v}, u$ e $v$ & OND & 16,22 & 10,08 & 7,43 & 33,73 \\
{$[Y]_{1}$} & acpcp, $u$ e $v$ & JFM & 18,04 & 15,26 & 11,79 & 45,09 \\
{$[Y]_{2}$} & acpcp, $u$ e $v$ & AMJ & 19,37 & 15,62 & 11,11 & 46,10 \\
{$[Y]_{3}$} & acpcp, $u$ e $v$ & JAS & 16,50 & 11,37 & 9,69 & 37,56 \\
{$[Y]_{4}$} & acpcp, $u$ e $v$ & OND & 21,35 & 12,96 & 10,82 & 45,13 \\
{$[Z]_{1}$} & $a c p c p, u$ & JFM & 33,43 & 25,81 & 12,60 & 71,84 \\
{$[Z]_{2}$} & $a c p c p, u$ & AMJ & 31,99 & 28,61 & 12,54 & 73,14 \\
{$[Z]_{3}$} & acpcp, $u$ & JAS & 29,26 & 20,10 & 13,02 & 62,38 \\
{$[Z]_{4}$} & acpcp, $u$ & OND & 29,39 & 22,12 & 16,32 & 67,83 \\
\hline
\end{tabular}

Os autovetores foram calculados a partir da matriz $[Z]$, haja vista que os três primeiros autovalores da mesma explicam melhor a variância dos dados. Na Tabela 5 são mostrados os três primeiros autovetores referentes à chuva. Nela, pode-se observar que os dois primeiros autovetores apresentaram valores muito fracos, enquanto que o terceiro autovetor identificou anomalias significativas. Esses valores são positivos para JFM, AMJ e JAS e negativo para OND.

Tabela 5: Três primeiros autovetores da precipitação para cada período do ano.

\begin{tabular}{cccc}
\hline Período & $e_{1}$ & $e_{2}$ & $e_{3}$ \\
\hline JFM & 0,03 & $-0,06$ & 0,95 \\
AMJ & $-0,03$ & $-0,10$ & 0,97 \\
JAS & 0,02 & 0,05 & 0,93 \\
OND & 0,16 & $-0,18$ & $-0,49$ \\
\hline
\end{tabular}

Quanto ao perfil vertical de autovetores do vento zonal (Figura 5), percebem-se fortes anomalias negativas em baixos e médios níveis em $e_{2}$ para JFM e em $e_{1}$ para AMJ. Esse resultado indica que essas EOF identificaram ocasiões com ventos de leste mais intensos nesses níveis, pois nos trópicos os ventos são predominantemente de leste em níveis mais baixos (ACEITUNO, 1987).

Anomalias negativas em baixos níveis e positivas em altos níveis são observadas nos perfis de autovetores $e_{1}$ para JAS e $e_{2}$ para OND, revelando situações de ventos de leste mais fortes em baixos níveis associados à ventos de oeste (leste) mais fortes (fracos) em altos níveis. O oposto é observado no perfil de $e_{1}$ em JFM, onde essa EOF apresenta anomalias positivas em baixos níveis e negativas em altos níveis e, consequentemente, 
identifica ventos de leste menos intensos em baixos níveis e de leste (oeste) mais (menos) intensos em altos níveis.

No período de AMJ, o segundo autovetor apresenta anomalias significativas apenas em altos níveis, sendo as mesmas positivas, já no período de JAS esse autovetor apresenta anomalias negativas em todo o perfil vertical. No gráfico referente a OND, $e_{1}$ aparece com anomalias positivas em todo o seu perfil vertical.

A terceira EOF mostrou-se com um perfil muito próximo de zero em JFM e AMJ, o que estaria relacionado a dias em que o perfil do vento zonal encontra-se próximo da média para o período. Em JAS, $e_{3}$ apresentou uma anomalia de $u$ positiva em $1000 \mathrm{hPa}$ e negativa em $700 \mathrm{hPa}$, o que pode estar relacionado a um jato de baixos níveis. Esse jato estaria associado a anomalias positivas de acpcp.

No período referente a OND, a terceira EOF apresentou um comportamento diferente dos outros períodos, oscilando entre fortes anomalias negativas em baixos e altos níveis e positivas em médios níveis. Na Tabela 5 é possível verificar que a terceira EOF do vento zonal está associada a acumulados de chuva acima da média para JFM, AMJ e JAS e abaixo da média para OND, as demais EOF relacionam-se a acumulados de chuva muito próximos da média.

Os coeficientes de expansão (série temporal das EOF) para $e_{1}, e_{2}$ e $e_{3}$ são mostrados nas Figuras 6, 7 e 8, respectivamente. Neles, é possível verificar os dias em que os autovetores representam melhor a variabilidade dos dados. Quanto maior for o módulo do coeficiente de expansão mais representativa é a EOF, e se o sinal do coeficiente de expansão for negativo inverte-se completamente o sinal das anomalias identificas pelas EOF. 

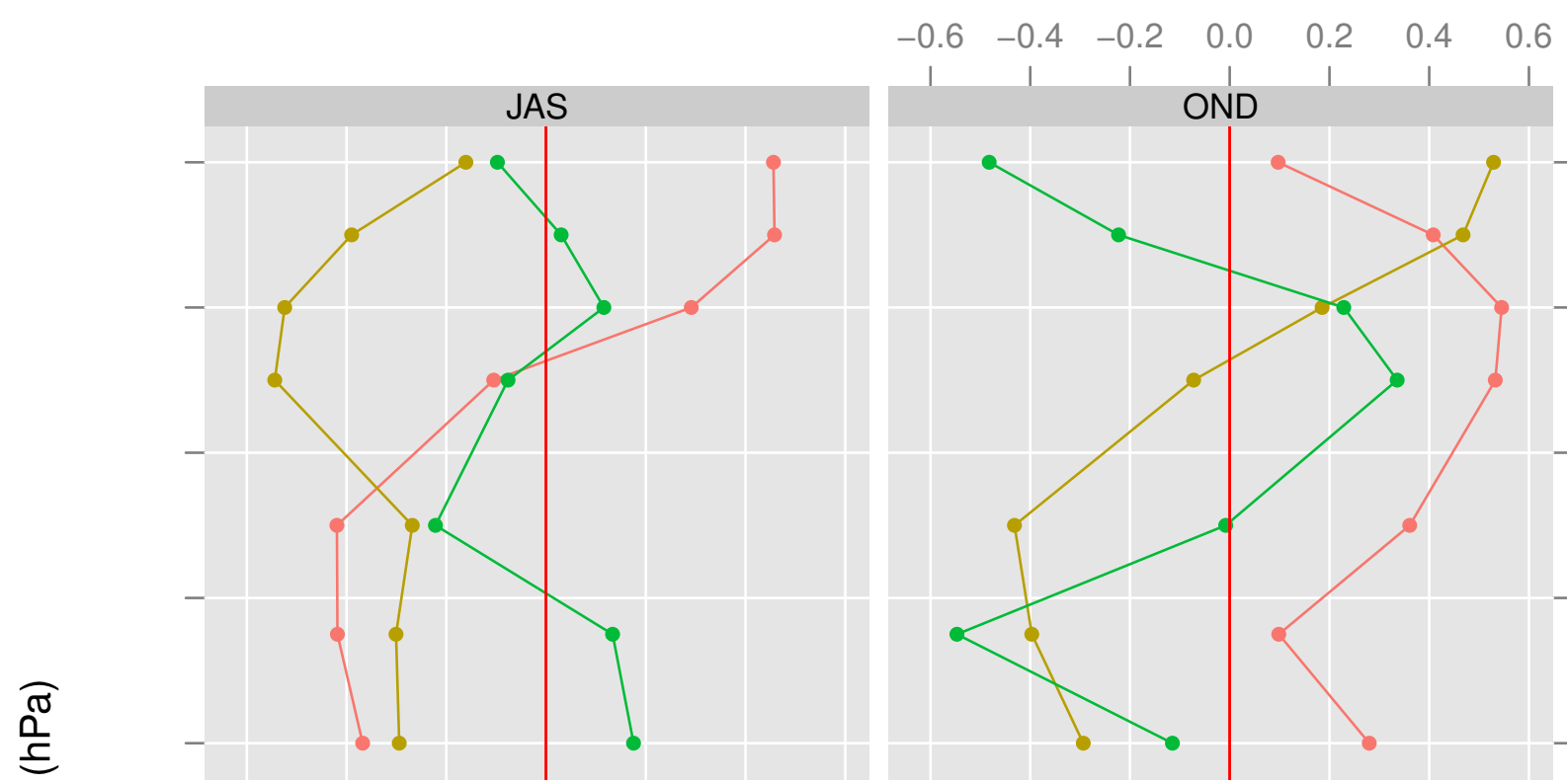

엃
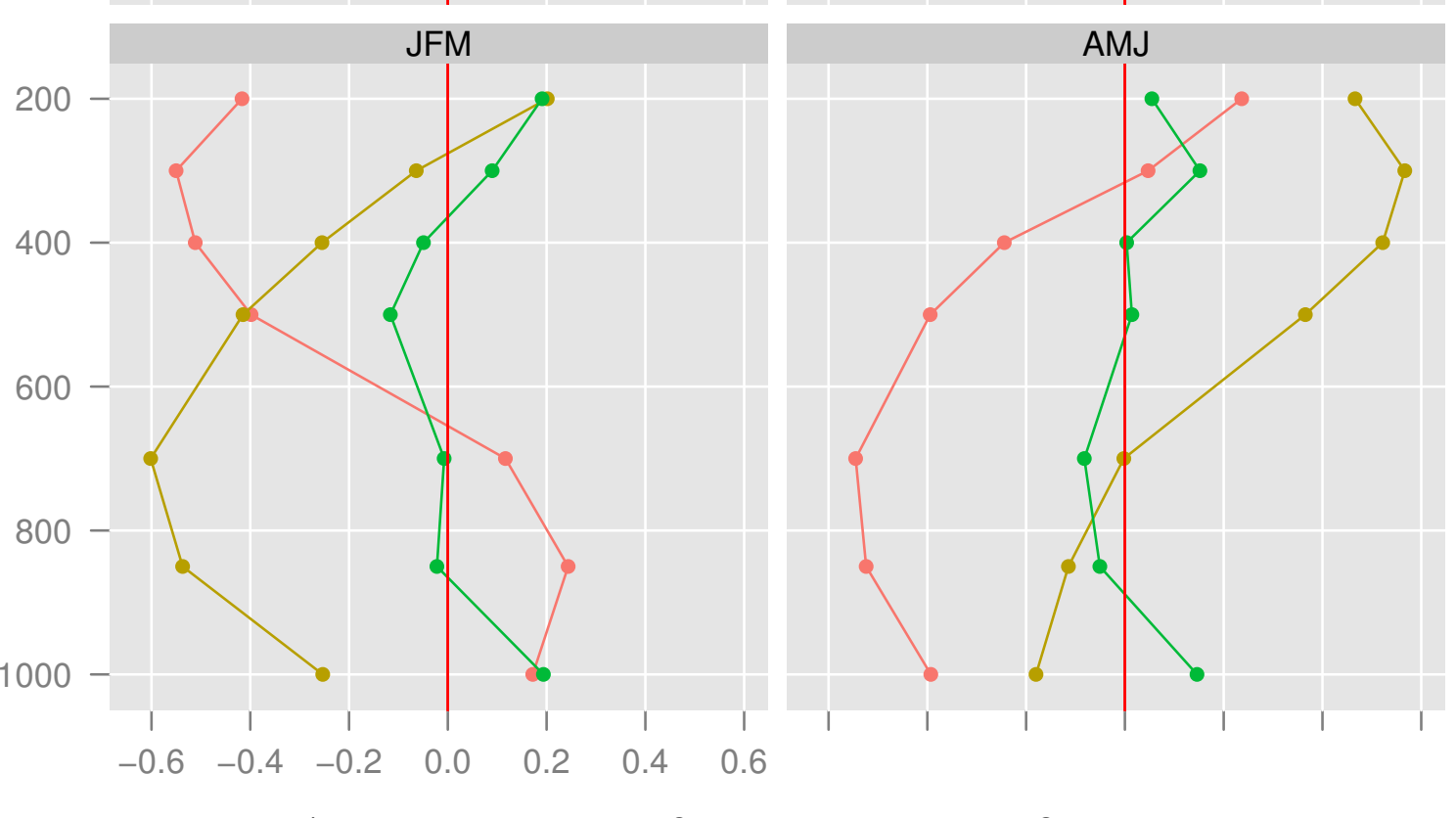

e1 - e2

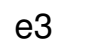

Figura 5: Perfil vertical dos três primeiros autovetores do vento zonal de cada período do ano. 


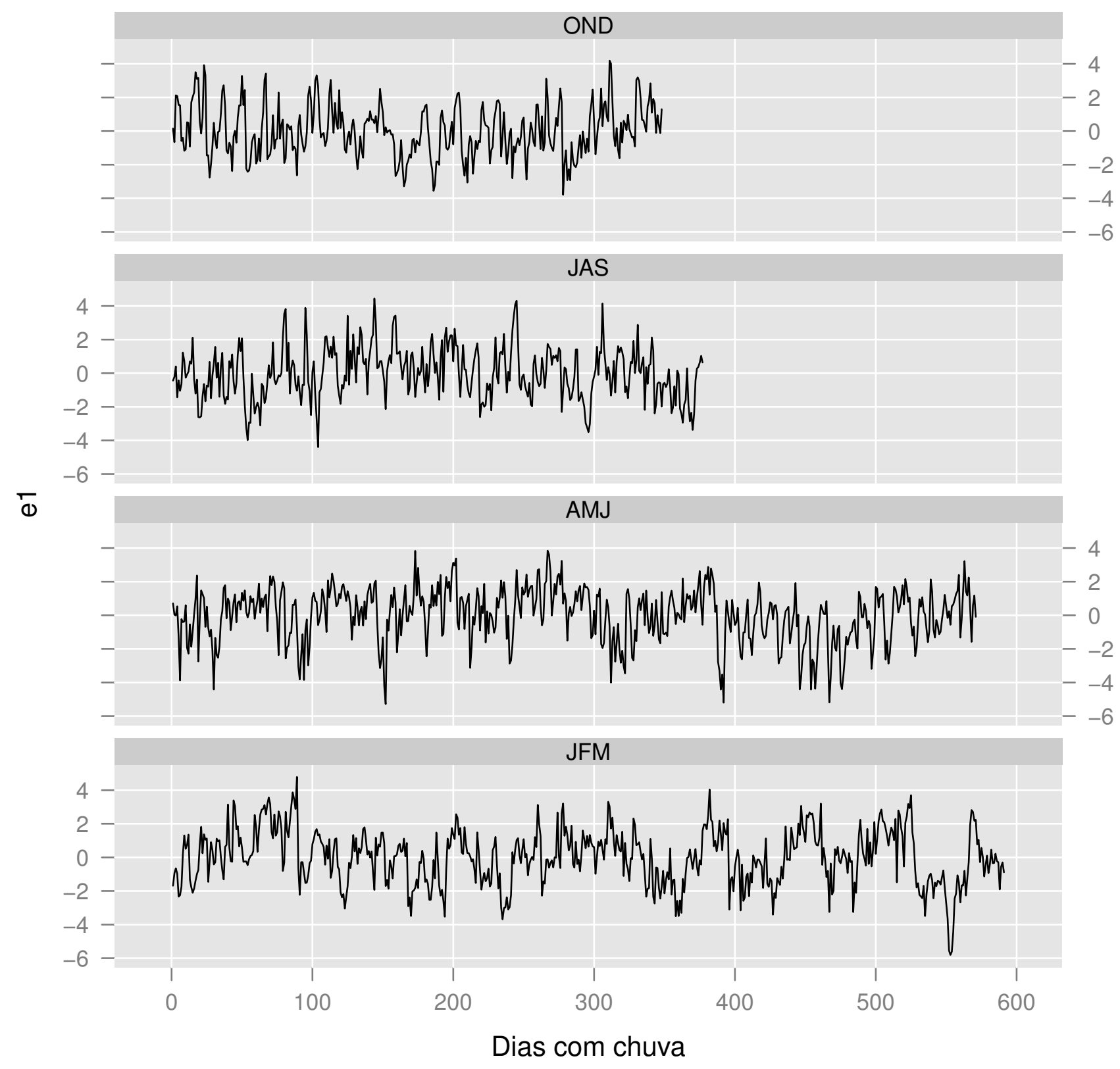

Figura 6: Série dos coeficientes de expansão de $e_{1}$ para os dias que o TRMM registrou chuva em cada período do ano. 


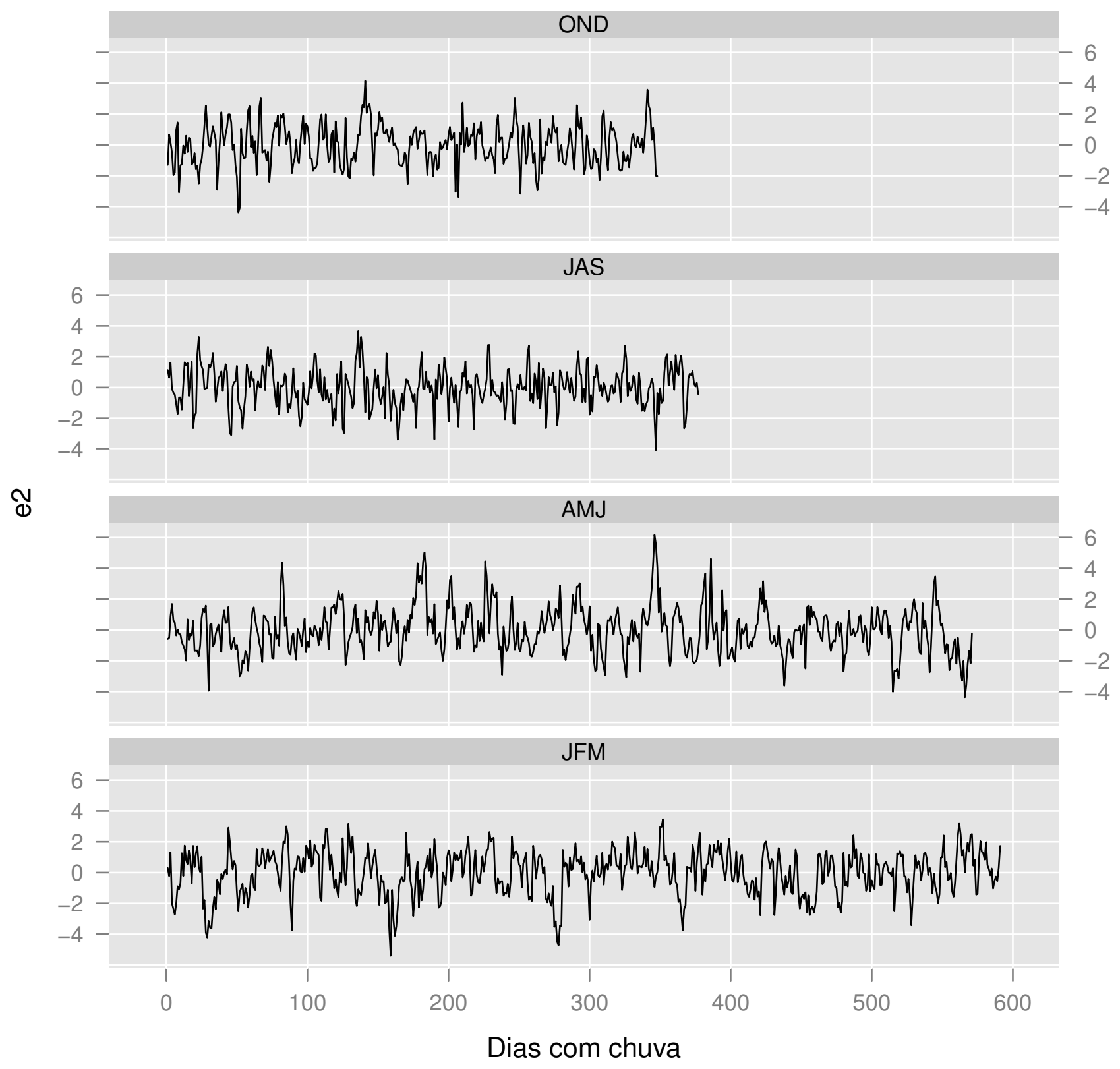

Figura 7: Série dos coeficientes de expansão de $e_{2}$ para os dias que o TRMM registrou chuva em cada período do ano. 


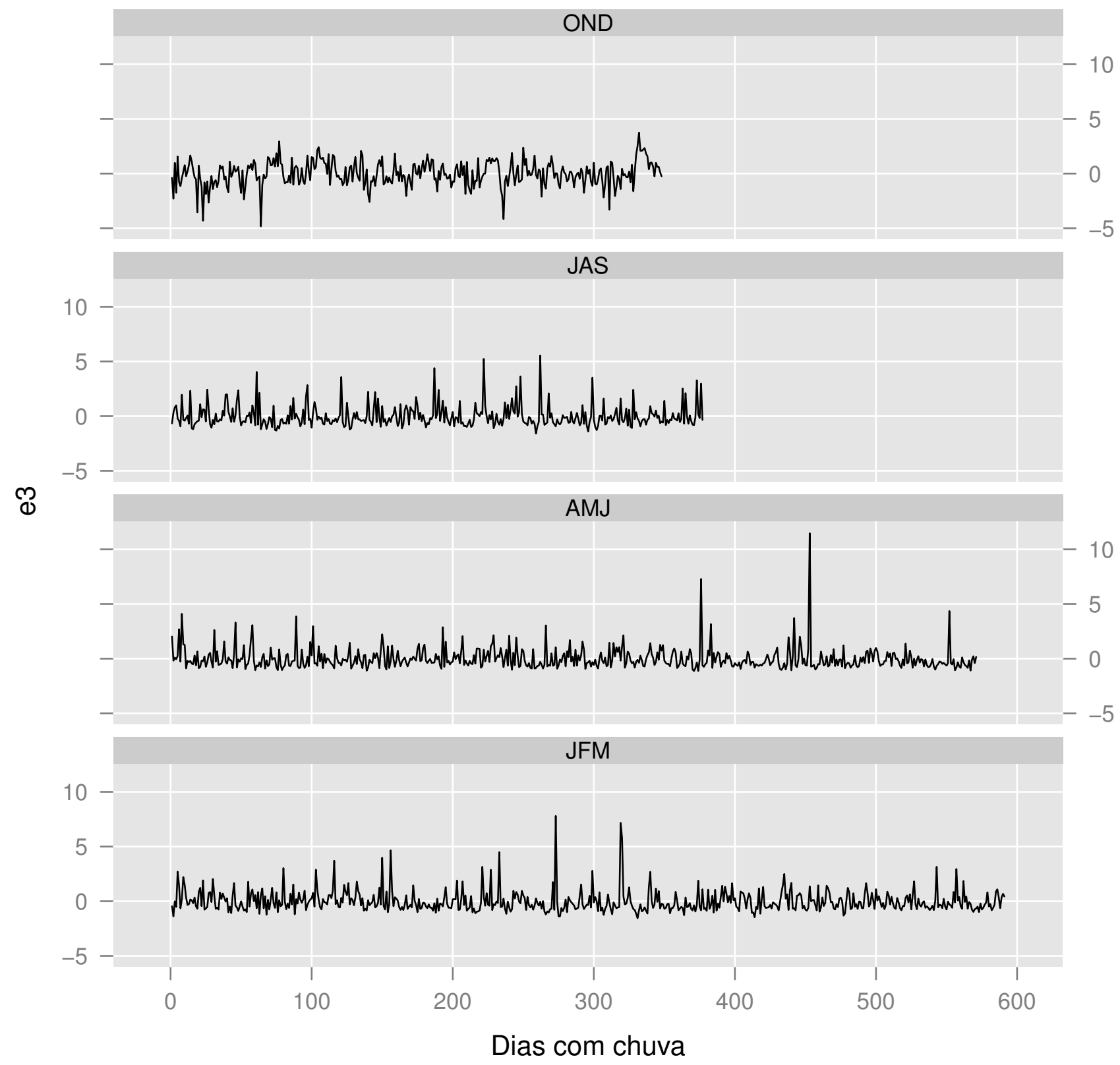

Figura 8: Série dos coeficientes de expansão de $e_{3}$ para os dias que o TRMM registrou chuva em cada período do ano. 
A Tabela 6 mostra os valores dos três primeiros autovetores das anomalias de acpcp para $[C]<0$. Como já discutido, quando a série temporal das EOF é negativa inverte-se o sinal dos autovetores, dessa forma a Tabela 6 mostra um padrão oposto ao apresentado na Tabela 5. Nesse caso, $e_{3}$ configura-se com anomalias de acpcp positivas para OND e negativas para JFM, AMJ e JAS, ou seja, esse autovetor está associado a acumulados diários de chuva abaixo da média para a maioria dos períodos, exceto para OND.

Tabela 6: Três primeiros autovetores da precipitação de cada período do ano para a série de coeficientes de expansão negativos.

\begin{tabular}{cccc}
\hline Período & $e_{1}$ & $e_{2}$ & $e_{3}$ \\
\hline JFM & $-0,03$ & 0,06 & $-0,95$ \\
AMJ & 0,03 & 0,10 & $-0,97$ \\
JAS & $-0,02$ & $-0,05$ & $-0,93$ \\
OND & $-0,16$ & 0,18 & 0,49 \\
\hline
\end{tabular}

As EOF relativas a sua série temporal negativa podem serem vistas na Figura 9. Os autovetores $e_{1}$ em JAS e $e_{2}$ em OND, neste contexto, estão associados a ventos de leste mais fracos que o valor médio dos dados em baixos níveis e ventos de leste (oeste) mais fortes (fracos) em altos níveis. No período de JFM, $e_{1}$ possui um padrão oposto ao de JAS e OND possui um perfil vertical completamente negativo. O segundo autovetor possui um perfil completamente positivo em JAS, enquanto que em AMJ esse autovetor tem anomalias significativas apenas em altos níveis, as quais são negativas. O terceiro autovetor somente apresentou anomalias significativas em OND, que oscilam entre positivas em baixos e altos níveis e negativas em médios níveis. 


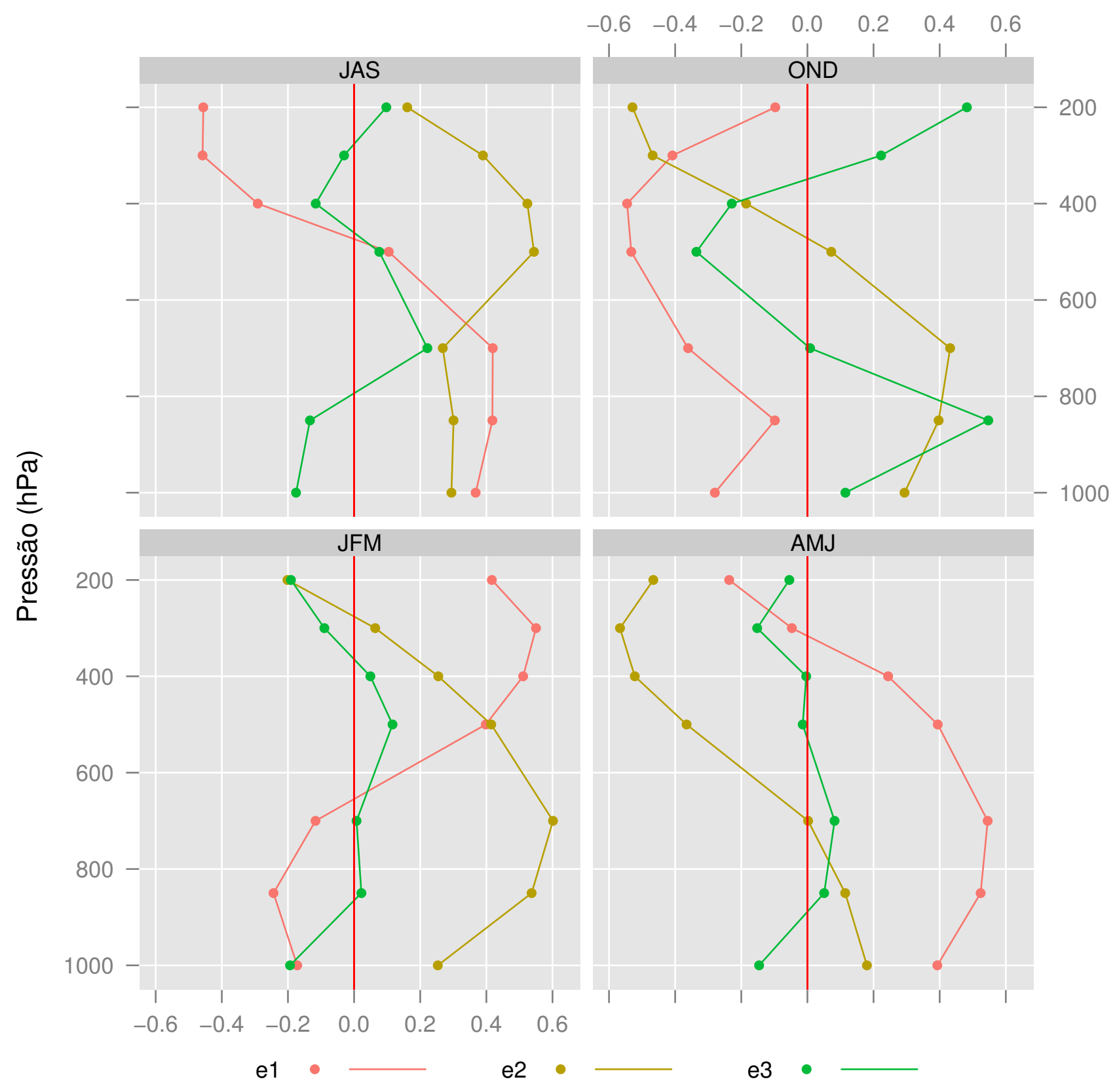

Figura 9: Perfil vertical dos três primeiros autovetores do vento zonal de cada período do ano para a série dos coeficientes de expansão negativos. 
As Tabelas 7 e 8 exibem o acumulado de chuva total para JFM, AMJ, JAS e OND referente a $[C]_{+10 \%}$ e $[C]_{-10 \%}$, respectivamente. Nota-se que os resultados concordam com a Tabela 5, pois quando têm-se anomalias positivas (negativas) de acumulado de chuva tem-se acpcp acima (abaixo) da média e quanto maior forem as anomalias positivas (negativas) maior (menor) tende a ser o acumulado registrado. O terceiro autovetor é o que apresenta as maiores anomalias de acpcp e em função disso possui os maiores acumulados de chuva de cada período e as maiores diferenças entre os acumulados de chuva relativos $\mathrm{a}[C]_{+10 \%}$ e $[C]_{-10 \%}$.

Tabela 7: Acumulado de chuva total de cada período do ano para $[C]_{+10 \%}$.

\begin{tabular}{cccc}
\hline Período & $e_{1}$ & $e_{2}$ & $e_{3}$ \\
\hline JFM & $1021 \mathrm{~mm}$ & $733 \mathrm{~mm}$ & $3887 \mathrm{~mm}$ \\
AMJ & $795 \mathrm{~mm}$ & $749 \mathrm{~mm}$ & $3417 \mathrm{~mm}$ \\
JAS & $552 \mathrm{~mm}$ & $414 \mathrm{~mm}$ & $1951 \mathrm{~mm}$ \\
OND & $706 \mathrm{~mm}$ & $189 \mathrm{~mm}$ & $142 \mathrm{~mm}$ \\
\hline
\end{tabular}

Tabela 8: Acumulado de chuva total de cada período do ano para $[C]_{-10 \%}$.

\begin{tabular}{cccc}
\hline Período & $e_{1}$ & $e_{2}$ & $e_{3}$ \\
\hline JFM & $796 \mathrm{~mm}$ & $1232 \mathrm{~mm}$ & $173 \mathrm{~mm}$ \\
AMJ & $938 \mathrm{~mm}$ & $1433 \mathrm{~mm}$ & $147 \mathrm{~mm}$ \\
JAS & $393 \mathrm{~mm}$ & $468 \mathrm{~mm}$ & $51 \mathrm{~mm}$ \\
OND & $247 \mathrm{~mm}$ & $843 \mathrm{~mm}$ & $1226 \mathrm{~mm}$ \\
\hline
\end{tabular}

Os histogramas do acumulado diário de chuva para cada período do ano referentes a $[C]_{+10 \%}$ e $[C]_{-10 \%}$ são mostrados nas Figuras 10 e 11, respectivamente. Neles, vemos que o terceiro autovetor foi o que mais destacou-se, pois seus os histogramas relativos às anomalias negativas do acumulado diário de chuva não registraram nenhum extremo chuvoso, exceto para OND que identificou alguns casos. Isso deve-se, provavelmente, ao fato de $e_{3}$ para OND possuir a menor anomalia de acpcp dentre os quatro períodos do ano.

Na comparação dos distribuições de frequência de acpcp de $[C]_{+10 \%}$ e $[C]_{-10 \%}$ entre cada período do ano, averígua-se que os histogramas $e_{1}$ são os mais semelhantes, provavelmente por estarem associados a pequenas anomalias de acumulados diários de chuva. Já $e_{2}$, por possuir anomalias maiores, distingue-se melhor entre as figuras, rastreando melhor os extremos de chuva.

Desta forma, podemos inferir que quanto maior for a anomalia de acpcp da EOF, melhor a EOF consegue separar os dias mais chuvosos dos menos chuvosos, ou seja, quanto maior a anomalia maior a capacidade da EOF de diferenciar os extremos de chuva. Tendo 
em vista que $e_{3}$ foi a EOF que melhor identificou os extremos chuvosos, a partir daqui será dada uma maior atenção a esse autovetor, fazendo-se uma análise mais detalhada do mesmo.

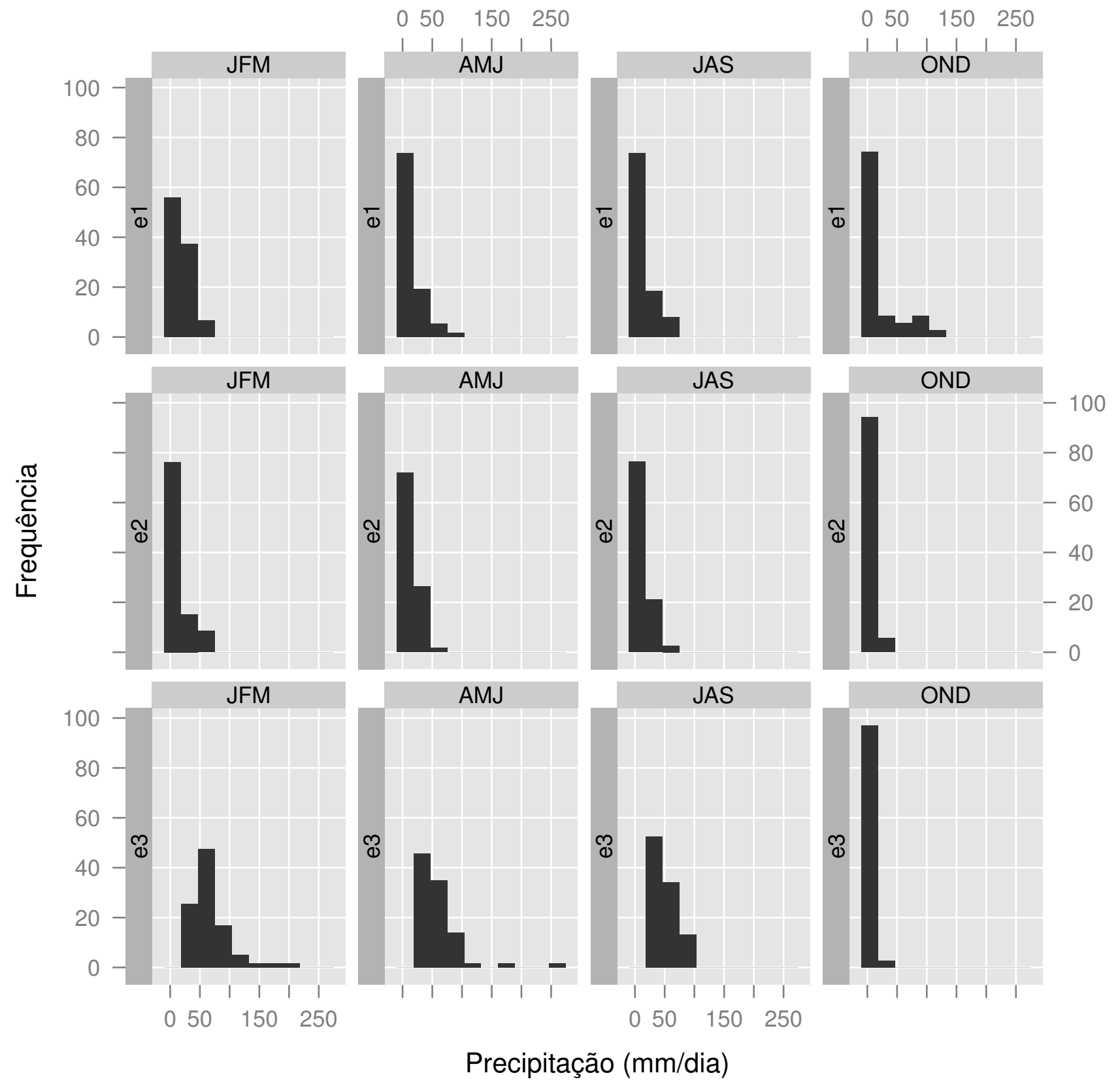

Figura 10: Histogramas de frequência do acumulado diário de chuva para $[C]_{+10 \%}$. 


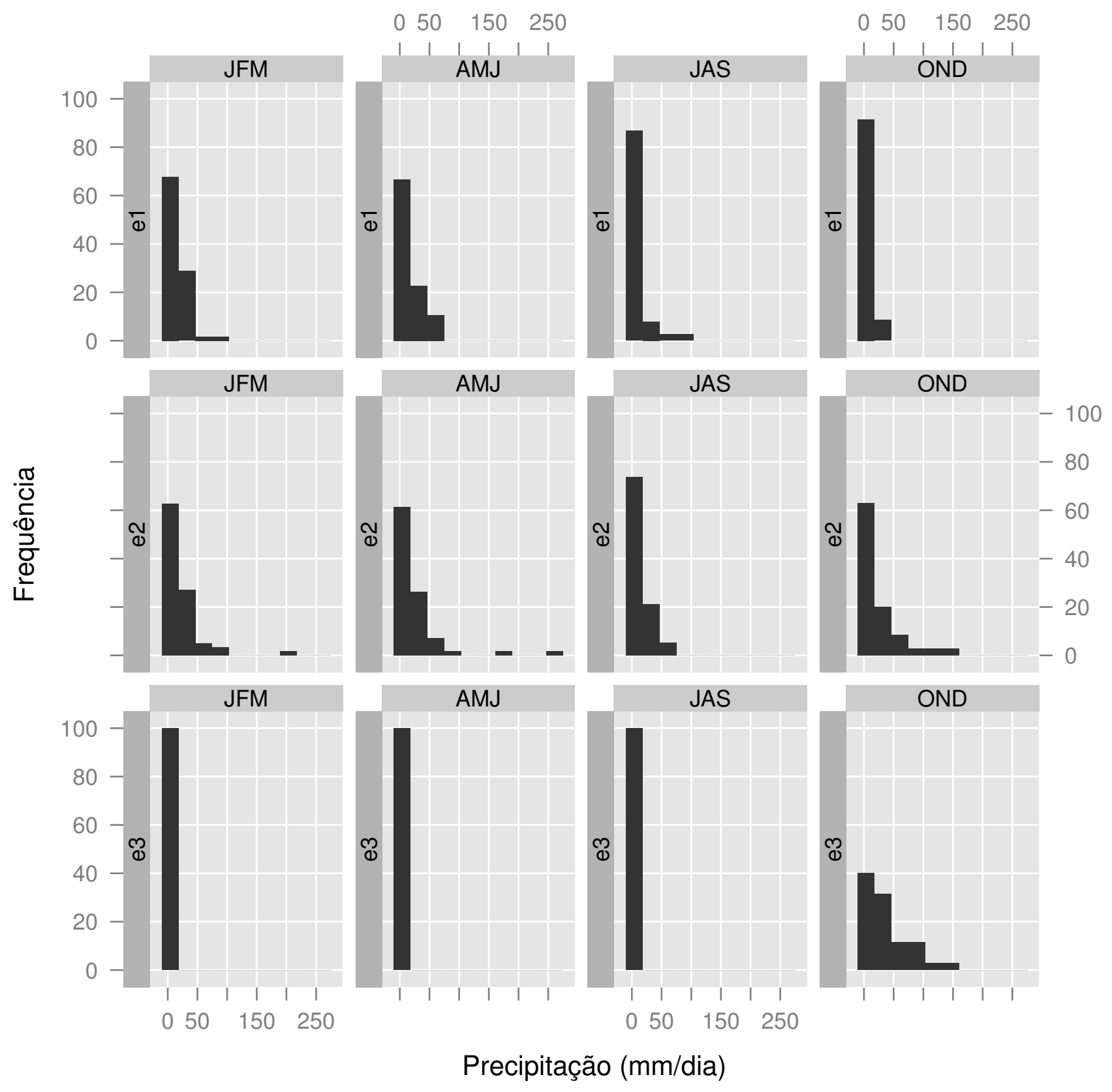

Figura 11: Histogramas de frequência do acumulado diário de chuva para $[C]_{-10 \%}$. 
As Figuras 12 e 13 exibem histogramas bidimensionais de frequência do vento zonal $(\mathrm{m} / \mathrm{s})$ de $e_{3}$ para $10 \%$ da série de dados com os maiores valores positivos $\left([C]_{+10 \%}^{e_{3}}\right)$ e negativos $\left([C]_{-10 \%}^{e_{3}}\right)$ do coeficiente de expansão, respectivamente. Como esperado, ambas as figuras apresentam ventos de leste nos níveis mais baixos (1000 a $700 \mathrm{hPa}$ ), sendo que em AMJ e JAS, tanto na Figura 12 quanto na Figura 13, o vento zonal é de leste em praticamente todo o perfil vertical. Nos níveis intermediários, não existe uma preferência tão bem definida como nos níveis baixos. Predomínio de ventos de oeste em altos níveis é observado para OND em 400 e 300 hPa na Figura 12b e em 300 e 200 hPa na Figura 13b, e para JAS em 200 hPa na Figura 13a.

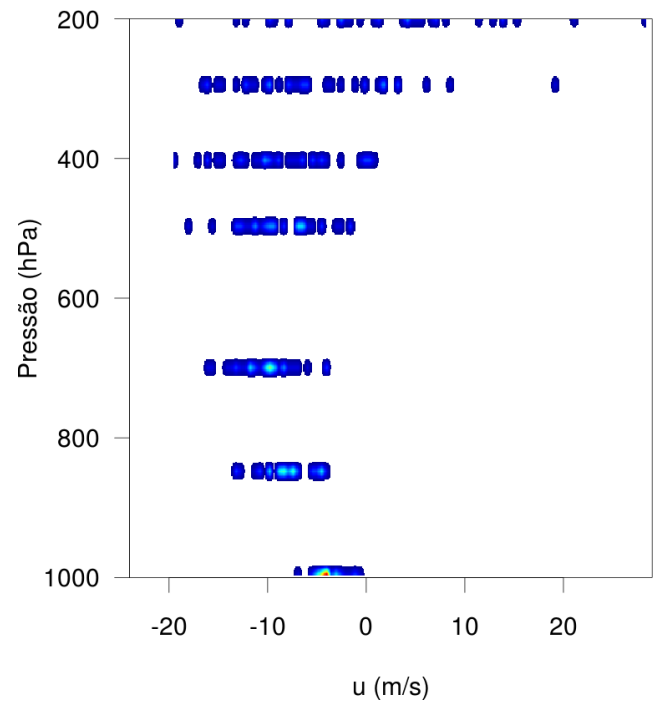

(a)

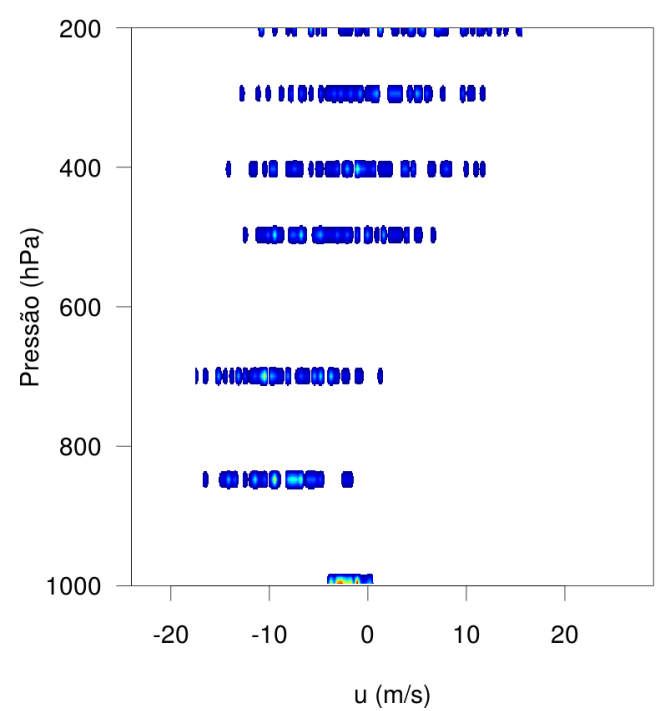

(c)
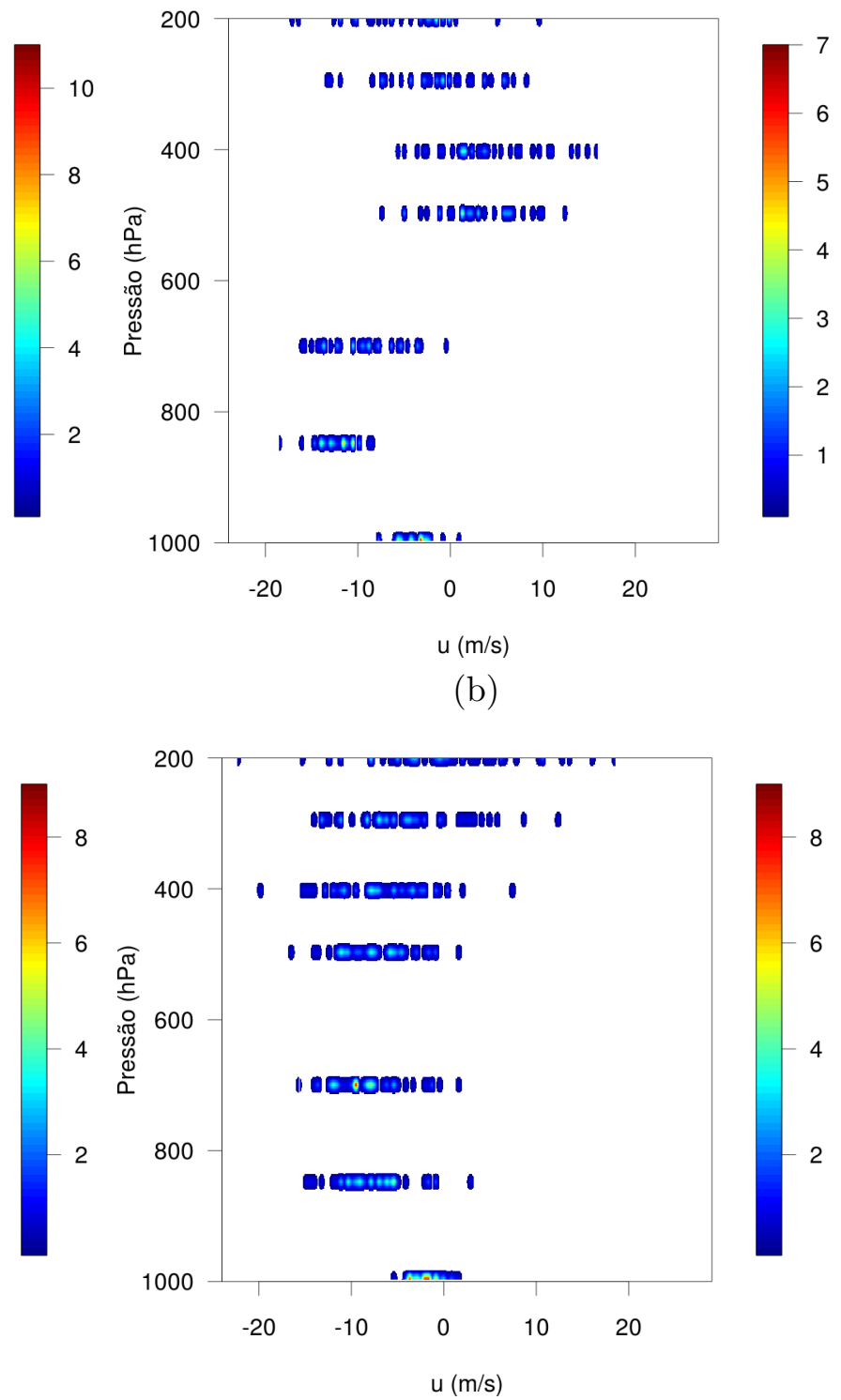

(d)

Figura 12: Histogramas bidimensionais de frequência do vento zonal $(\mathrm{m} / \mathrm{s})$ para $[C]_{+10 \%}^{e_{3}}$ em (a) JAS, (b) OND, (c) JFM e (d) AMJ. 


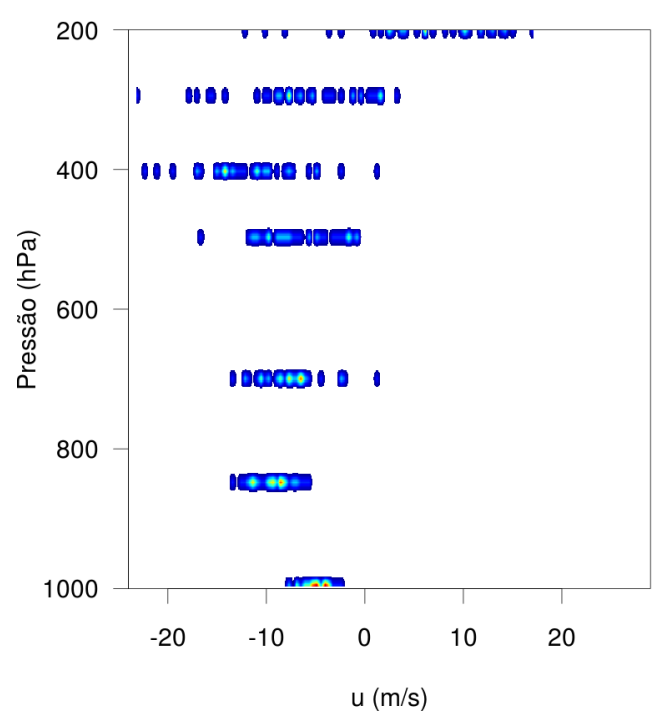

(a)

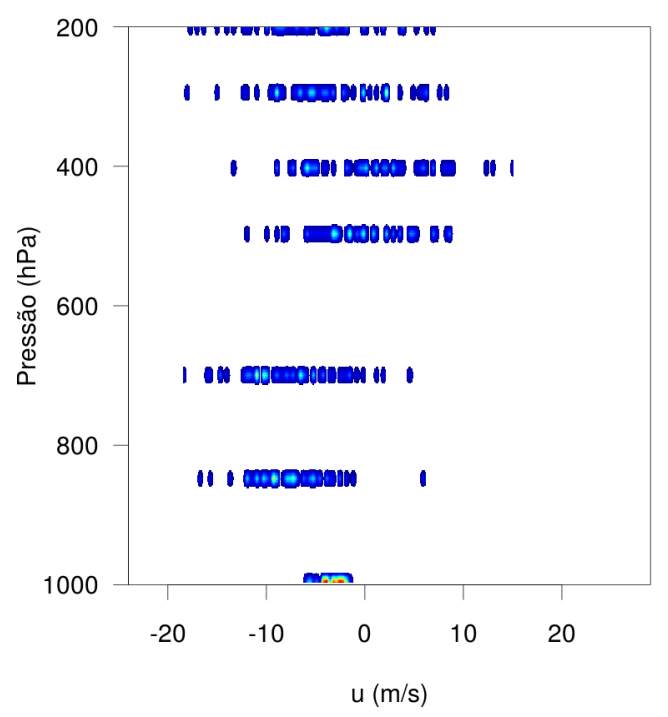

(c)

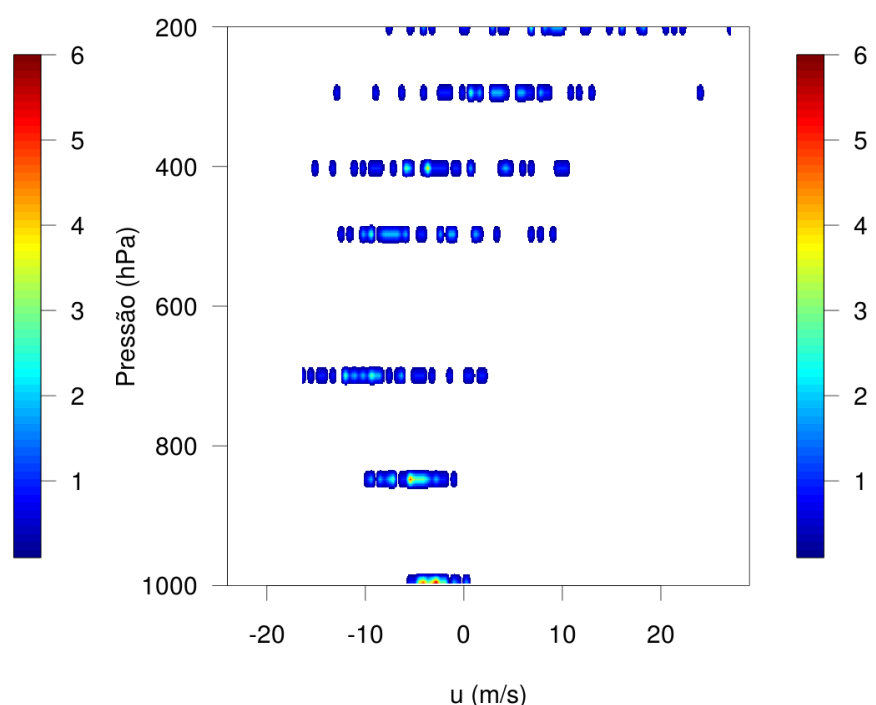

(b)

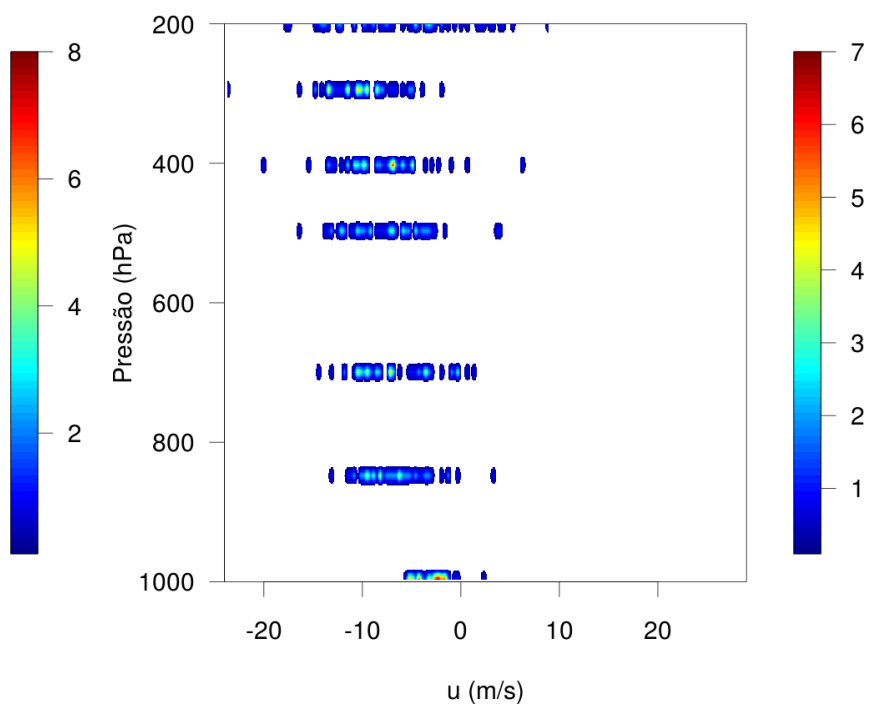

(d)

Figura 13: Histogramas bidimensionais de frequência do vento zonal $(\mathrm{m} / \mathrm{s})$ para $[C]_{-10 \%}^{e_{3}}$ em (a) JAS, (b) OND, (c) JFM e (d) AMJ. 
Similarmente aos histogramas de precipitação, foram confeccionados histogramas de CAPE, CINE e CISZ. Entretanto, esses histogramas foram feitos apenas para $e_{3}$, autovetor que melhor identificou extremos chuvosos como já foi discutido.

Logo adiante, seguem as Figuras 14 e 15, que apresentam histogramas de CAPE para $[C]_{+10 \%}^{e_{3}}$ e $[C]_{-10 \%}^{e_{3}}$, respectivamente. As distribuições de frequência de CAPE entre as duas figuras não apresentaram grandes diferenças. Porém, os períodos associados a anomalias positivas de chuva obtiveram uma leve tendência a possuírem valores maiores de CAPE. Aparentemente essa variável não é um fator determinante para ocorrência de extremos de chuva rastreados em Belém.

As Figuras 16 e 17 revelam distribuições de frequência de CINE para $[C]_{+10 \%}^{e_{3}}$ e $[C]_{-10 \%}^{e_{3}}$, respectivamente. Comparando-as, percebe-se que não há praticamente nenhuma diferença entre as mesmas, exceto para OND. O período OND apresentou uma distribuição de frequência um pouco mais espalhada na Figura 17 do que na Figura 16, tendo uma pequena inclinação a valores maiores de CINE associados a anomalias positivas de chuva. Contudo, assim como o CAPE, o CINE não se mostrou um parâmetro decisivo para a ocorrência de extremos na região em estudo.

A variável CISZ para $[C]_{+10 \%}^{e_{3}}$ e $[C]_{-10 \%}^{e_{3}}$ é apresentada logo em seguida nas Figuras 18 e 19 , respectivamente. Visualizando ambas as figuras, percebe-se que os maiores valores de frequência localizam-se mais à esquerda na Figura 18 do que na Figura 19 para JFM, AMJ e JAS, ou seja, maior frequência de valores mais expressivos de cisalhamento do vento zonal negativos para anomalias positivas de acumulados de chuva. Entretanto quando se compara a Tabela 10 a Tabela 11, nota-se que essa maior frequência é praticamente insignificante.

Os valores negativos de CISZ são explicados pela predominância de ventos de leste em baixos níveis e pela tendência do vento zonal em 700 hPa ser maior que em 1000 hPa. O período OND associado a anomalias positivas de chuva $\left([C]_{-10 \%}^{e_{3}}\right)$ exibiu um espectro de frequência de CISZ mais bem distribuído que o período OND associado a anomalias negativas de chuva.

A Tabela 9 mostra as frequências de eventos com valores de CISZ próximos de zero, entre $-1 \times 10^{-3}$ e $1 \times 10^{-3} \mathrm{~s}^{-1}$. Nota-se que os períodos de JFM, AMJ e JAS com $[C]_{-10 \%}^{e_{3}}$ apresentaram maiores frequências de dias com CISZ próximo de zero, destacando-se JAS com $52,6 \%$. Em OND não houve nenhuma diferença entre $[C]_{+10 \%}^{e_{3}}$ e $[C]_{-10 \%}^{e_{3}}$. 


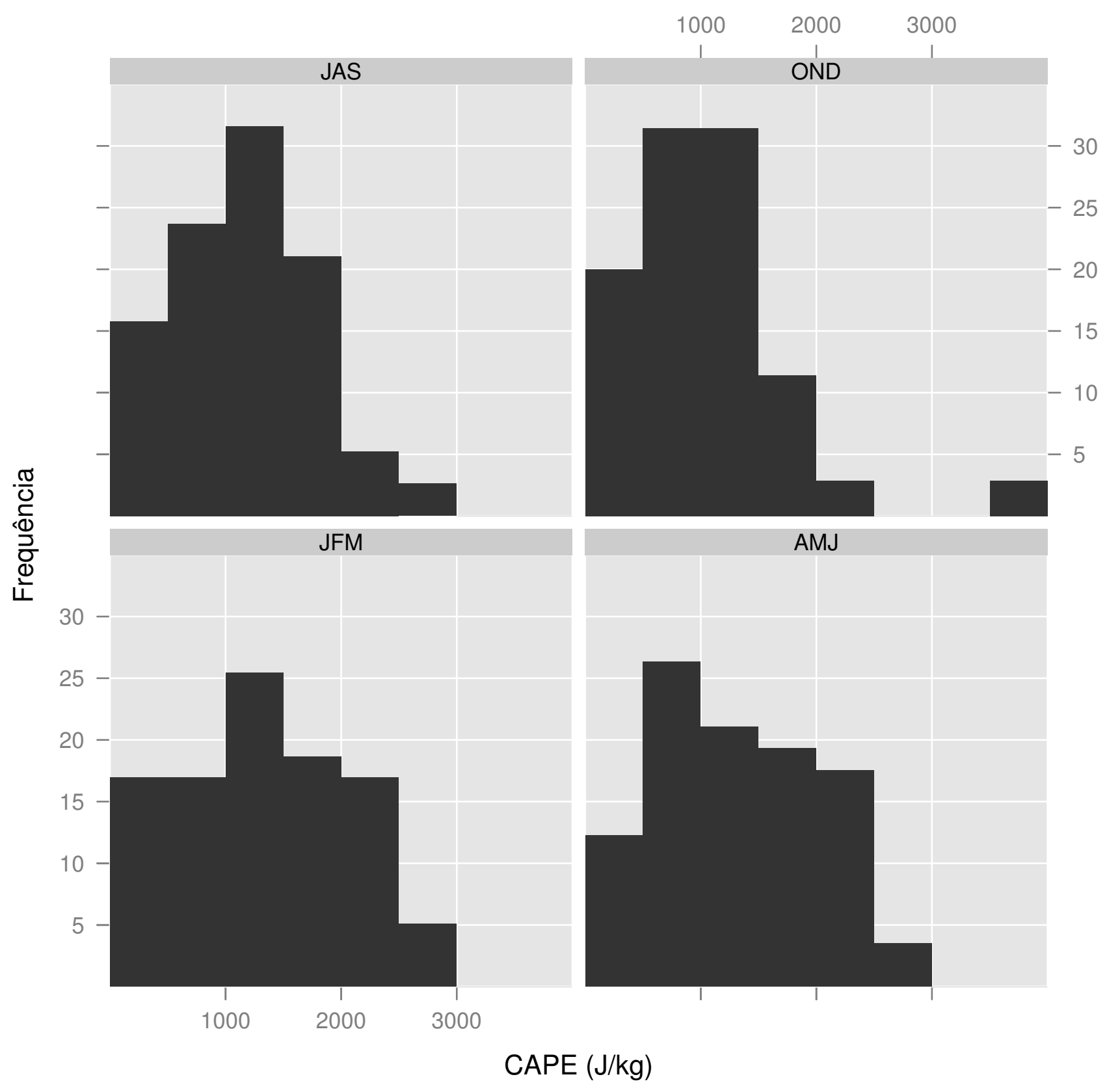

Figura 14: Histogramas de frequência de CAPE para $[C]_{+10 \%}^{e_{3}}$. 


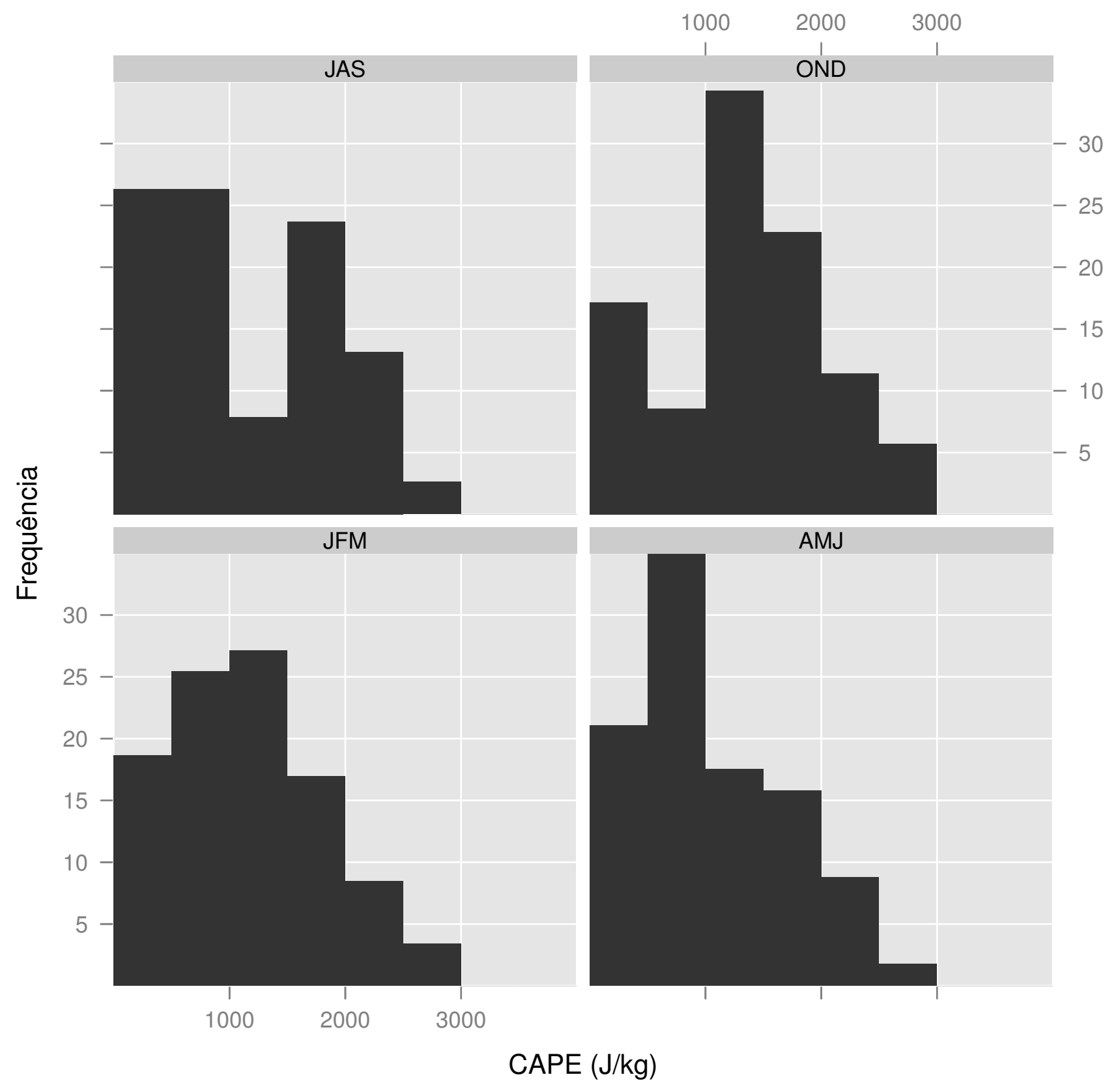

Figura 15: Histogramas de frequência de CAPE para $[C]_{-10 \%}^{e_{3}}$. 


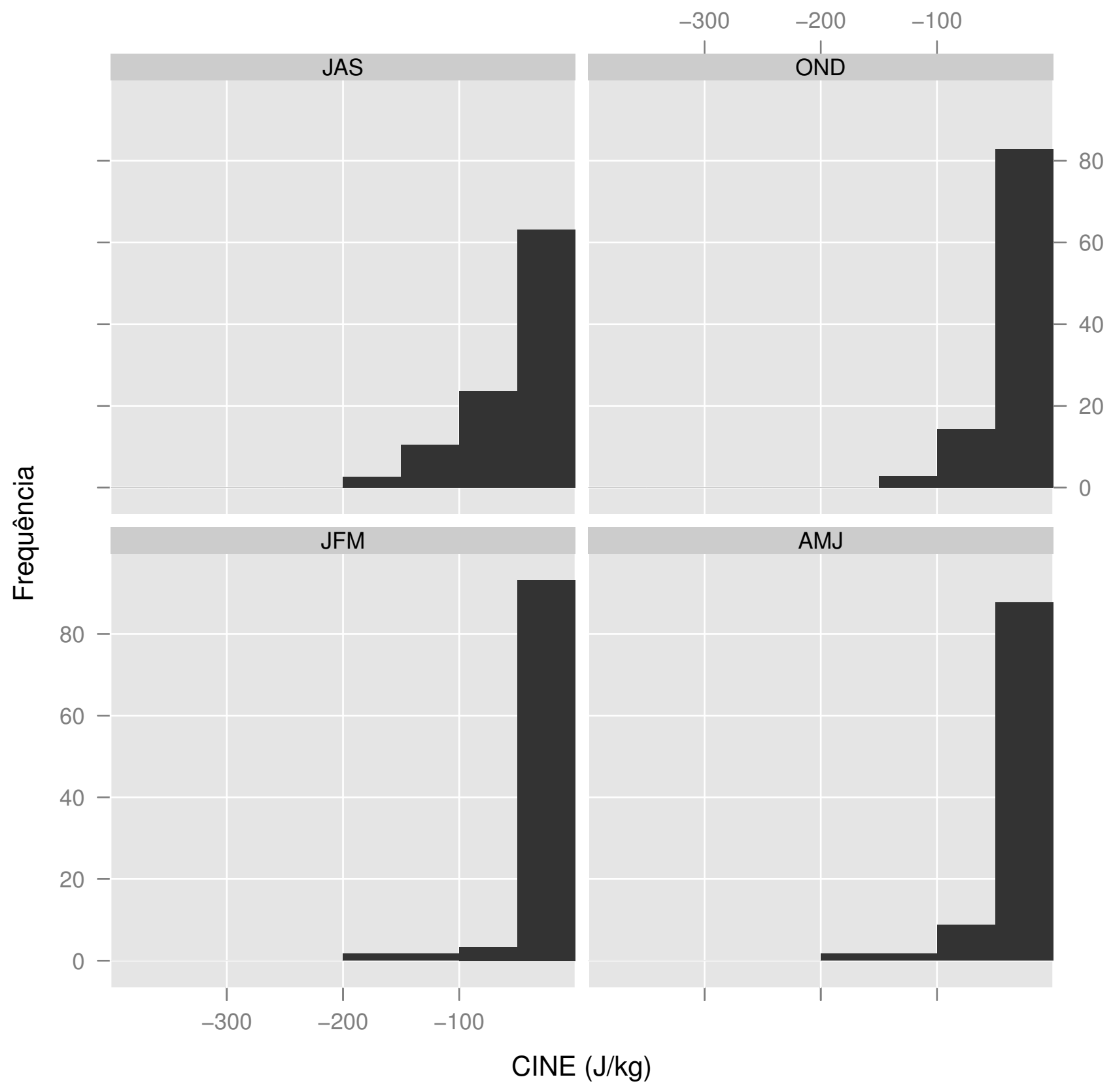

Figura 16: Histogramas de frequência de CINE para $[C]_{+10 \%}^{e_{3}}$. 


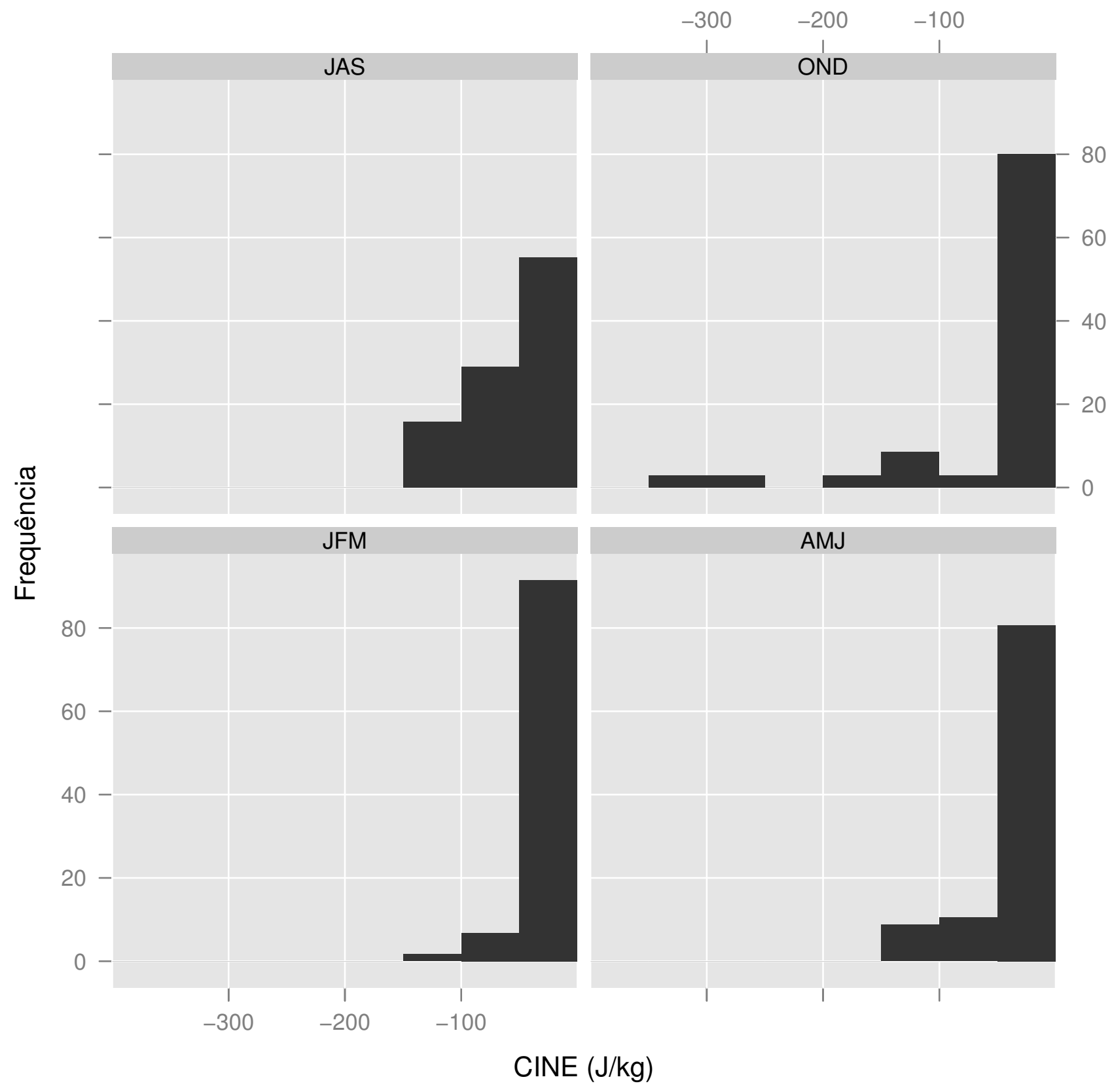

Figura 17: Histogramas de frequência de CINE para $[C]_{-10 \%}^{e_{3}}$. 


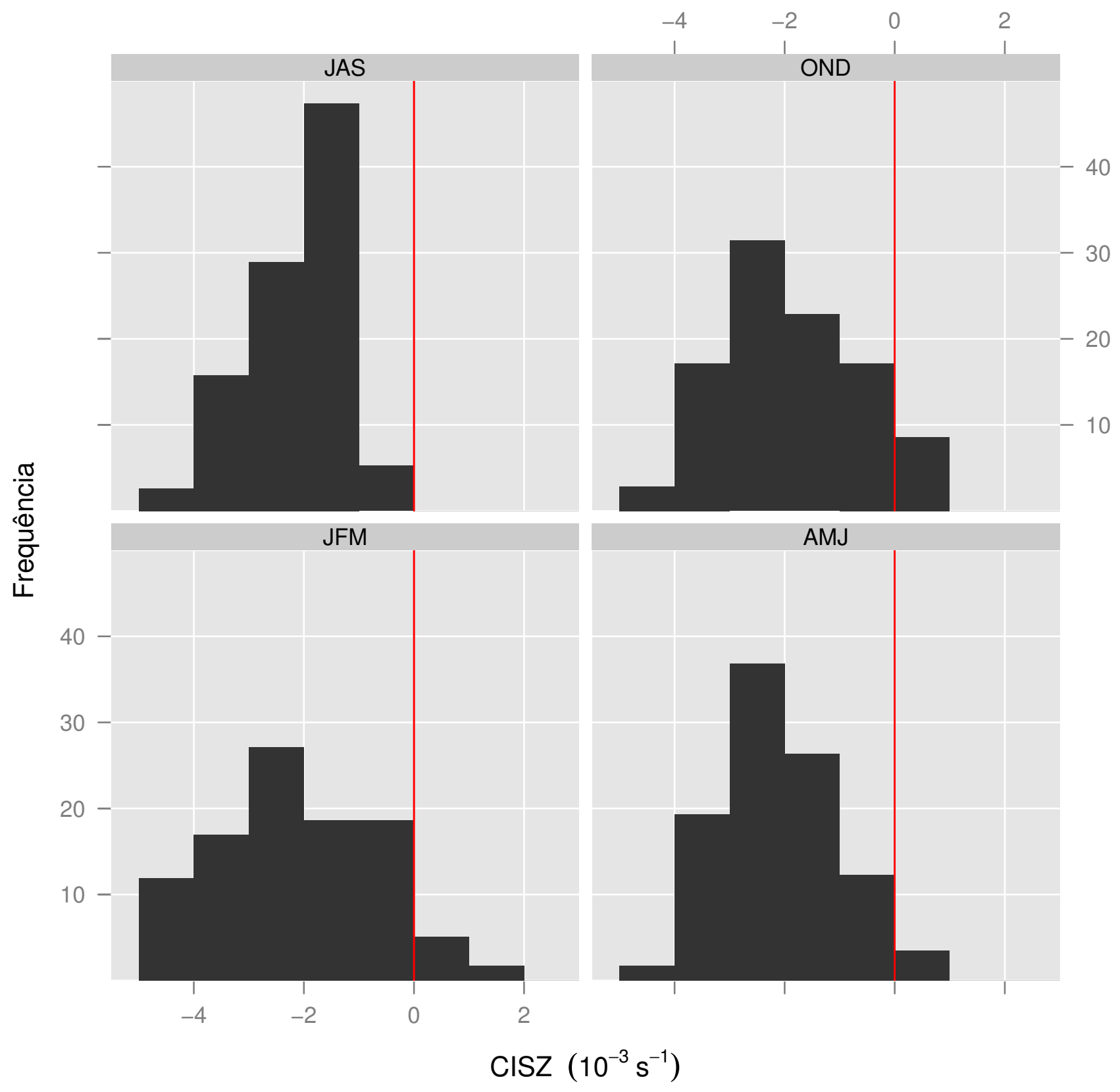

Figura 18: Histogramas de frequência de CISZ para $[C]_{+10 \%}^{e_{3}}$. 


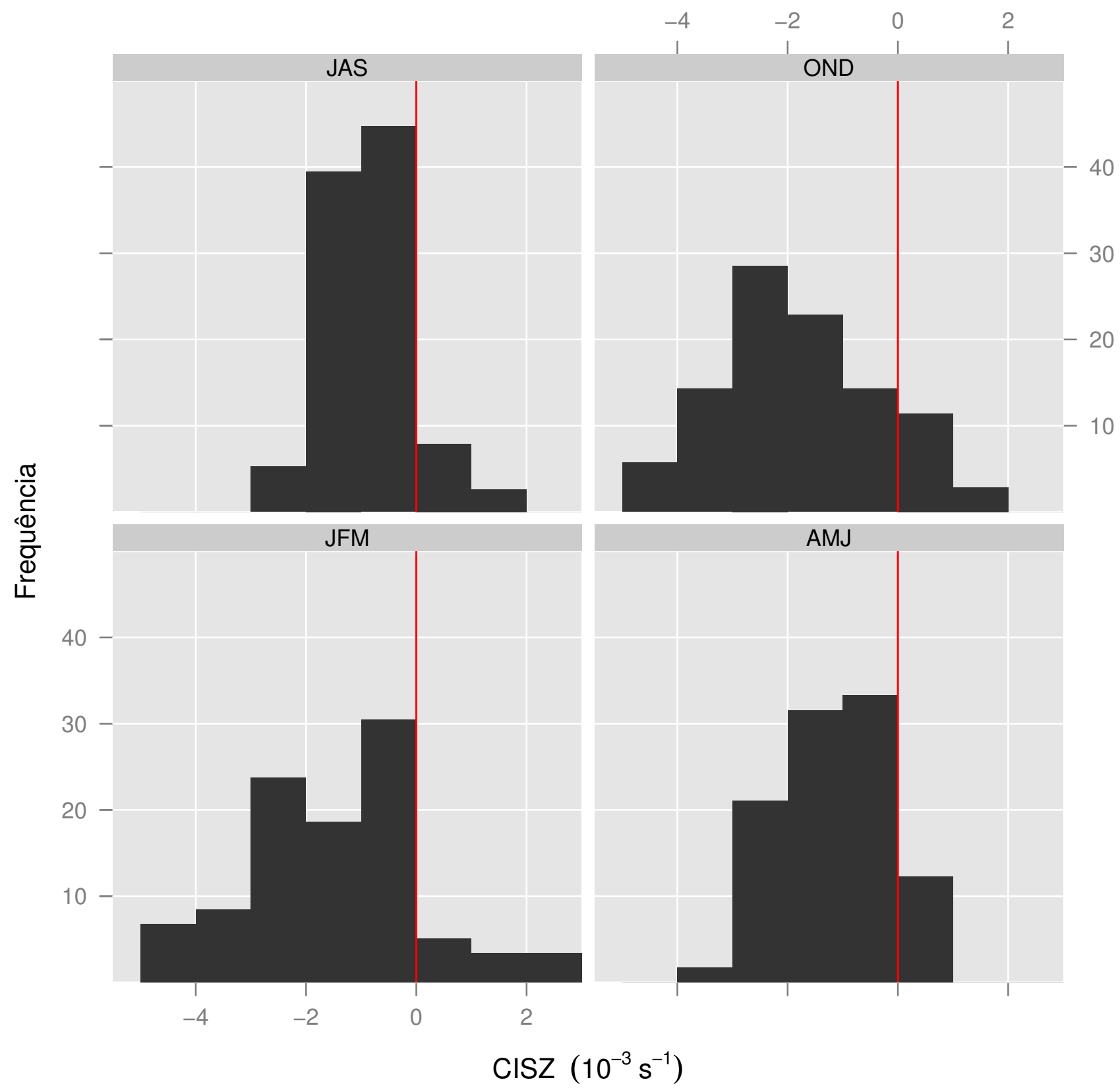

Figura 19: Histogramas de frequência de CISZ para $[C]_{-10 \%}^{e_{3}}$. 
Tabela 9: Frequência de eventos com CISZ entre $-1 \times 10^{-3} \mathrm{~s}^{-1}$ e $1 \times 10^{-3} \mathrm{~s}^{-1}$ para $[C]_{+10 \%}^{e_{3}}$ e $[C]_{-10 \%}^{e_{3}}$ em cada período de dados.

\begin{tabular}{ccc}
\hline Período & {$[C]_{+10 \%}^{e_{3}}$} & {$[C]_{-10 \%}^{e_{3}}$} \\
\hline JFM & $23,7 \%$ & $35,6 \%$ \\
AMJ & $15,8 \%$ & $45,6 \%$ \\
JAS & $5,3 \%$ & $52,6 \%$ \\
OND & $25,7 \%$ & $25,7 \%$ \\
\hline
\end{tabular}

Tabela 10: Frequência de eventos com CISZ positivo para $[C]_{+10 \%}^{e_{3}}$ em cada período de dados.

\begin{tabular}{ccc}
\hline Período & CISZ >0 & CISZ < 0 \\
\hline JFM & $6,78 \%$ & $93,22 \%$ \\
AMJ & $3,51 \%$ & $96,49 \%$ \\
JAS & $0 \%$ & $100 \%$ \\
OND & $8,57 \%$ & $91,43 \%$ \\
\hline
\end{tabular}

Tabela 11: Frequência de eventos com CISZ positivo para $[C]_{-10 \%}^{e_{3}}$ em cada período de dados.

\begin{tabular}{ccc}
\hline Período & CISZ $>0$ & CISZ $<0$ \\
\hline JFM & $11,86 \%$ & $88,14 \%$ \\
AMJ & $12,28 \%$ & $87,72 \%$ \\
JAS & $10,53 \%$ & $89,47 \%$ \\
OND & $14,29 \%$ & $85,71 \%$ \\
\hline
\end{tabular}

Através da série dos coeficientes de expansão de $e_{3}$, foram identificados os dias em que os mesmos são máximos e mínimos (máximos negativos) para cada período do ano. Os perfis de vento zonal desses dias são os que melhor correlacionam-se com os perfis da componente vento zonal da terceira EOF, portanto são ideais para averiguar os padrões associados a chuva. Desta forma, serão feitas análises sinóticas para identificar os sistemas atuantes e simulações numéricas com grades de 1x1 km de resolução horizontal, a fim de avaliar o vigor da convecção sobre a região de interesse. A análise sinótica será apresentada na próxima seção (seção 3.2) e a análise das simulações numéricas realizadas com o BRAMS para grade 4 na seção 3.3. 
Logo abaixo, seguem os dias identificados pela série temporal das EOF:

Para os coeficientes de expansão máximos:

- JFM - 16 de janeiro de 2004;

- AMJ - 9 de abril de 2009;

- JAS - 22 de agosto de 2007;

- OND - 4 de dezembro de 2009.

Para os coeficientes de expansão mínimos:

- JFM - 4 de janeiro de 2005;

- AMJ - 1 de junho de 2007;

- JAS - 16 de agosto de 2007;

- OND - 3 de outubro de 2007.

O dia 3 de outubro de 2007 corresponde ao terceiro menor (maior negativo) coeficiente de expansão de $e_{3}$. Optou-se por esse dia, pois para os casos referentes ao primeiro e ao segundo menor coeficiente não havia dados de análise do GFS com pelo menos $1^{\circ} \times 1^{\circ}$ de resolução espacial para inicializar o modelo. Todavia, os valores entre esses coeficientes de expansão são bem próximos.

As Tabelas 12 e 13 mostram o асрсp para os dias rastreados pelos coeficientes positivos e negativos, respectivamente. Apenas recordando que os acumulados de 24 horas de chuva foram computados a partir das 12 UTC das datas expostas nessas tabelas.

Os dias associados às anomalias positivas de acpcp (16/01/2004, 09/04/2009, 22/08/2007 e 03/10/2007) foram os que registraram os maiores acumulados de chuva, os quais, segundo a análise feita através de quantis (Tabela 3), foram considerados extremos chuvosos para a série de dados de precipitação registrados pelo TRMM. As datas relativas às anomalias negativas de асрср (04/01/2005, 01/06/2007, 16/08/2007 e 04/12/2009) apresentaram acumulados de chuva muito próximos de zero. Os períodos JFM e AMJ da Tabela 12 possuem os maiores acumulados diários de chuva e compreendem o período mais chuvoso de Belém. Esses resultados evidenciam o bom desempenho de $e_{3}$ na identificação dos extremos chuvosos. 
Tabela 12: Acumulado diário de chuva de cada período do ano para os dias com coeficiente de expansão máximo.

\begin{tabular}{cc}
\hline Data & acpcp $(\mathrm{mm})$ \\
\hline $16 / 01 / 2004$ & 209,55 \\
$09 / 04 / 2009$ & 264,46 \\
$22 / 08 / 2007$ & 101,28 \\
$04 / 12 / 2009$ & 1,04 \\
\hline
\end{tabular}

Tabela 13: Acumulado diário de chuva de cada período do ano para os dias com coeficiente de expansão mínimo ou máximo negativo.

\begin{tabular}{cc}
\hline Data & acpcp $(\mathrm{mm})$ \\
\hline $04 / 01 / 2005$ & 1,79 \\
$01 / 06 / 2007$ & 0,46 \\
$16 / 08 / 2007$ & 0,77 \\
$03 / 10 / 2007$ & 83,93 \\
\hline
\end{tabular}

\subsection{Análise sinótica}

\subsubsection{6 de janeiro de 2004}

Os campos sinóticos de linhas de corrente e divergência do vento em 1000, 500, e 200 hPa são apresentados na Figura 20 para 16 de janeiro de 2004 às 12 UTC. Em superfície (Figura 20a), verifica-se um escoamento perpendicular à costa do Pará e convergente sobre a mesma, agindo como um gatilho para disparar a convecção na região. Mais acima, em médios níveis (Figura 20b), há uma região de divergência imersa em um escoamento de nordeste sobre a região citada.

Pode-se notar um vórtice ciclônico em altos níveis sobre o oceano Atlântico e a oeste do mesmo, sobre o continente, a Alta da Bolívia. Juntos, formam uma região de difluência do escoamento situada entre os dois sistemas sinóticos, o que contribui para convecção profunda na região de Belém. Embora exista uma pequena região de convergência fraca, a mesma encontra-se rodeada por campos divergentes mais significativos, sendo facilmente suprimida por sistemas convectivos vizinhos. Desta forma, pode-se inferir que Belém está sob uma atmosfera favorável ao desenvolvimento de nebulosidade e consequentemente precipitação neste dia.

As imagens realçadas do canal do infravermelho do satélite GOES 12 (Figura 21) mostram inúmeras tempestades embebidas nesse ambiente. Sobre Belém, em particular, verifica-se um sistema convectivo de mesoescala que provavelmente foi originado por uma ação conjunta entre aquecimento diurno, brisa marítima e difluência em níveis superiores, 
sendo que a fase mais ativa da tempestade ocorreu por volta das 20:45 UTC.

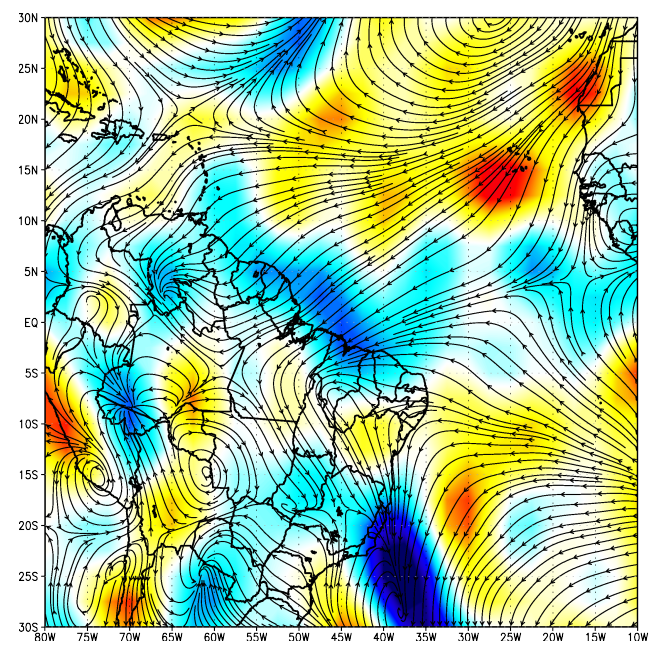

(a)
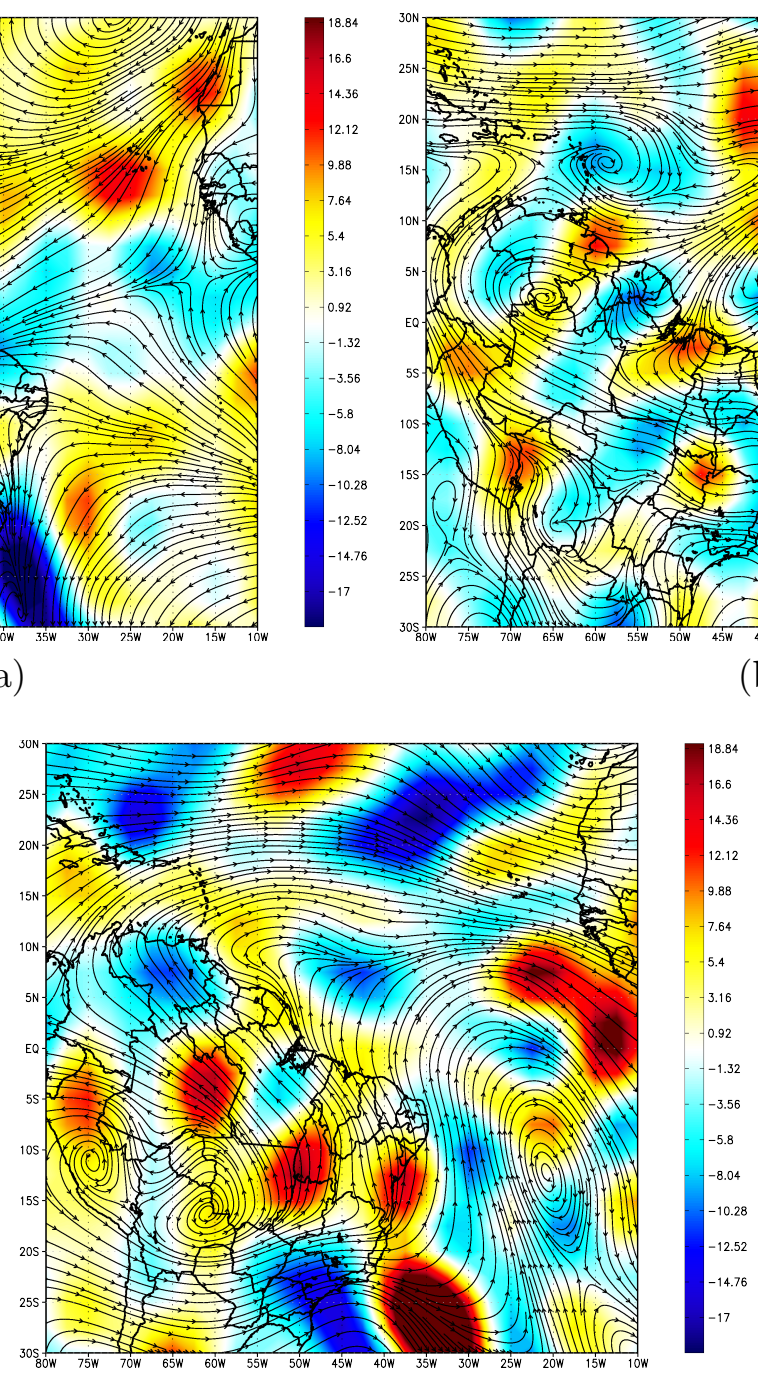

(c)

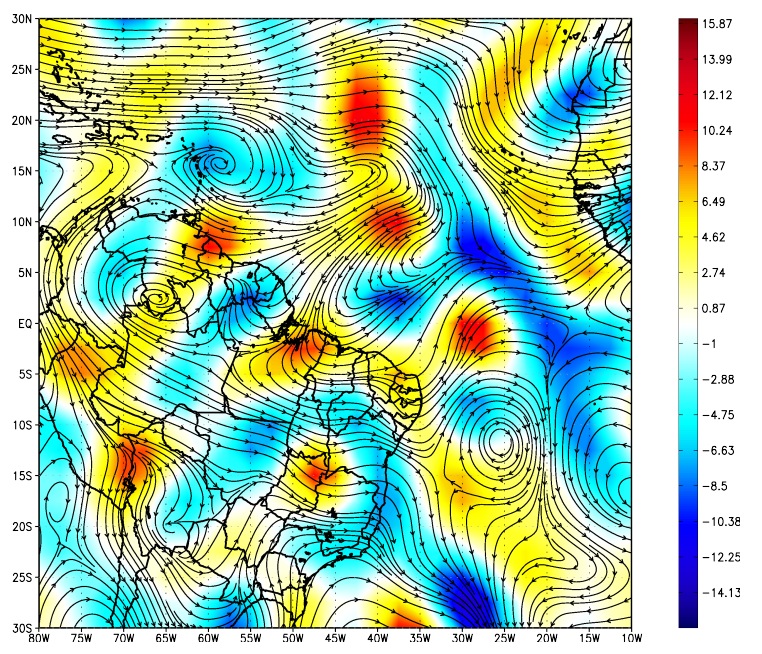

(b)

Figura 20: Campos de linhas de corrente e divergência do vento (sombreado) em $10^{-6} \mathrm{~s}^{-1}$ para 16/01/2004 às 12 UTC em (a) 1000, (b) 500 e (c) $200 \mathrm{hPa}$. 


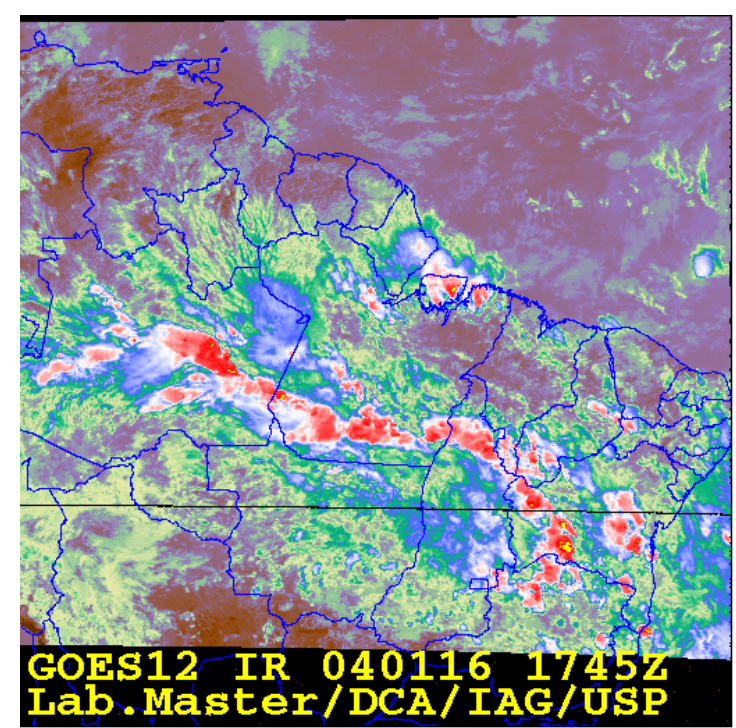

(a)

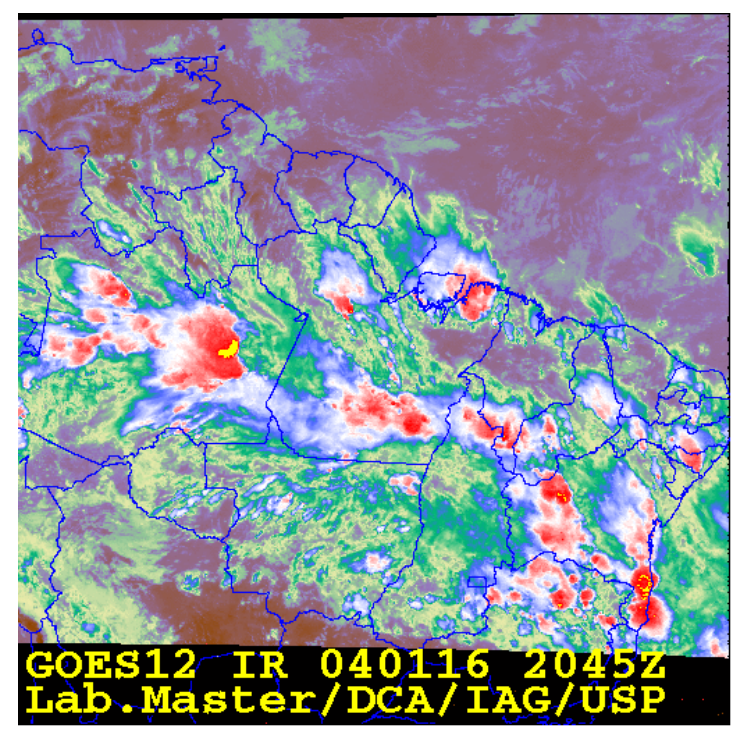

(c)

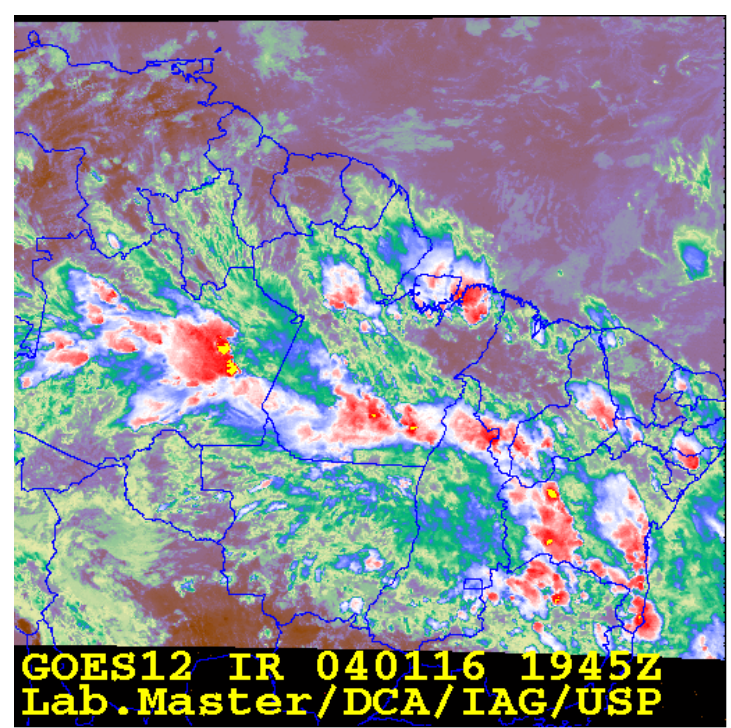

(b)

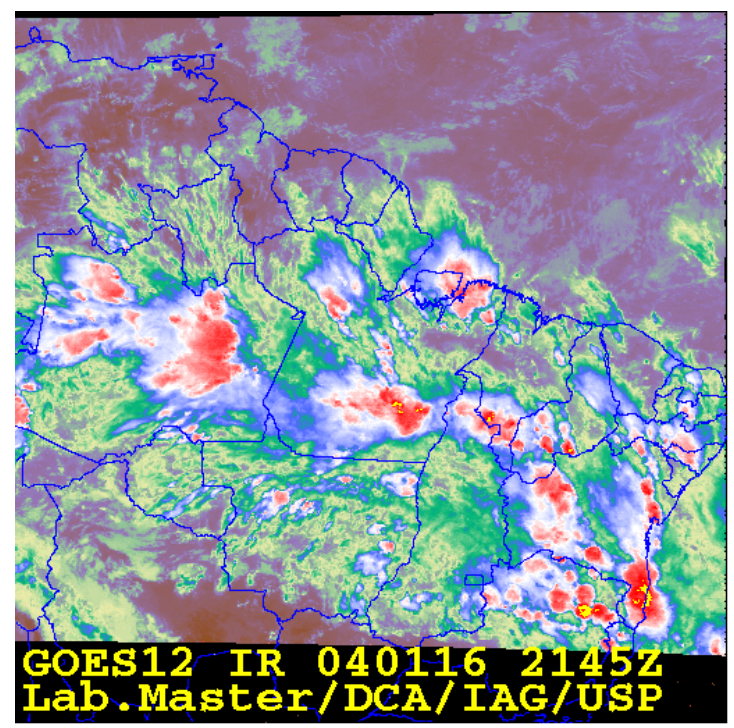

(d)

Figura 21: Imagens do satélite GOES 12 realçadas no canal do infravermelho para 16/01/2004 para os horários das (a) 17:45, (b) 19:45, (c) 20:45 e (d) 21:45 UTC. 


\subsubsection{9 de abril de 2009}

A Figura 22 exibe linhas de corrente e divergência do vento em 1000, 500 e 200 hPa para 9 de abril de 2009 às 12 UTC. Neste dia, como no caso anterior, o escoamento estava perpendicular à costa paraense em superfície (Figura 22a). No mapa sinótico de $500 \mathrm{hPa}$ (Figura 22b), foi identificada uma zona de divergência entre ventos de leste sobre a metade norte do Pará.

De forma similar ao caso anterior, percebe-se um vórtice ciclônico próximo à costa nordeste do Brasil e, logo abaixo, encontra-se a Alta da Bolívia sobre o Centro-Oeste do Brasil em 200 hPa (Figura 22c). Novamente, observa-se uma zona de divergência em níveis mais altos entre dois sistemas sinóticos, favorecendo o movimento ascendente. Porém, neste caso, a zona de divergência é mais intensa e compreende praticamente todo o estado do Pará. Somada a esse efeito, existe a divergência gerada pela próprio VCAN como consequência da atividade convectiva no seu flanco oeste, criando assim um ambiente extremamente favorável ao desenvolvimento de convecção profunda.

Através de imagens de satélite (Figura 23), nota-se, inicialmente, a formação de uma linha de instabilidade sobre a costa nordeste brasileira, surgindo como um provável resultado do escoamento perpendicular à mesma, brisa marítima e aquecimento diurno. Logo em seguida, a parte oeste desse sistema separa-se e avança para noroeste, dividindo-se em três núcleos convectivos. Após chegar em Belém, a tempestade divide-se em cinco núcleos. Aparentemente esse sistema mantém a formação de uma linha, orientada no sentido nordeste-sudoeste. Esse episódio pode ter ocorrido como uma resposta ao cisalhamento do vento observado na Figura 24, pois quando têm-se cisalhamentos significativos há uma grande probabilidade de haver uma separação das células convectivas (ROTUNNO; KLEMP, 1982). 


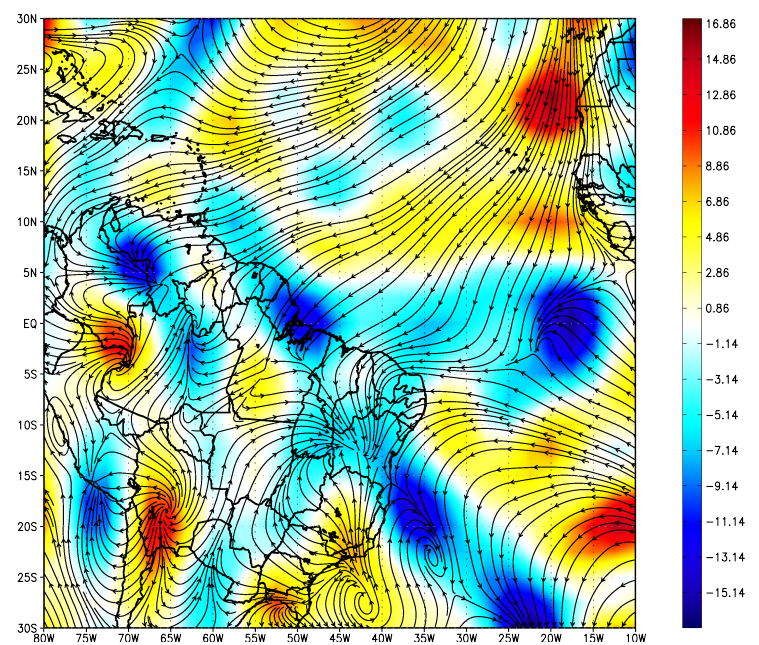

(a)

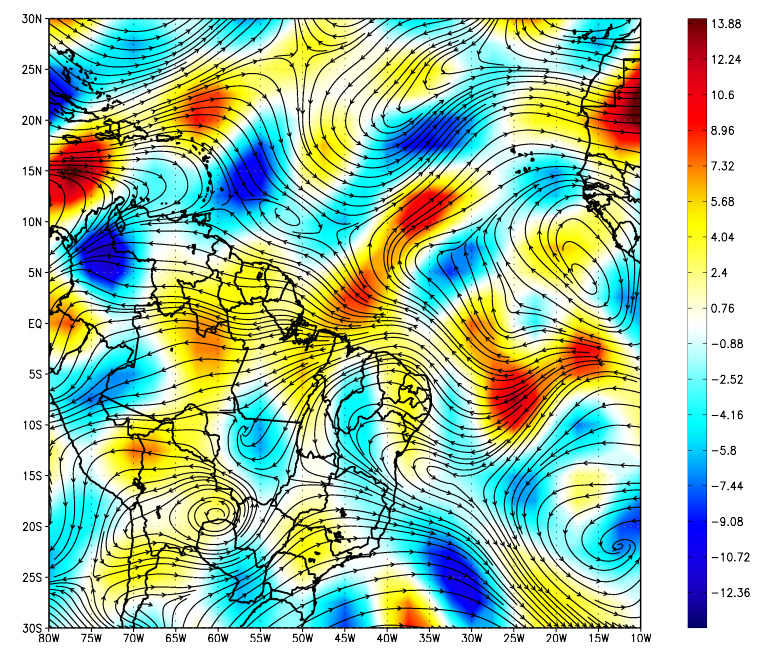

(b)

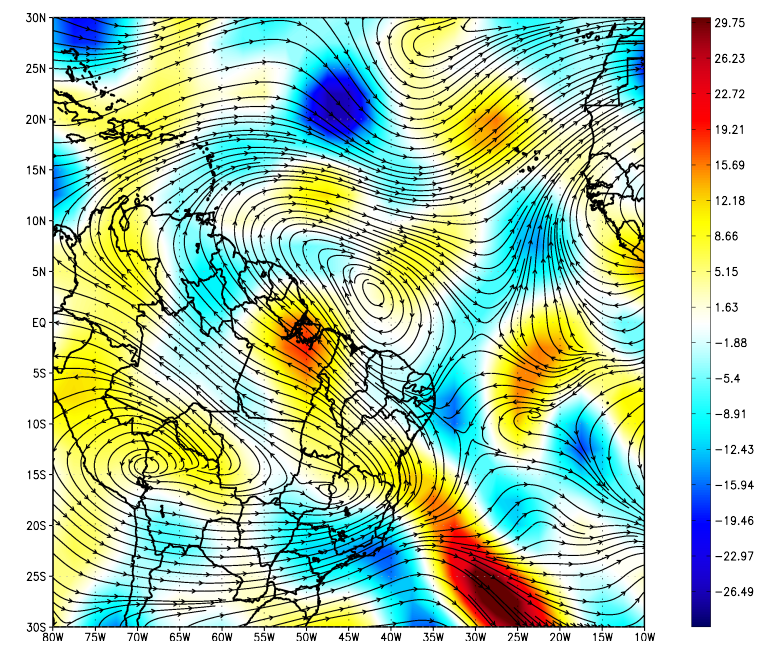

(c)

Figura 22: Campos de linhas de corrente e divergência do vento (sombreado) em $10^{-6} \mathrm{~s}^{-1}$ para 09/04/2009 às 12 UTC em (a) 1000, (b) 500 e (c) $200 \mathrm{hPa}$. 


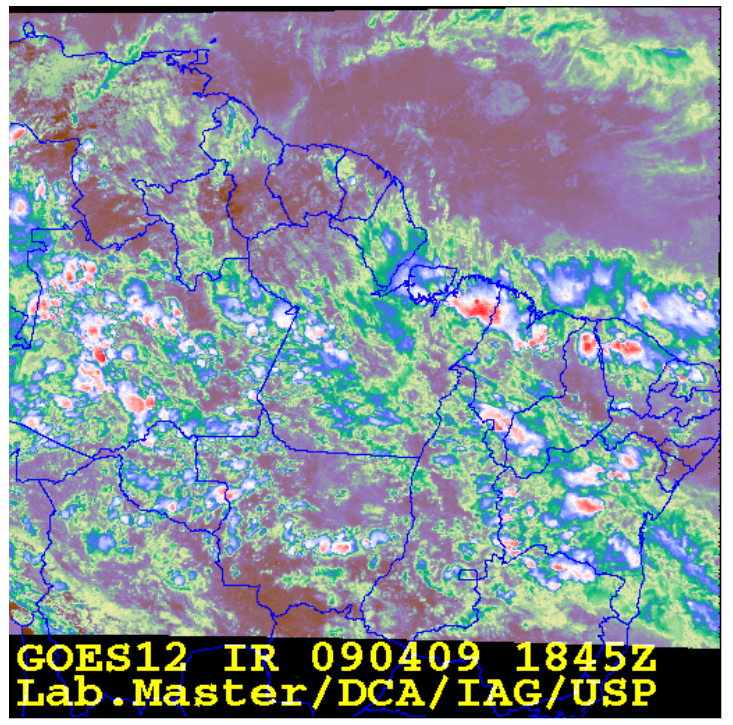

(a)

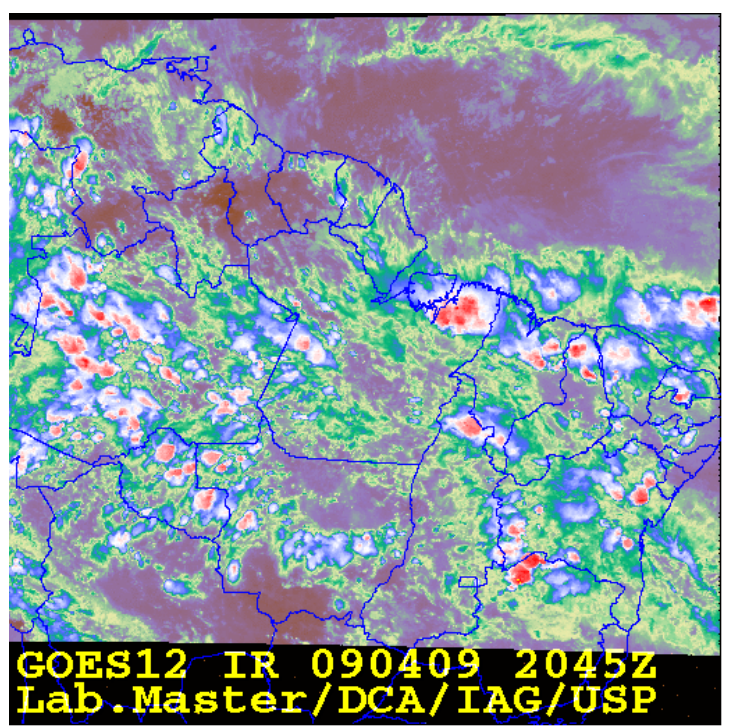

(c)

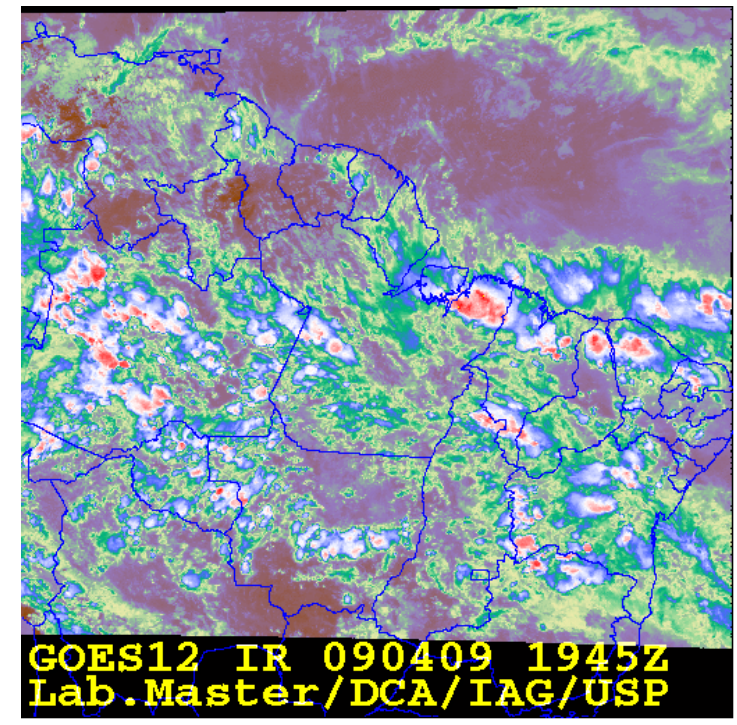

(b)

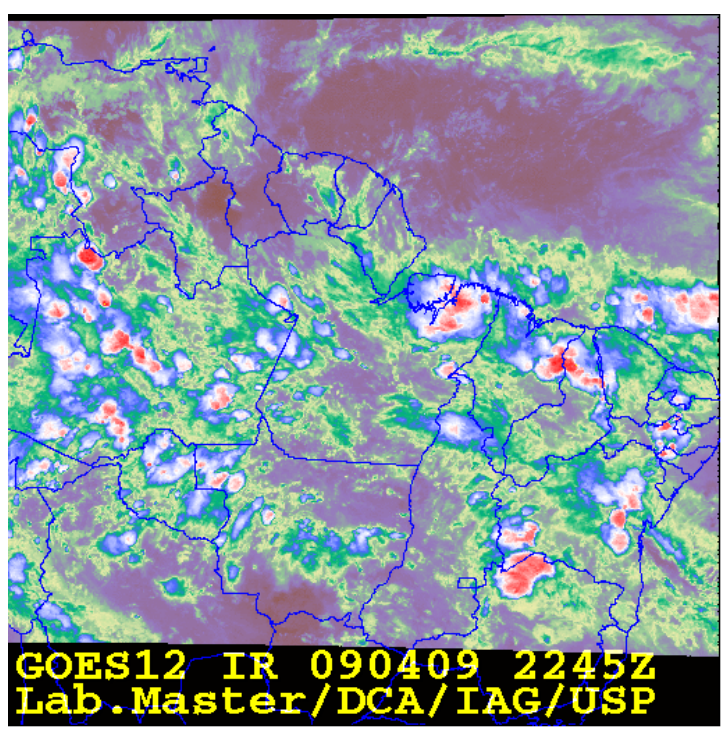

(d)

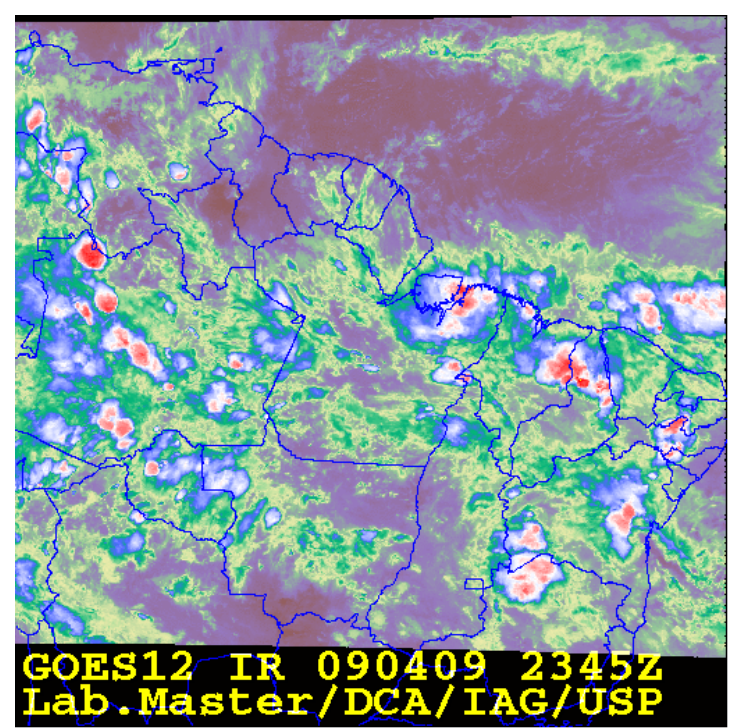

(e)

Figura 23: Imagens do satélite GOES 12 realçadas no canal do infravermelho para 09/04/2009 para os horários das (a) 18:45, (b) 19:45, (c) 20:45, (d) 22:45 e (e) 23:45 UTC. 


\section{SBBE Belem (Aeroporto)}

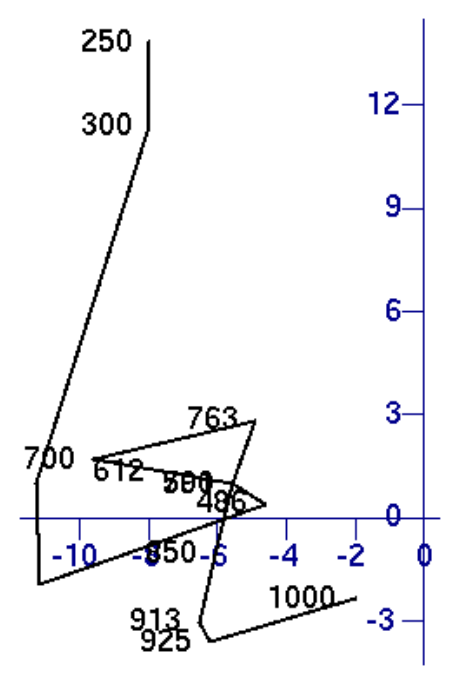

$12 Z 09$ Apr 2009

University of Wyoming

Figura 24: Hodógrafa de Belém para o dia 09/04/2009 às 12 UTC.

\subsubsection{2 de agosto de 2007}

O campo de vento em 1000 hPa (Figura 25a) do episódio ocorrido no dia 22/08/2007 mostra uma zona de convergência significativa sobre o nordeste do Pará e a metade oeste do Maranhão. Uma circulação anticiclônica foi identificada em 700 hPa (Figura 25b) abrangendo todo o Brasil. Essa circulação converge com os alísios sobre o norte e nordeste do Pará. Outro vórtice anticiclônico foi detectado em altos níveis (Figura 25c) atuando em grande parte do Brasil, também associado a uma região de fraca convergência do escoamento sobre a região de Belém.

As imagens de satélite exibidas na Figura 26, mostram a formação de uma linha de instabilidade sobre a costa do Pará. Essa linha de Cumulunimbus descoloca-se para nordeste, por volta das 23:45 UTC funde-se com outra linha que estava sobre o Amapá e avança para sudoeste, continente adentro.

Alcântara et al. (2011) explicam que o deslocamento das linhas de instabilidade continente adentro está associado, na maioria dos casos, a um jato em baixos níveis. Como critério de identificação desse jato, Alcântara et al. (2011) consideraram que a velocidade máxima do vento deve estar entre os níveis de 900 e 600 hPa.

A Figura 27 mostra o perfil vertical do vento zonal para o dia 22/08/2007 às 12 UTC. Nela observa-se o máximo de velocidade do vento zonal de -11,2 m/s em 700 hPa, 
comprovando a existência de um jato de baixos níveis nesse dia. Esse resultado, explica o deslocamento da linha de instabilidade das costas do Pará e Amapá para sudoeste.

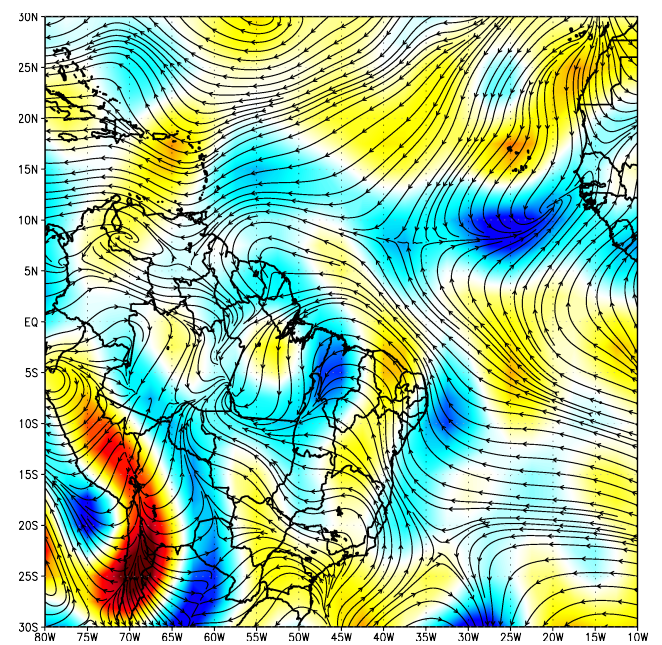

(a)
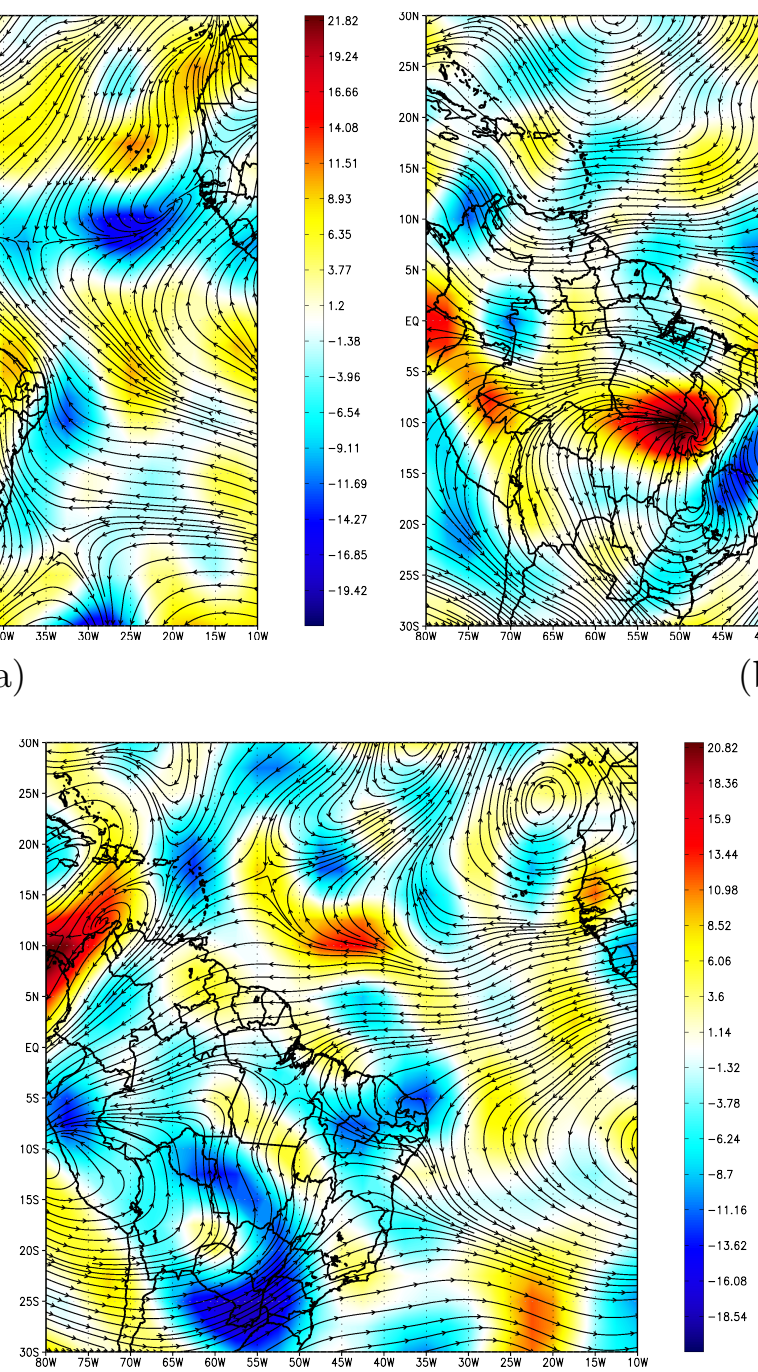

(c)

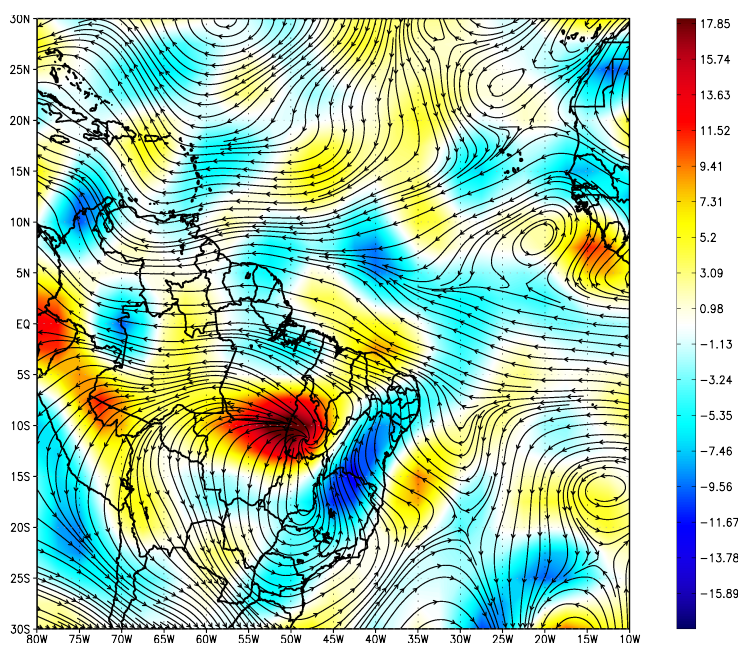

(b)

Figura 25: Campos de linhas de corrente e divergência do vento (sombreado) em $10^{-6} \mathrm{~s}^{-1}$ para 22/08/2007 às 12 UTC em (a) 1000, (b) 700 e (c) $200 \mathrm{hPa}$. 


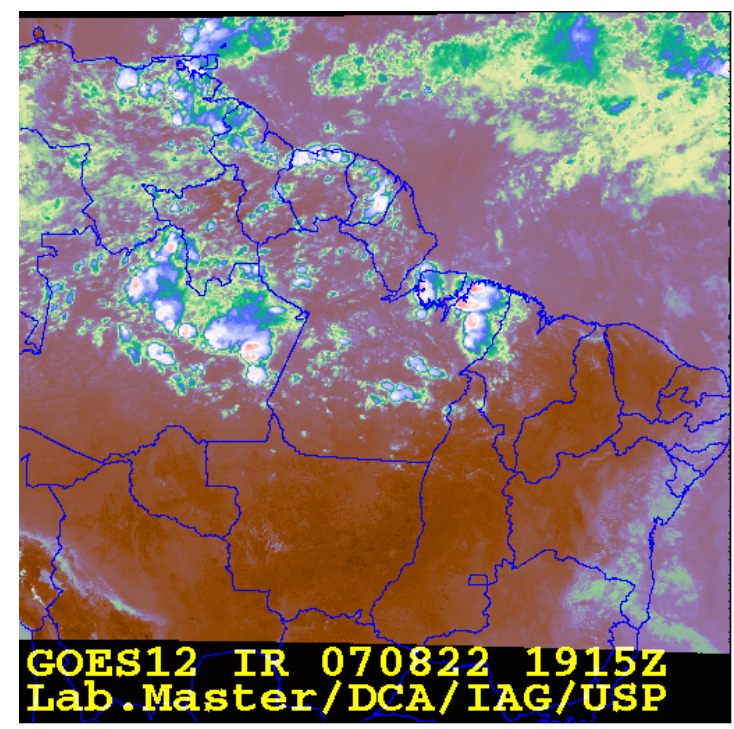

(a)

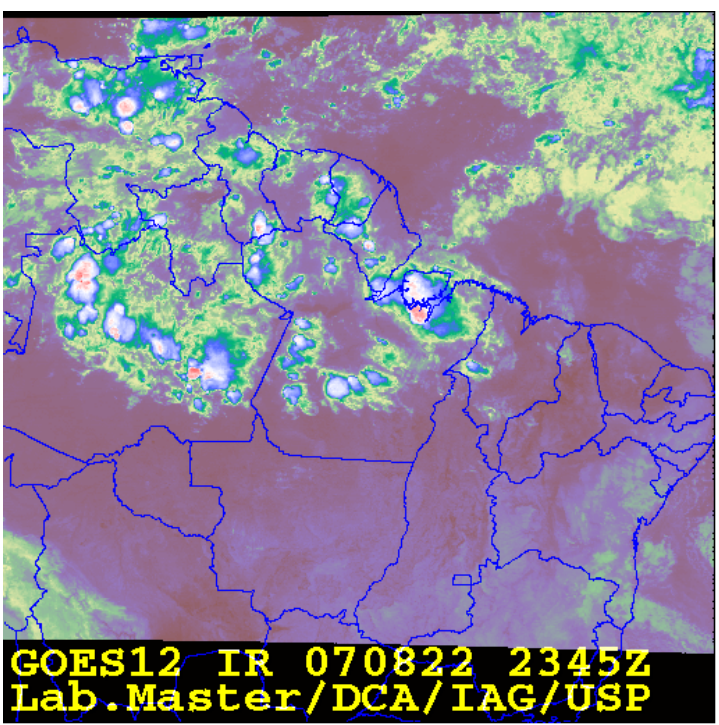

(c)

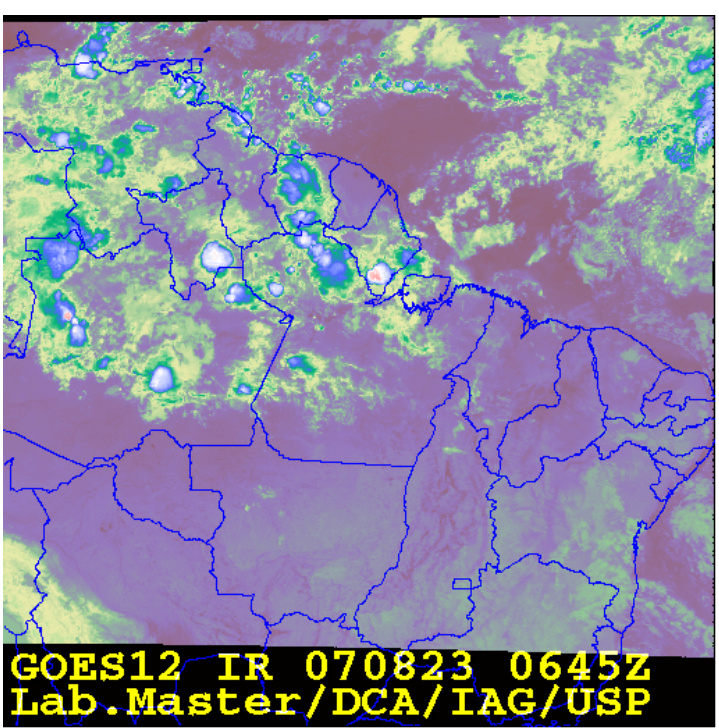

(e)

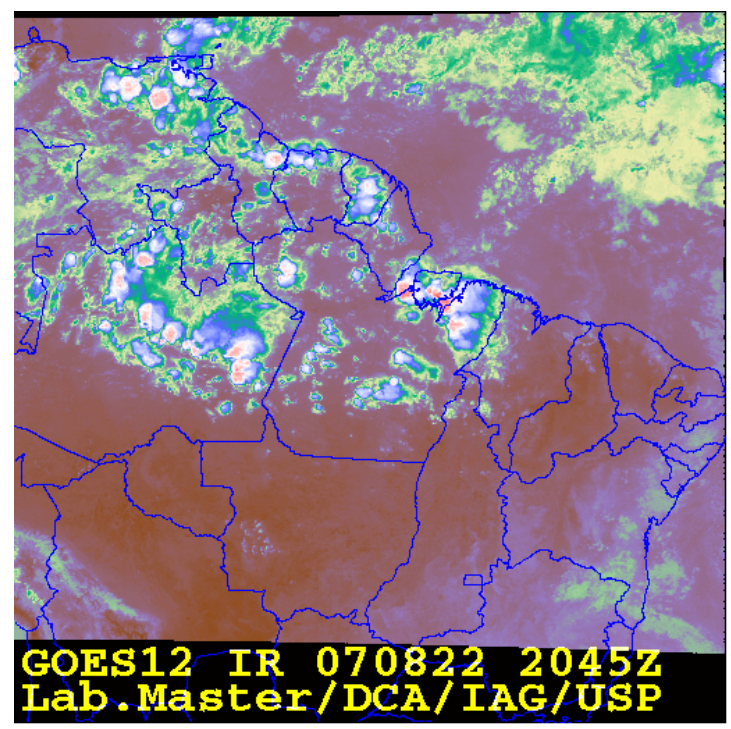

(b)

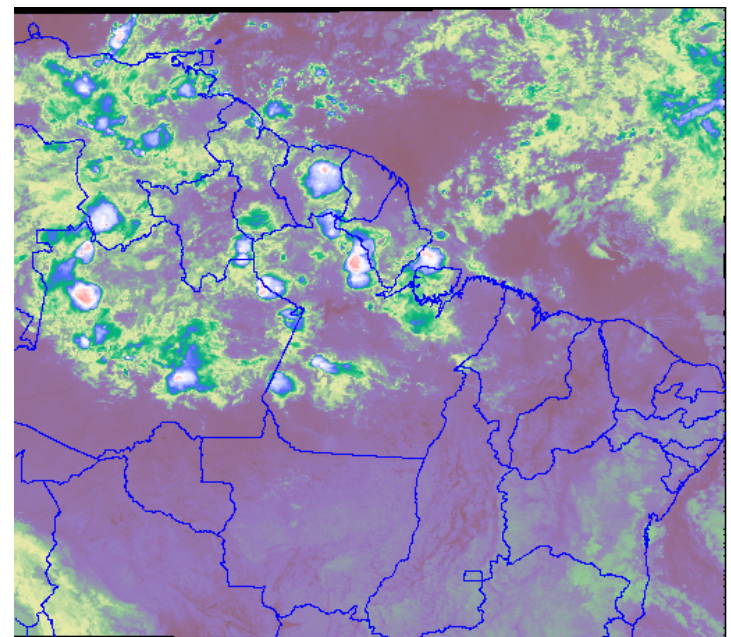

GOFS12 IR $0708230345 \mathrm{Z}$ Lab. Master/DCA/IAG/USP

(d)

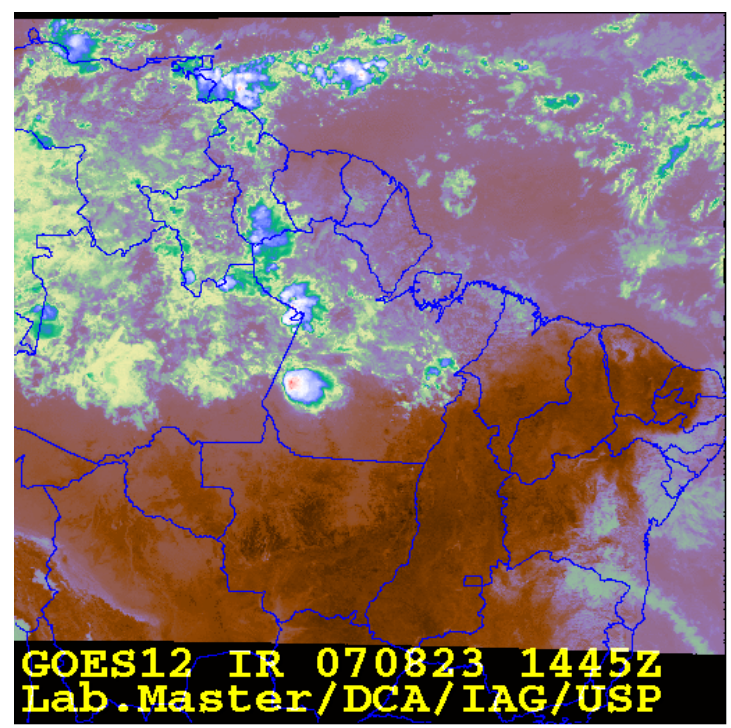

(f)

Figura 26: Imagens do satélite GOES 12 realçadas no canal do infravermelho a partir de 22/08/2007 para os horários das (a) 19:45, (b) 20:45, (c) 01:45, (d) 03:45, (e) 06:45 e (f) 14:45 UTC. 


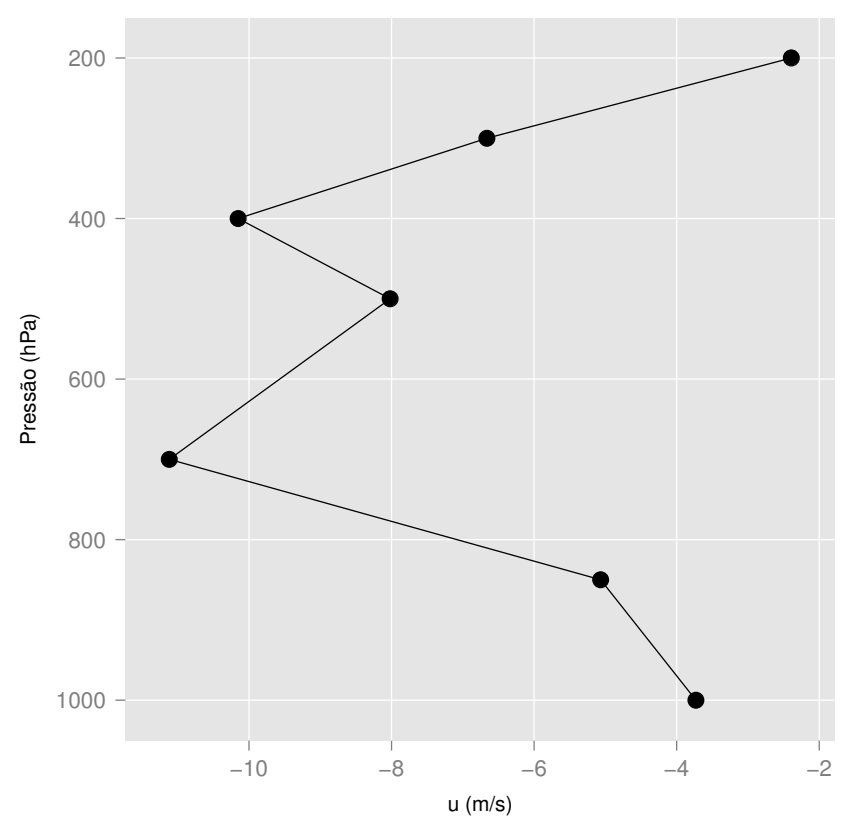

Figura 27: Perfil vertical do vento zonal (m/s) para o dia 22/08/2007 às 12 UTC.

\subsubsection{4 de dezembro de 2009}

Os campos de direção, velocidade e divergência do vento em 850 e 200 hPa são exibidos na Figura 28. Em baixos níveis para o horário das 12 UTC (Figura 28a) é possível averiguar a presença de ventos de leste na costa nordeste brasileira com velocidade em torno os $16 \mathrm{~m} / \mathrm{s}$ e um campo divergente sobre o nordeste do estado do Pará. Após $12 \mathrm{~h}$ (Figura 28b), percebe-se que o campo divergente deslocou-se para o oeste do Pará.

Em altos níveis, às 12 UTC (Figura 28c), como nos casos anteriores, verifica-se a presença de um vórtice anticiclônico, neste caso sobre a Bolívia, e um vórtice ciclônico sobre Oceano Atlântico com seu flanco oeste sobre a região Nordeste. Entre os dois sistemas, é possível notar uma zona de divergência sobre o estado do Pará. Nas horas seguintes, ambos os sistemas deslocam-se rumo a noroeste (Figura 28d). Além disso, há persistência de convergência sobre a costa nordeste brasileira.

Baseado na análise sinótica da figura anterior, não se constatou nenhum mecanismo de grande escala que favoreça a convecção na região de Belém. Entretanto, quando observase as imagens de satélite (Figura 29) percebe-se uma banda de nebulosidade muito estreita orientada no sentido noroeste-sudeste e que desloca-se para nordeste, chegando em Belém por volta das 3:45 UTC (Figura 29d). A banda de nebulosidade pode estar associada à região de convergência em baixos níveis e à atividade convectiva gerada pelo VCAN. Não 
foi possível observar esse fenômeno nos dados de reanálise, provavelmente devido à sua resolução que é muito grosseira para esse fenômeno $\left(2,5^{\circ} \times 2,5^{\circ}\right)$.

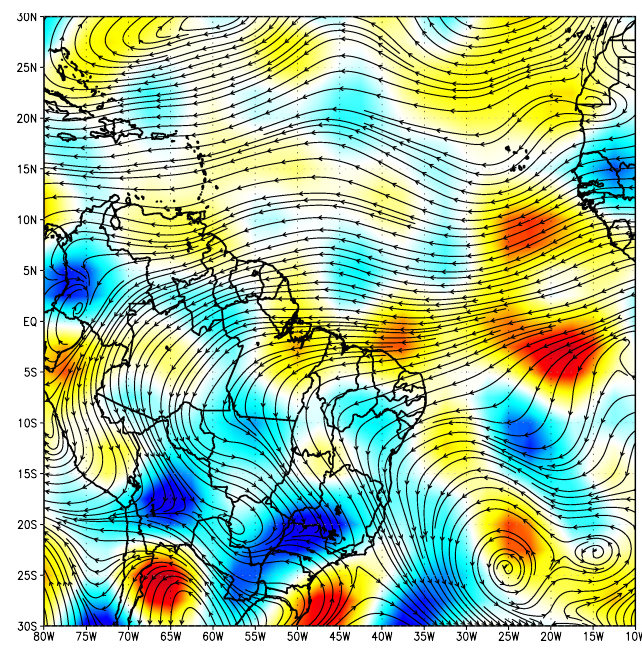

(a)

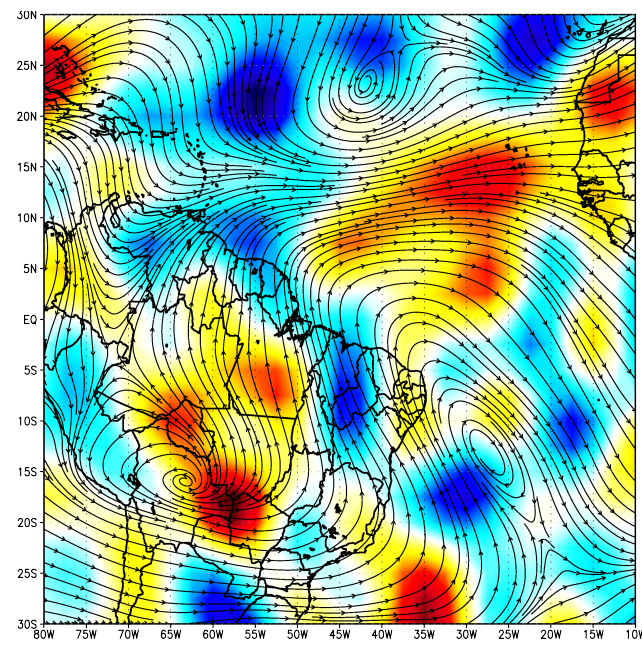

(c)

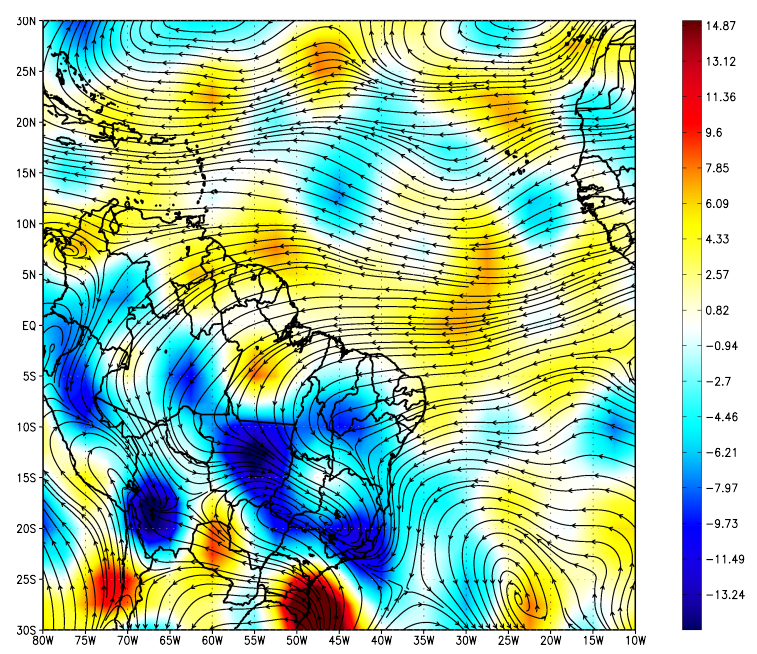

(b)

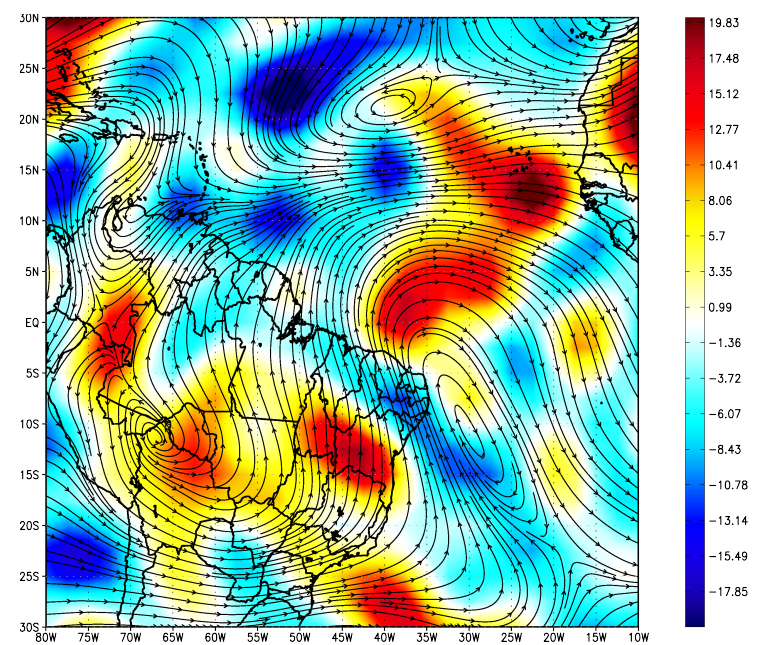

(d)

Figura 28: Campos de linhas de corrente e divergência do vento (sombreado) em $10^{-6} \mathrm{~s}^{-1}$ a parir de 04/12/2009 às (a) 12 e (b) 00 UTC em 850 hPa e às (c) 12 e (d) 00 UTC em 200 hPa. 


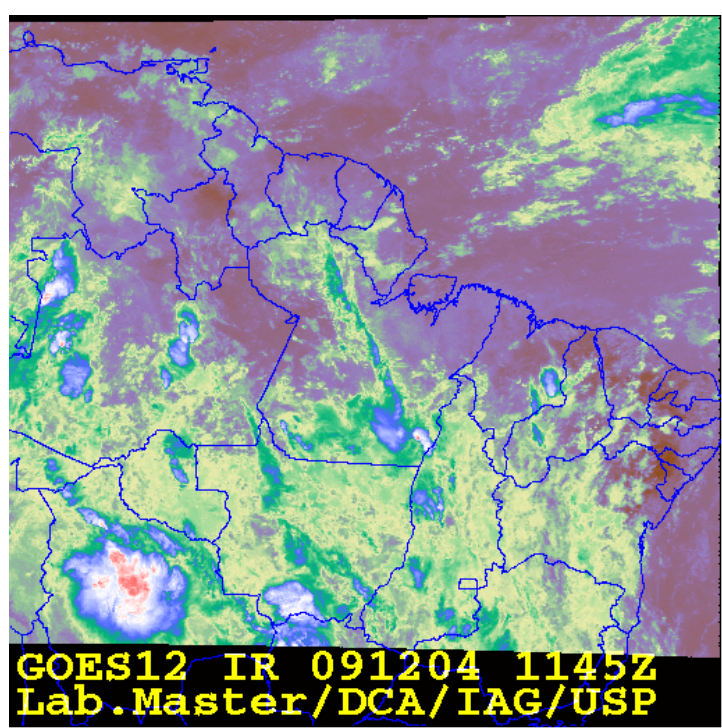

(a)

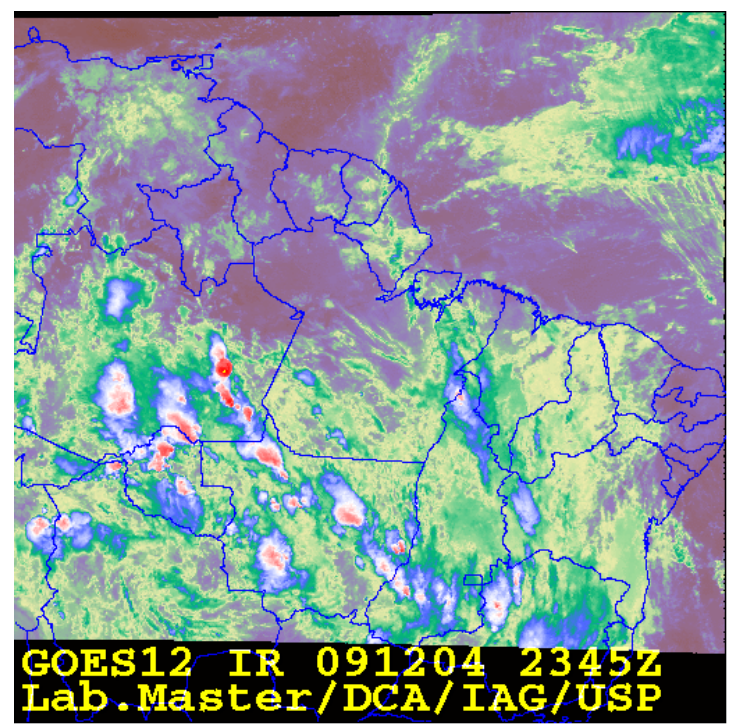

(c)

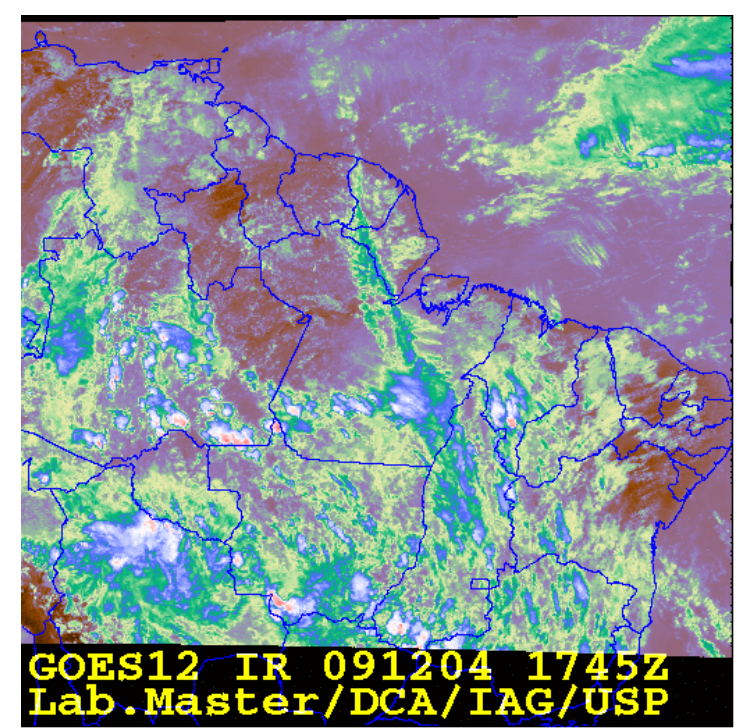

(b)

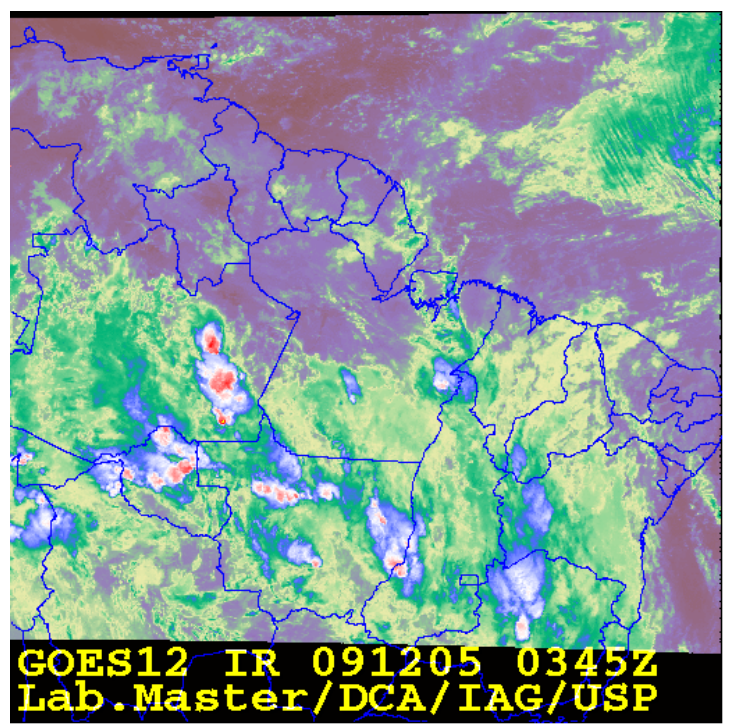

(d)

Figura 29: Imagens do satélite GOES 12 realçadas no canal do infravermelho a partir de 04/12/2009 para os horários das (a) 11:45, (b) 17:45, (c) 23:45, (d) 03:45 UTC. 


\subsubsection{4 de janeiro de 2005}

No caso do dia 04 de janeiro de 2005, novamente identificam-se a Alta da Bolívia e um VCAN. Entretanto, neste caso a região de divergência associada a esses sistemas está localizada sobre a Amazônia (Figura 30). O vórtice ciclônico de altos níveis aparece muito próximo de Belém, provocando convergência neste nível, o que dificulta a atividade convectiva.

Na Figura 30a pode-se observar região de forte convergência em superfície abrangendo as costas do Pará e do Amapá acompanhada de ventos praticamente de leste. Ao mesmo tempo, verifica-se uma circulação anticiclônica sobre o Maranhão provocando divergência no escoamento na costa do Pará e do Amapá.

A Figura 31 mostra uma pequena atividade convectiva sobre Belém, apesar do VCAN estar muito próximo de Belém. O sistema convectivo possivelmente foi favorecido pela convergência em baixos e a divergência médios níveis. 


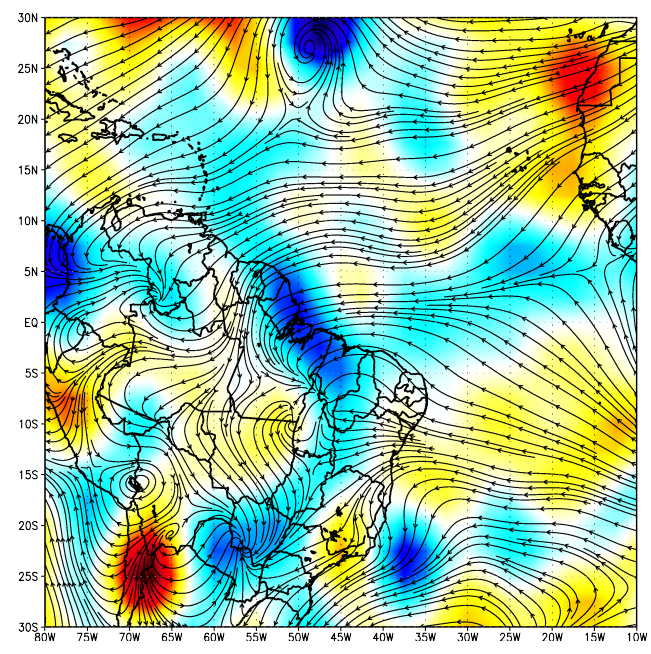

(a)
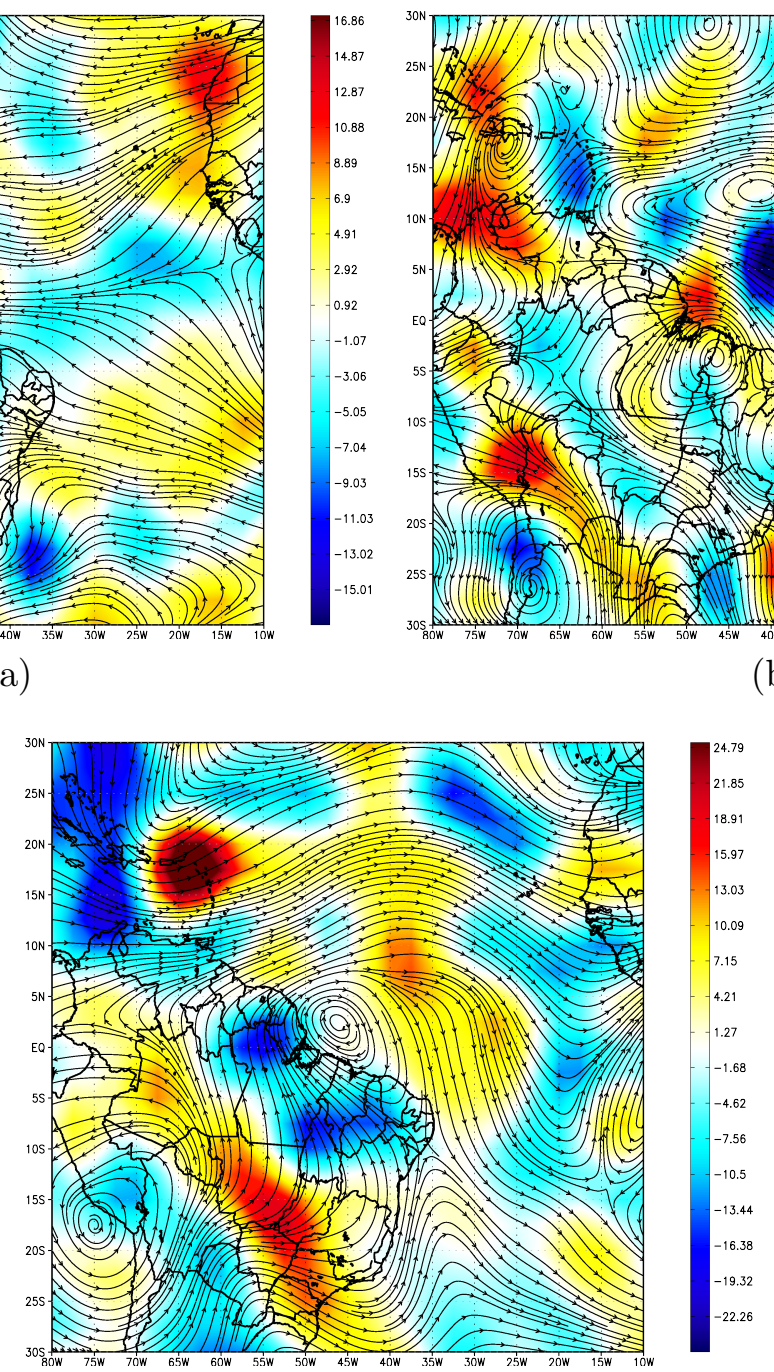

(c)

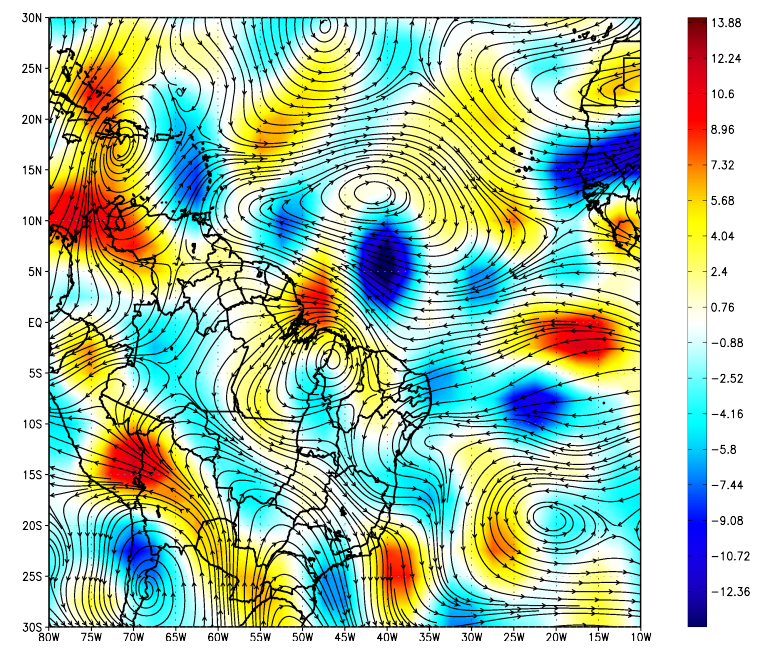

(b)

Figura 30: Campos de linhas de corrente e divergência do vento (sombreado) em $10^{-6} \mathrm{~s}^{-1}$ para 04/01/2005 às 12 UTC em (a) 1000, (b) 500 e (c) $200 \mathrm{hPa}$. 


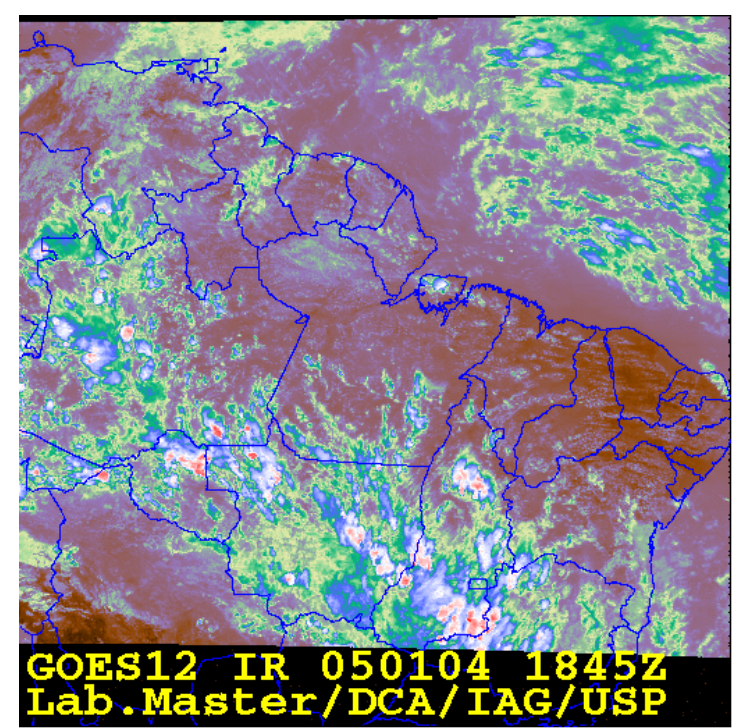

(a)

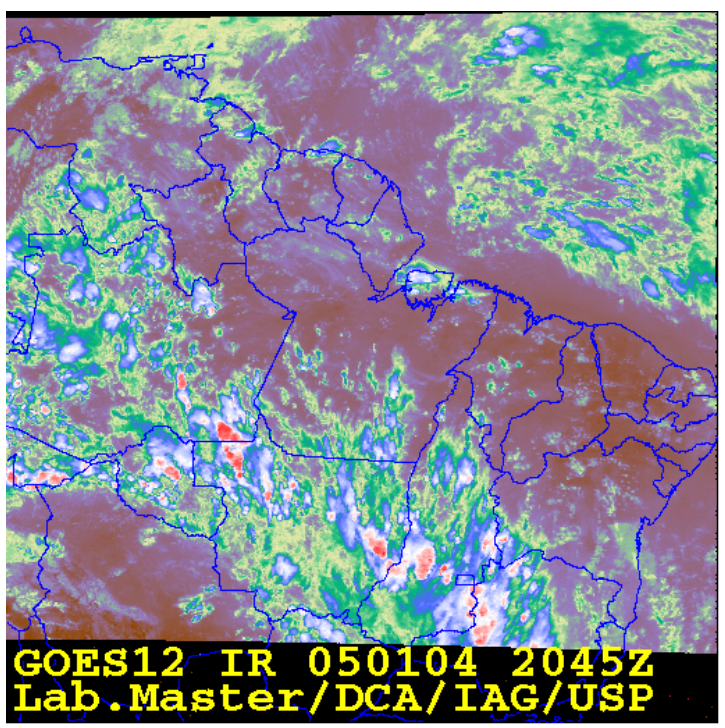

(c)

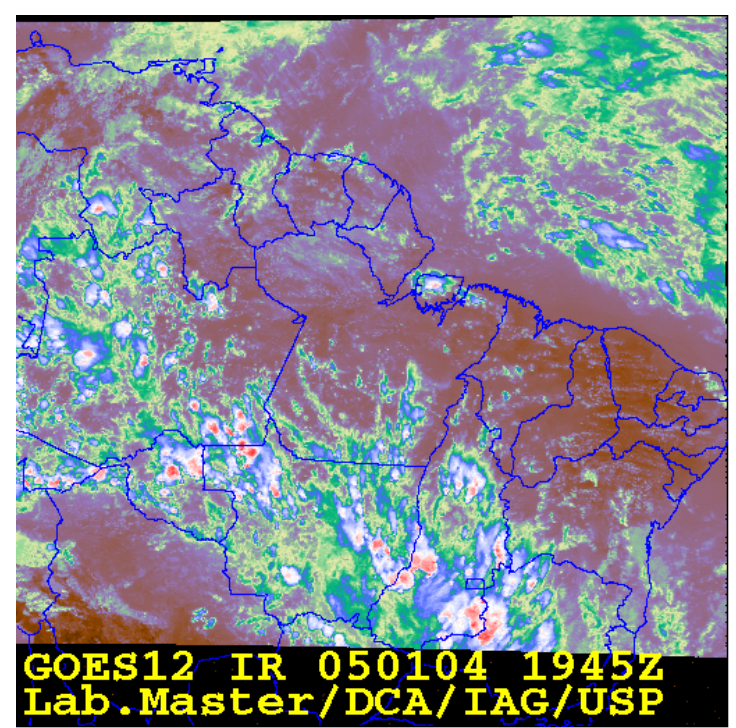

(b)

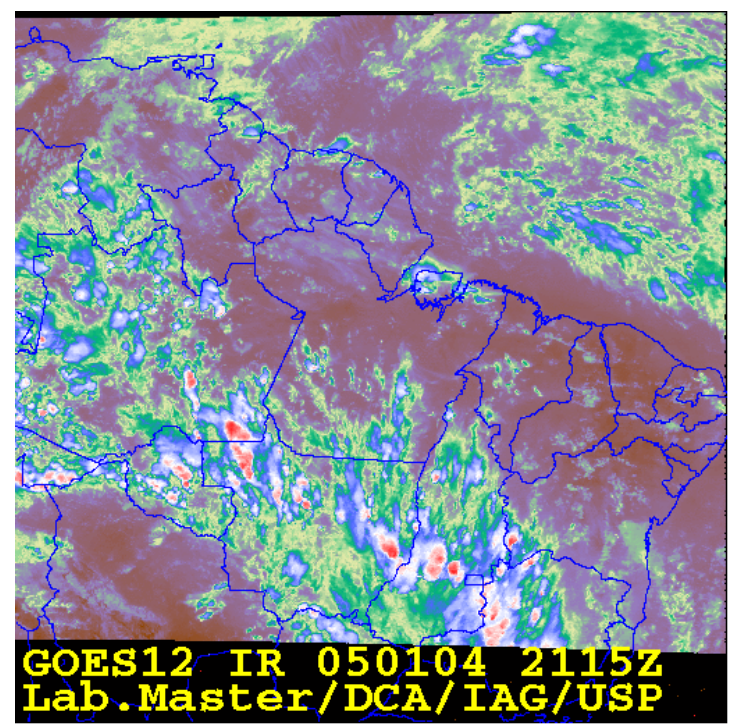

(d)

Figura 31: Imagens do satélite GOES 12 realçadas no canal do infravermelho para 04/01/2005 para os horários das (a) 18:45, (b) 19:45, (c) 20:45 e (d) 21:45 UTC. 


\subsubsection{1 de junho de 2007}

A Figura 32 traz informações de direção e divergência do vento em 1000 e 200 hPa. Pela carta de superfície (Figura 32a) é possível observar a ZCIT próxima da costa do Pará, a qual é marcada pela convergência dos ventos alísios e afeta praticamente toda a costa nordeste da América do Sul. A Alta Subtropical, situada na latitude $27^{\circ} \mathrm{S}$, estende sua crista sobre o Brasil favorecendo a supressão da convecção e ao mesmo tempo contribuindo para a convergência dos alísios, o que ajuda a promover a ascendência de ar próximo à costa nordeste do Brasil.

A atividade convectiva gerada pela ZCIT apresenta uma assinatura significativa em $200 \mathrm{hPa}$ (Figura 32b), assinalada por uma região de divergência expressiva sobre a região de convergência dos alísios em superfície. Em altos níveis, também é possível notar uma circulação anticiclônica sobre a América do Sul, que possivelmente está acoplada à circulação em baixos níveis, contribuindo para um ambiente desfavorável à convecção.

A assinatura da ZCIT é igualmente observada nas imagens de satélite (Figura 33) através de uma banda de nuvem que estende-se ao longo da costa. A partir das 20:45 UTC, verifica-se a formação de linhas de instabilidade sobre o litoral próximo à ZCIT. Provavelmente, o fato do vento estar aproximadamente perpendicular à costa e a proximidade com a zona de convergência favoreceram formação das linhas.

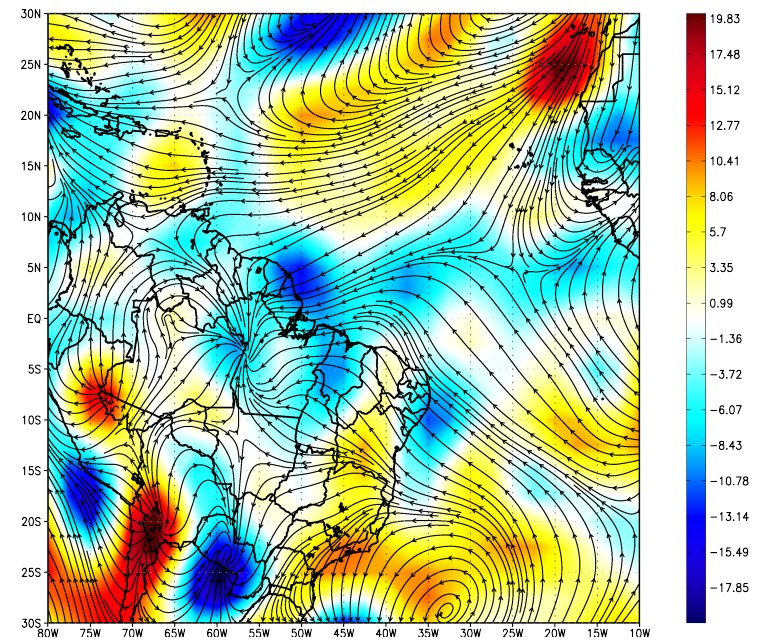

(a)

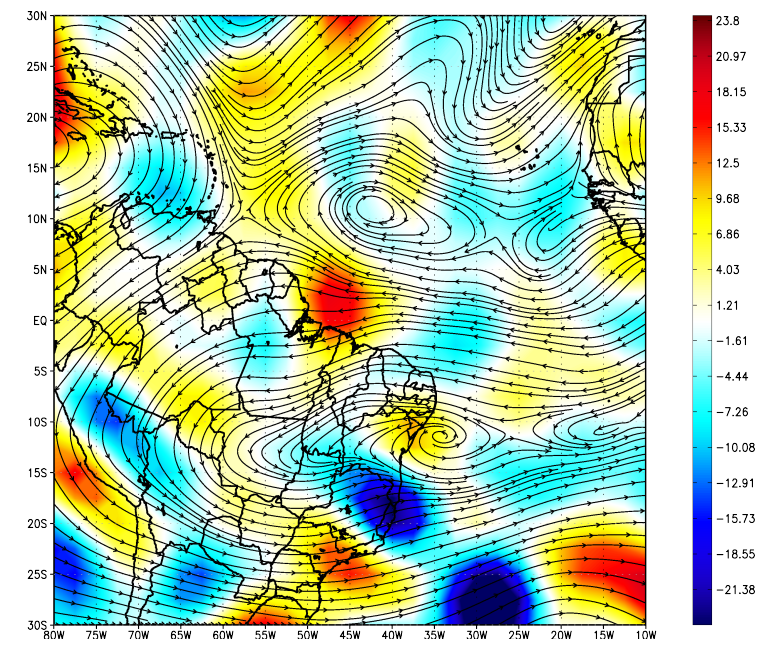

(b)

Figura 32: Campos de linhas de corrente e divergência do vento (sombreado) em $10^{-6} \mathrm{~s}^{-1}$ para 01/06/2007 às 12 UTC em (a) 1000 e (b) 200 hPa. 


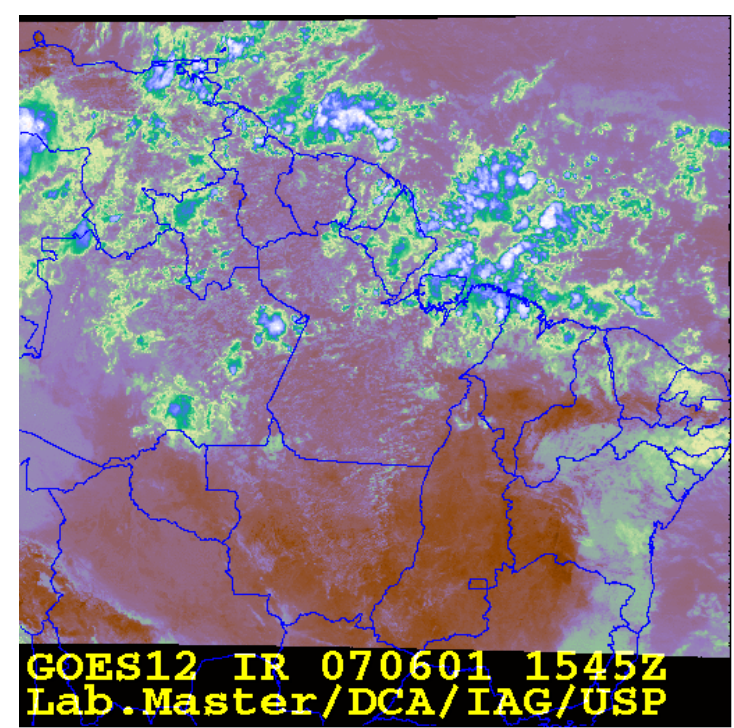

(a)

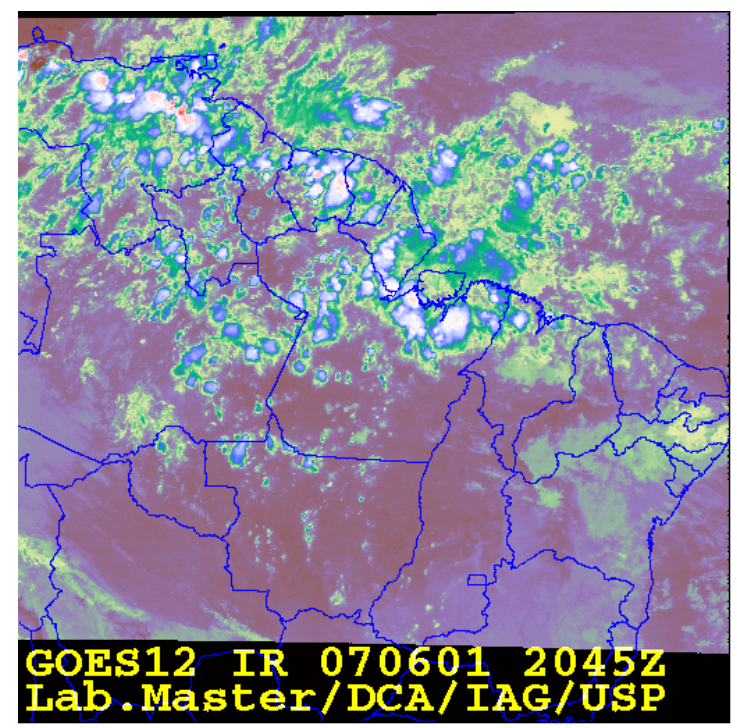

(c)

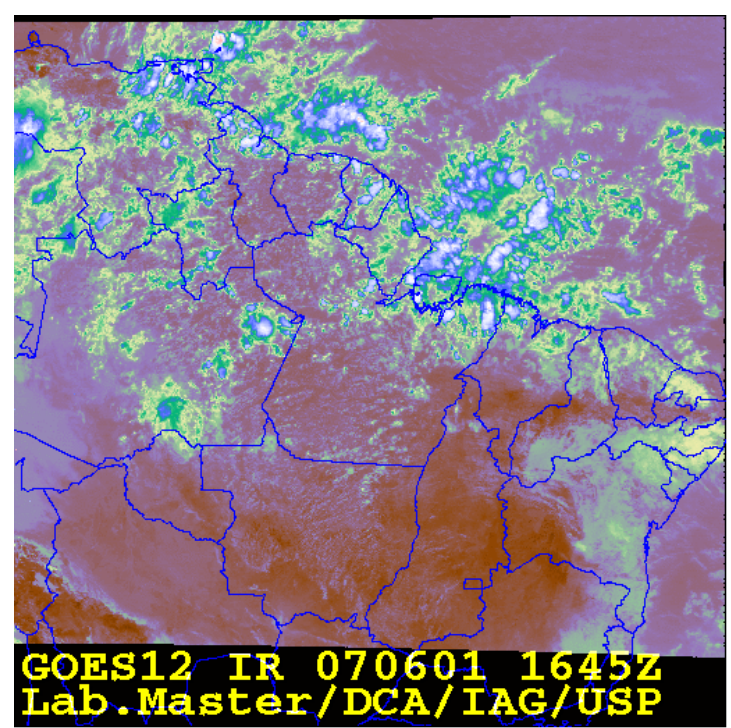

(b)

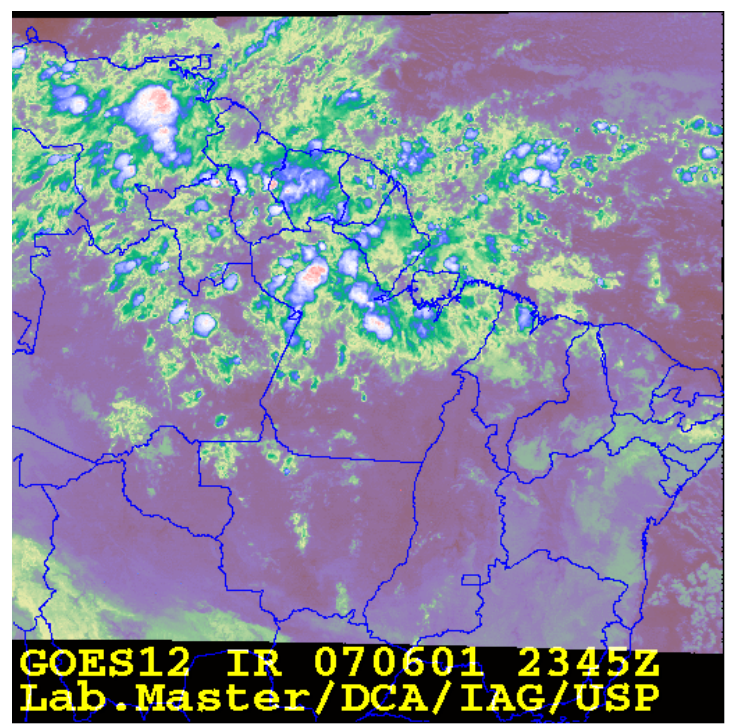

(d)

Figura 33: Imagens do satélite GOES 12 realçadas no canal do infravermelho para 01/06/2007 para os horários das (a) 15:45, (b) 16:45, (c) 20:45 e (d) 23:45 UTC. 


\subsubsection{6 de agosto de 2007}

A Figura 34 mostra linhas de corrente e divergência do vento para os níveis de 1000 e $500 \mathrm{hPa}$ às 12 UTC e à 00 UTC seguinte. Na figura de superfície às 12 UTC (Figura 34a), pode-se verificar uma região de convergência sobre o nordeste do Pará embebida em um escoamento de sudeste. Após 12 horas, o escoamento passa a ser de nordeste sobre Belém e a região de maior convergência desloca-se para o Maranhão. Sobre o Atlântico Norte, próximo ao equador, percebe-se uma região de convergência associada à ZCIT.

Uma região de convergência é observada em médios níveis às 12 UTC sobre a maior parte do Pará (Figura 34c). Esse cavado desloca-se para oeste direcionando o escoamento e gerando divergência do vento sobre a costa dos estados do Pará e Amapá como pode ser visto na Figura 34d.

Pelas imagens de satélite é possível verificar a convecção gerada pela ZCIT através de uma banda de nebulosidade sobre o Atlântico. Parte desta nebulosidade foi advectada para Belém por intermédio do escoamento em médios níveis, ocasionando precipitação na região durante a madrugada. 


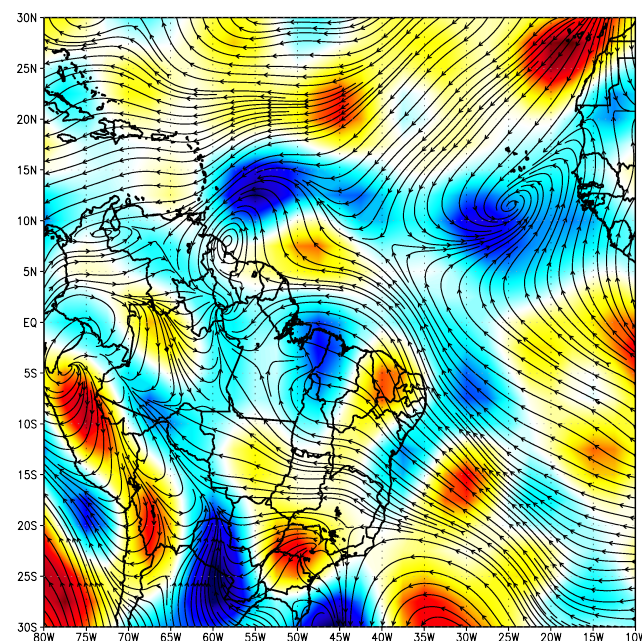

(a)

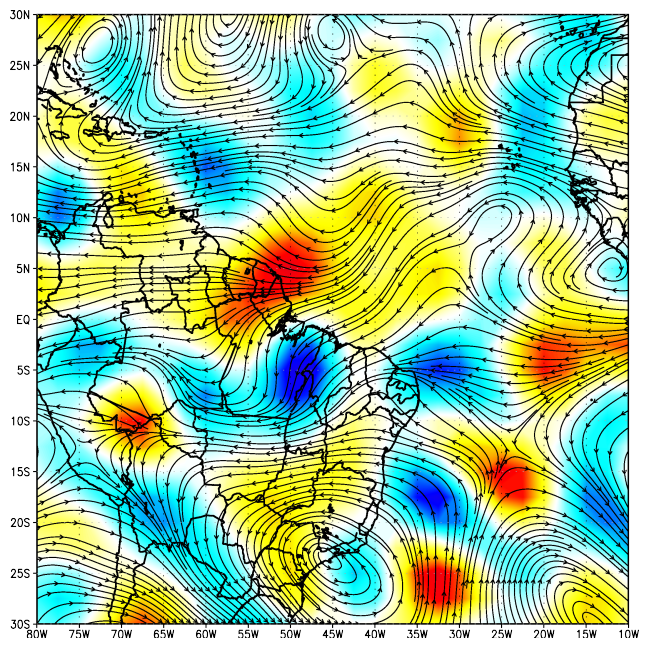

(c)

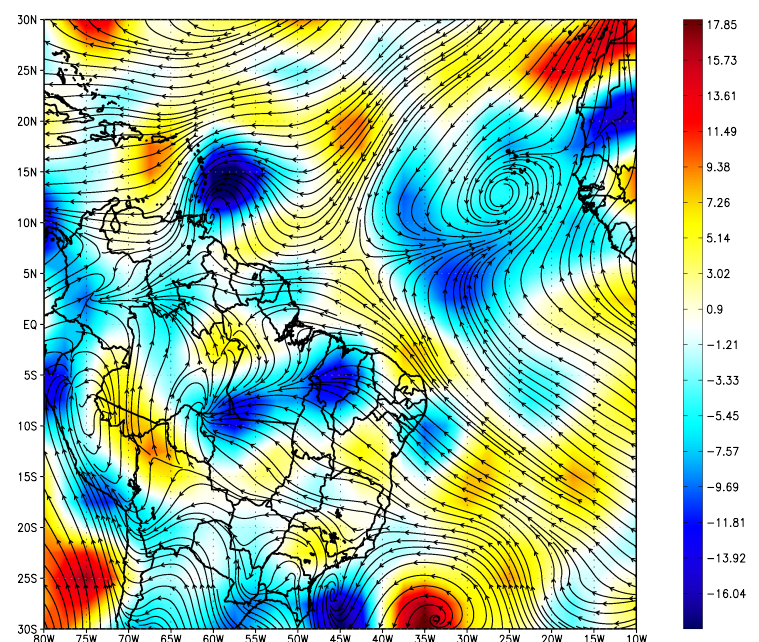

(b)

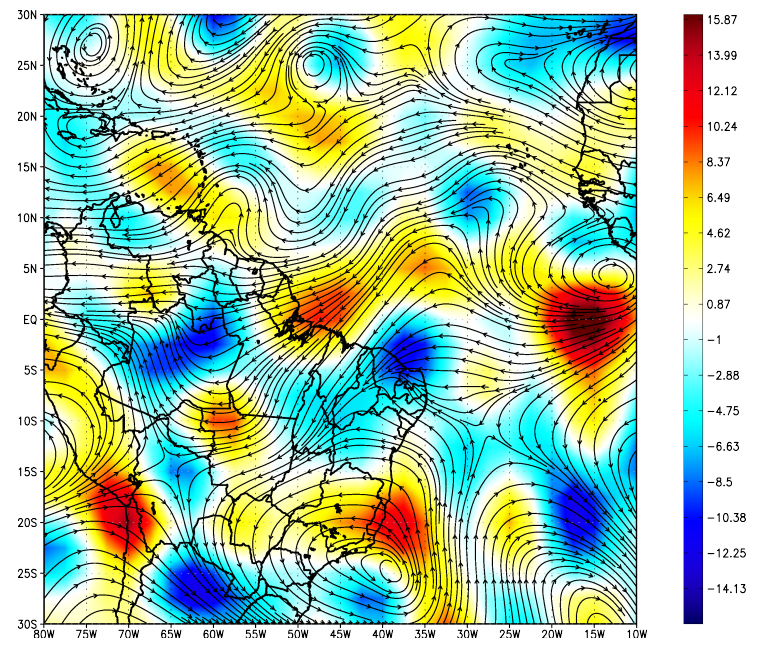

(d)

Figura 34: Campos de linhas de corrente e divergência do vento (sombreado) em $10^{-6} \mathrm{~s}^{-1}$ a partir de 16/08/2007 às (a) 12 e (b) 00 UTC em 1000 hPa e às (c) 12 e (d) 00 UTC em 500 hPa. 


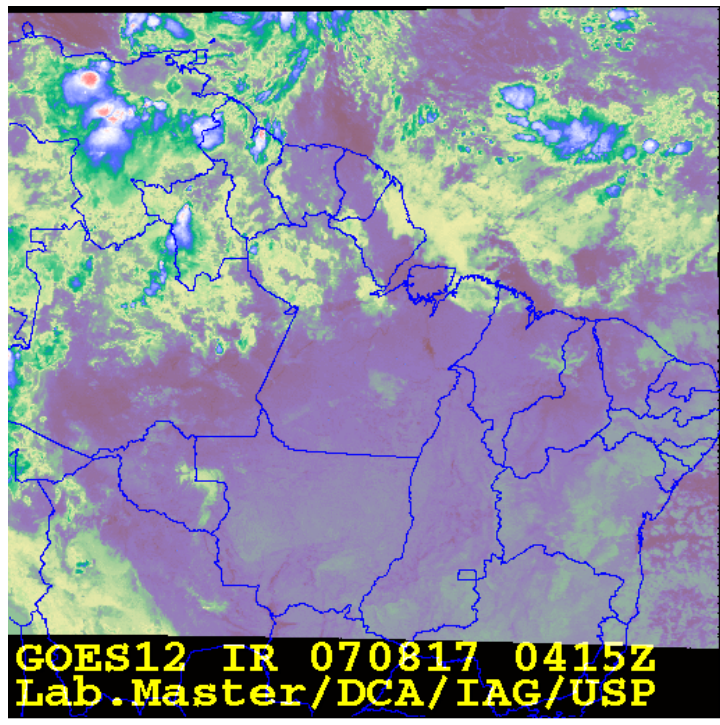

(a)

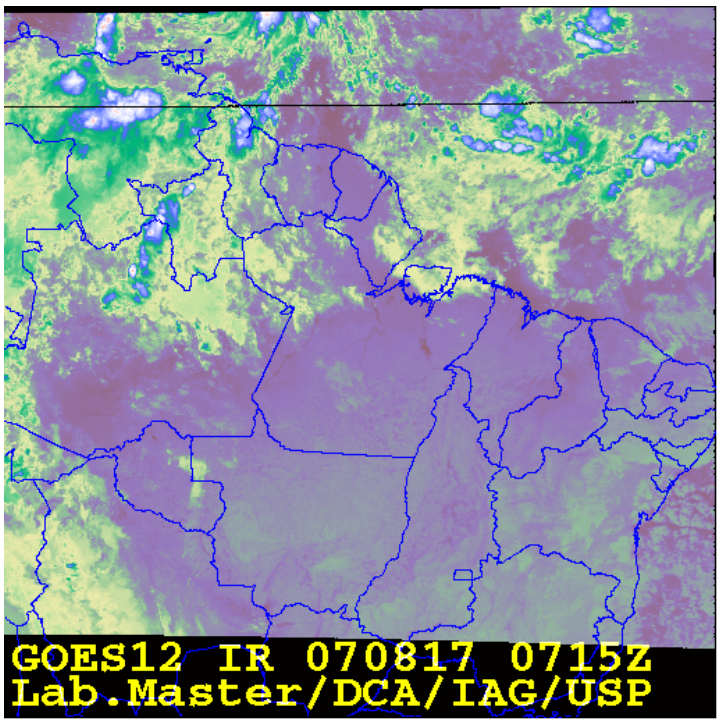

(b)

Figura 35: Imagens do satélite GOES 12 realçadas no canal do infravermelho para 17/08/2007 para os horários das (a) 04:15 e (b) 07:15 UTC.

\subsubsection{3 de outubro de 2007}

Finalmente, o último caso referente ao dia 3 de outubro de 2007 é representado por gráficos de linhas de corrente e divergência de vento para os níveis de 1000, 500 e 200 hPa (Figura 36). Através da Figura 36a, nota-se um cavado sobre a costa do Pará e a região Nordeste do Brasil. Esse sistema modula o escoamento, tornando-o perpendicular à costa paraense, e gera convergência à sua vanguarda.

Um vórtice anticiclônico foi identificado em $500 \mathrm{hPa}$ (Figura 36b) próximo à costa brasileira na latitude de $6^{\circ} \mathrm{S}$. Sobre a costa do Pará, verifica-se uma região de divergência imersa em um escoamento de nordeste modulado pelo vórtice. Logo abaixo do anticlone há um cavado de latitudes médias que se projeta até Tocantins. Esse cavado estende-se até a alta troposfera (Figura 36c) e ocasiona divergência à sua vanguarda propiciando uma região favorável ao desenvolvimento de nuvens dos médios aos altos níveis.

A Figura 37 mostra uma sequência de imagens do GOES 12 que retratam a atuação do cavado descrito nas cartas sinóticas. A divergência à vanguarda da onda de latitudes médias somada à convergência em superfície propiciaram um ambiente favorável à atividade convectiva e, consequentemente, à chuva registrada em Belém. 


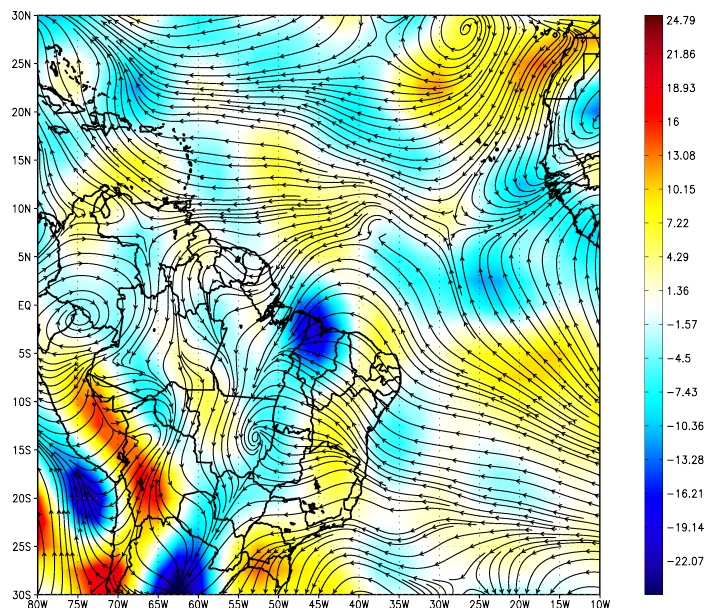

(a)

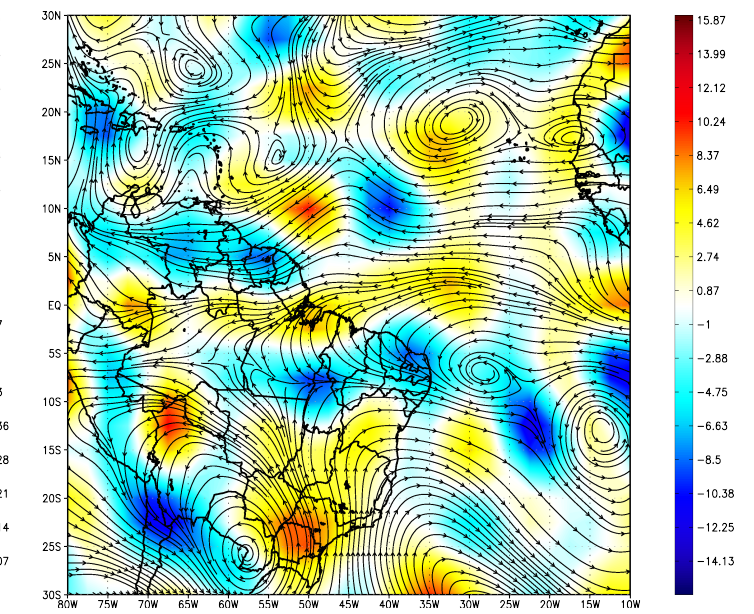

(b)

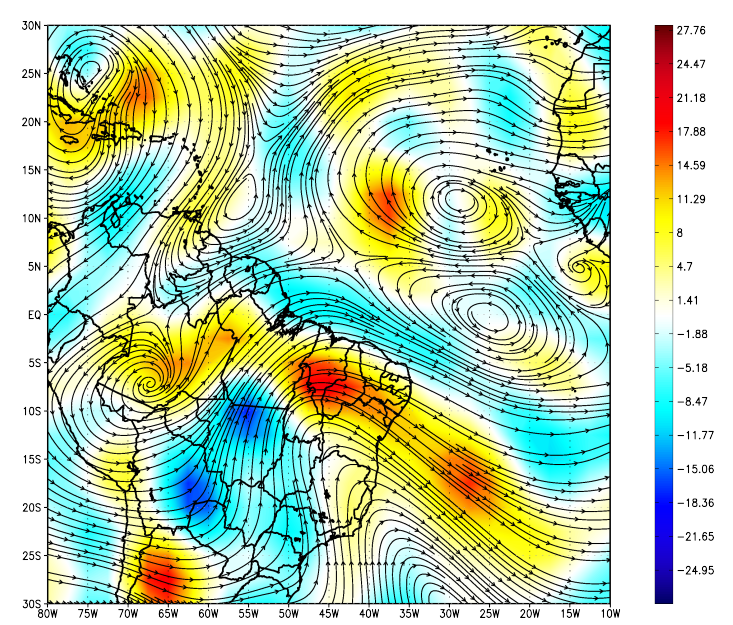

(c)

Figura 36: Campos de linhas de corrente e divergência do vento (sombreado) em $10^{-6} \mathrm{~s}^{-1}$ para 03/10/2007 às 12 UTC em (a) 1000, (b) 500 e (c) $200 \mathrm{hPa}$. 


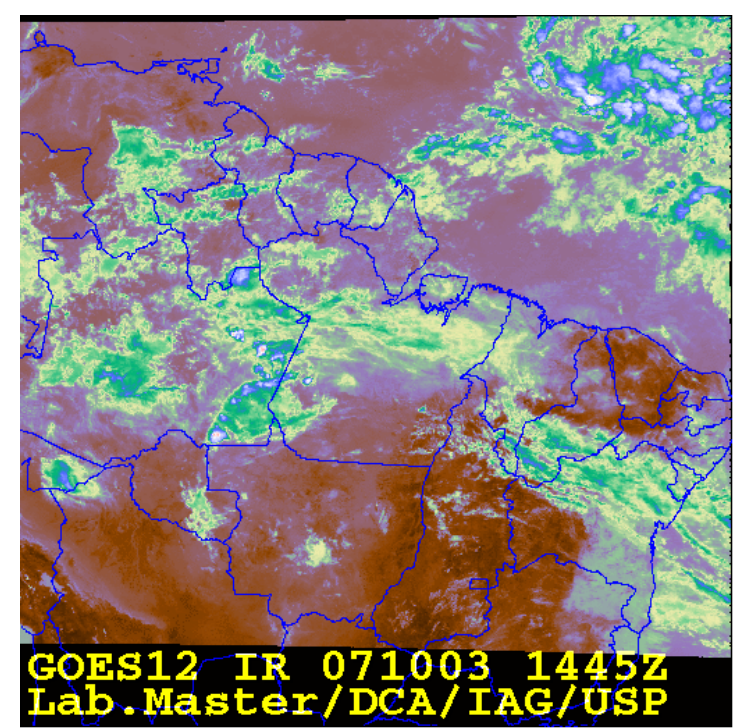

(a)

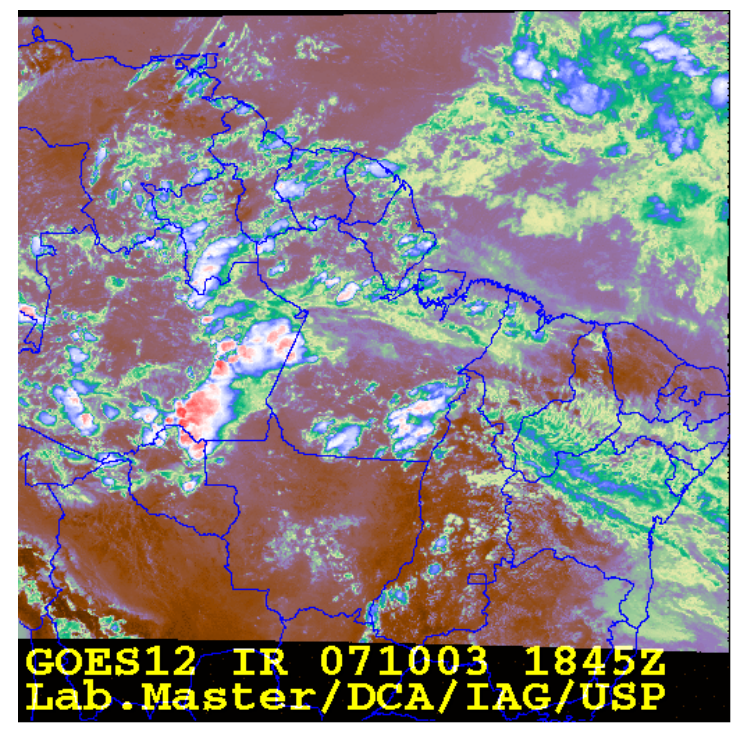

(c)

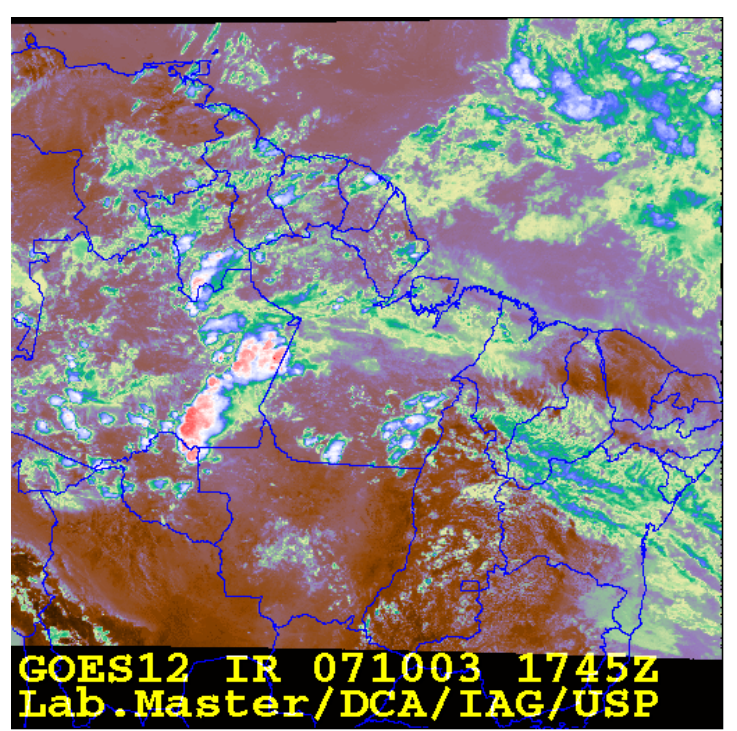

(b)

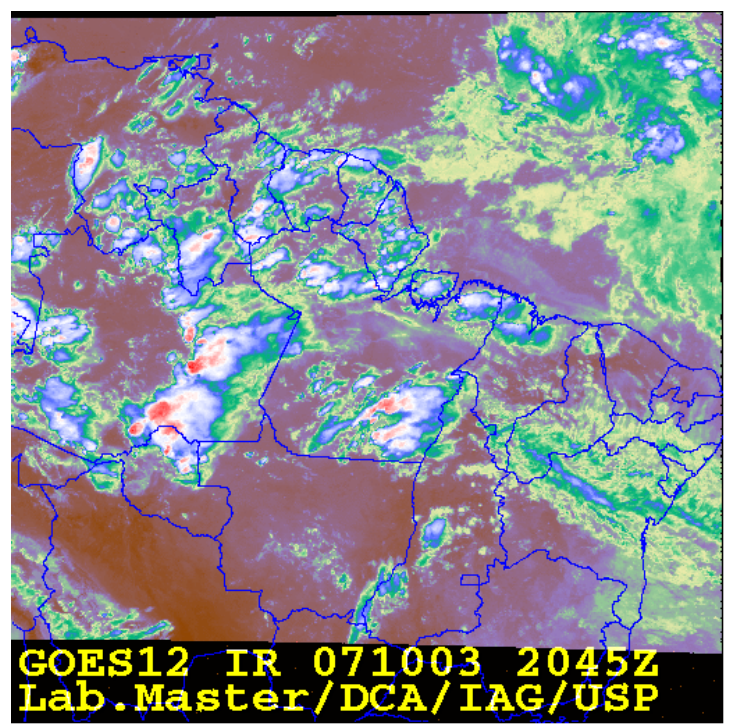

(d)

Figura 37: Imagens do satélite GOES 12 realçadas no canal do infravermelho para 03/10/2007 para os horários das (a) 15:45, (b) 16:45, (c) 20:45 e (d) 23:45 UTC. 
3.3 Análise das simulações numéricas

Os dias relativos ao coeficiente de expansão máximo e mínimo serão identificados pelos períodos do ano em que estão situados (JFM, AMJ, JAS ou OND). Isso será feito no intuito de facilitar a comparação entre os dias referentes as anomalias positivas e negativas de aсpсp. Nessas análises se fará um diagnóstico do vigor da convecção simulada em cada caso a partir da grade 4 do modelo.

\subsubsection{Total de precipitação}

A Figura 38 contém os o acumulado de chuva em superfície total da grade 4. Pode-se facilmente observar que os experimentos relacionados aos acumulados de chuva acima da média para JFM e AMJ (Figura 38a) apresentaram um comportamento bem semelhante entre si. O BRAMS conseguiu distinguir bem os dias que registraram mais chuva dos demais, ou seja, identificou mais chuva para os dias relacionados aos acumulados de chuva acima da média do que para os dias de acumulados abaixo da média, distinguindo-os de forma clara, como pode ser visto na Figura 38.

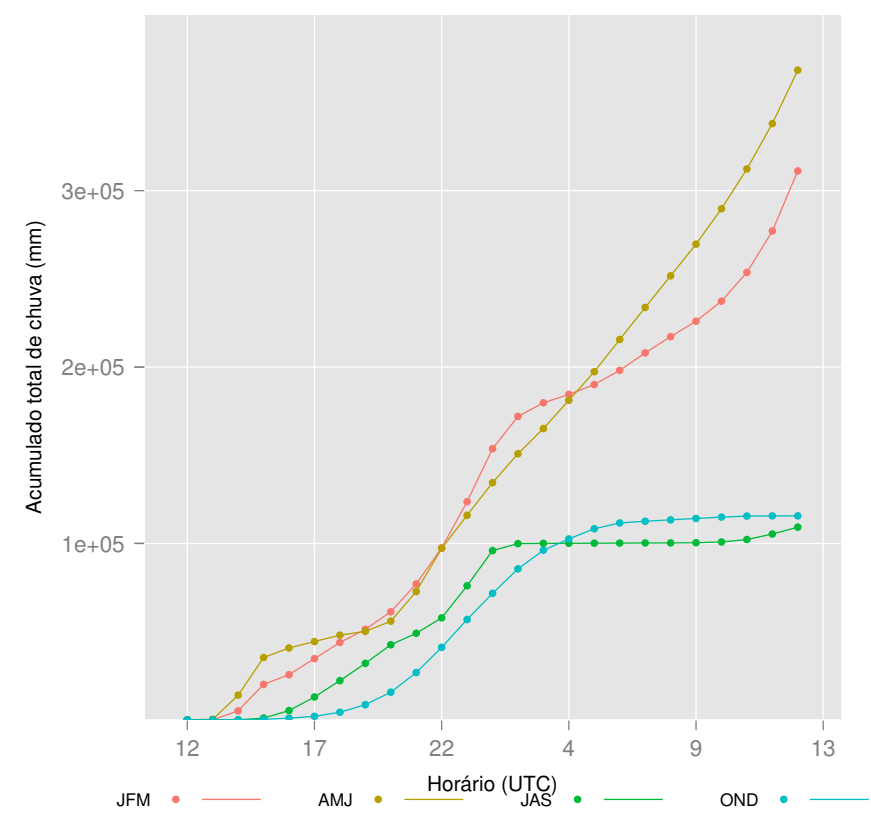

(a)

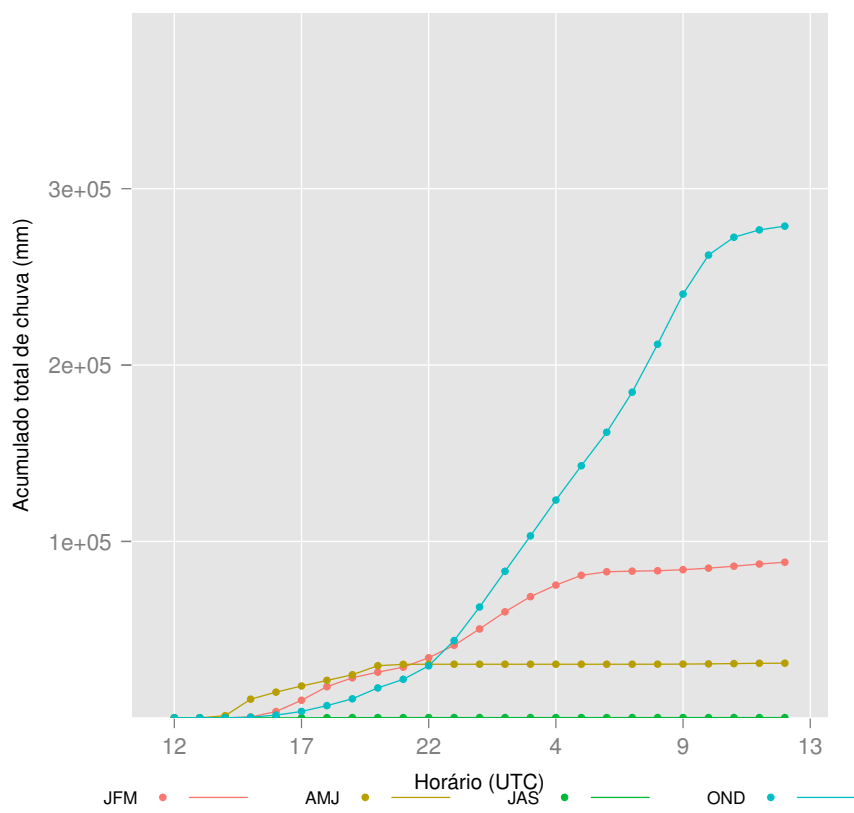

(b)

Figura 38: Acumulado de chuva total da grade 4 para os dias em que o coeficiente de expansão é máximo (a) positivo e (b) negativo. 
A Figura 39 mostra os dados normalizados do acumulado diário de chuva total da grade 4 do BRAMS e da região referente a grade 4 do TRMM-3B42 para os dias identificados por $e_{3}$. Percebe-se que os dados observados e simulados apresentam máximos e mínimos coincidentes, ou seja, anomalias de acpcp aproximadas mostrando que o modelo representou de forma satisfatória as anomalias de chuva para a região de Belém.

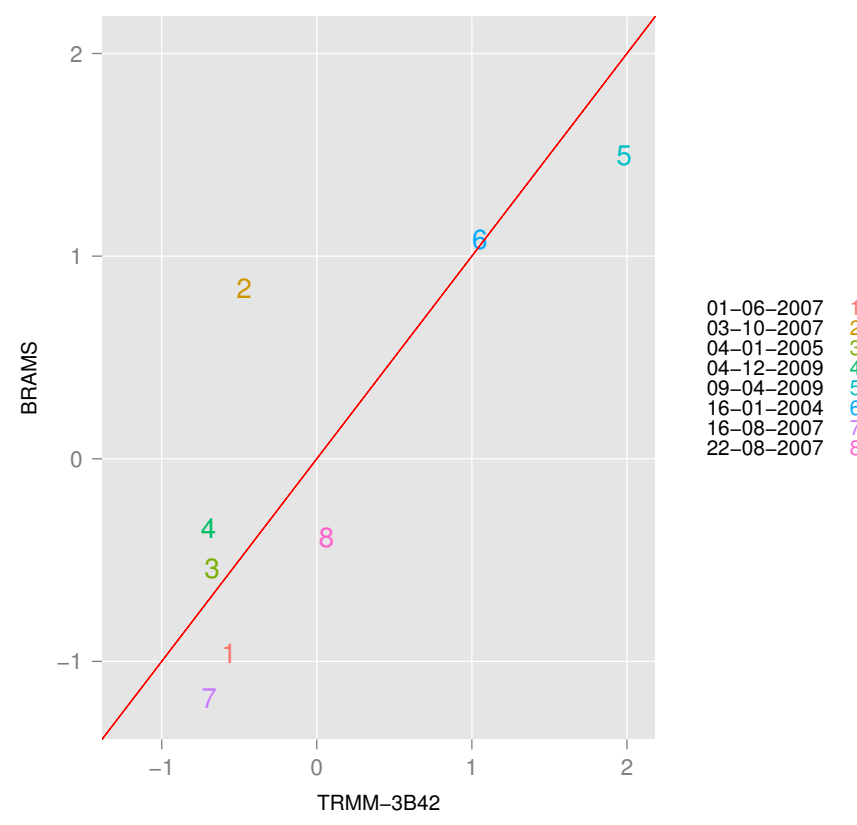

Figura 39: Acumulado diário de precipitação observado e simulado normalizados para os casos identificados por $e_{3}$.

\subsubsection{Movimento vertical}

A Figura 40a foi preparada escolhendo o nível de 1992 m como representante dos níveis baixos das nuvens, haja vista que a partir dos dados de radiossondagem averiguouse que o Nível de Condensação por Levantamento (NCL) é em torno de 500 m para Belém. Observa-se que os dias de JFM e AMJ apresentam dois picos de correntes ascendentes, enquanto que os dias de JAS e OND apresentam apenas um pico bem definido. Esses picos estão associados a formação de novas células convectivas na região em estudo.

Os primeiros máximos de corrente ascendente dos dias de JFM e AMJ ocorrem praticamente no mesmo horário, por volta das 14 UTC. Entretanto, o segundo pico do AMJ surge antes do segundo pico do JFM. Os picos de movimento ascendente máximo para os dias de JAS e OND ocorrem juntos às 17 UTC. Após as 22 UTC, o dia de JAS aparece com as menores correntes ascendentes.

Através da Figura 40b, percebe-se que AMJ segue com dois picos de movimento 
ascendente como na Figura 40a, porém menos intensos. Os outros casos mostram apenas um pico de corrente ascendente, entre as quais OND destaca-se por apresentar as maiores correntes ascendentes, chegando próximas dos $8 \mathrm{~m} / \mathrm{s}$ às 17 UTC. Neste caso, OND está associado aos acumulados de chuva acima da média, ao passo que na Figura 40a aos acumulados abaixo da média. O dia de JAS, associado a anomalias negativas de acpcp, possui um pico de corrente ascendente mais fraco na média do que o outro dia de JAS relativo a anomalias positivas de aсpсp.

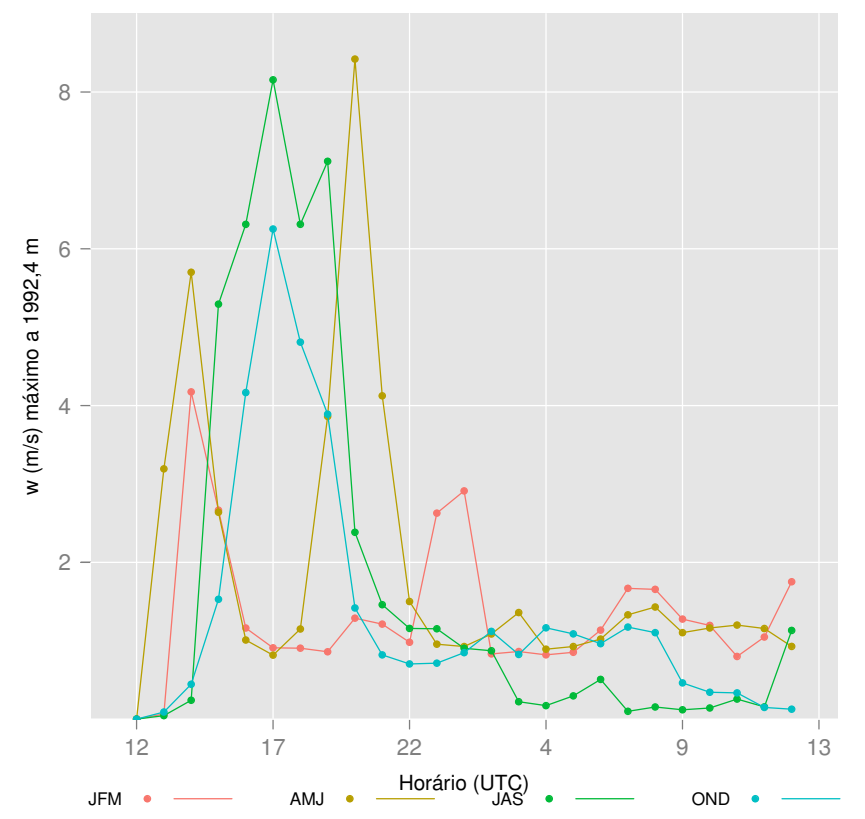

(a)

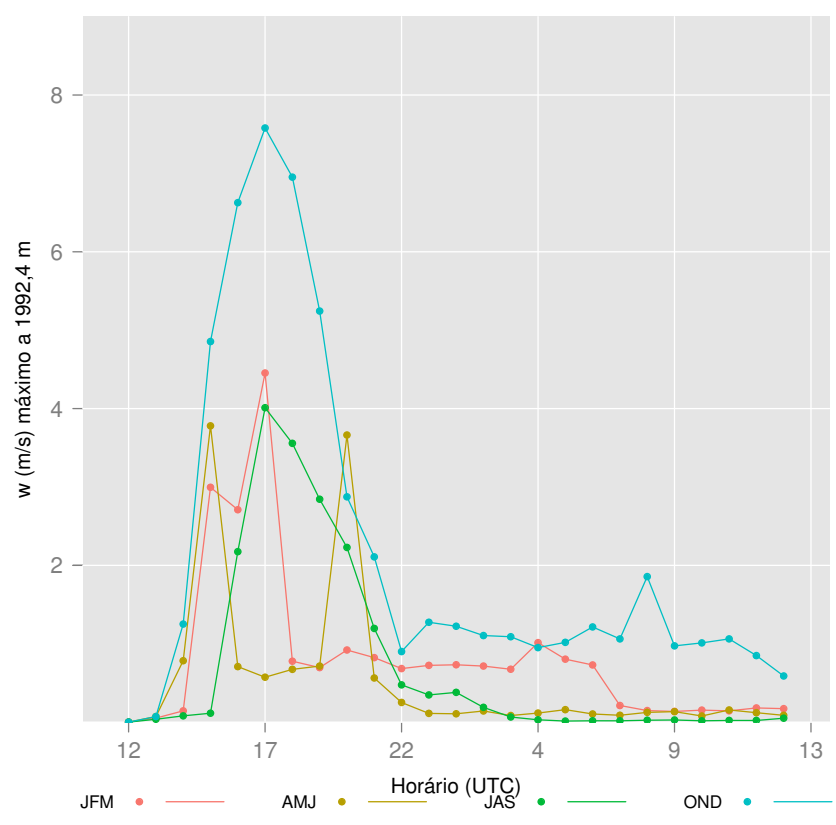

(b)

Figura 40: Velocidade vertical positiva máxima a 1992,4 $\mathrm{m}$ da grade 4 para os dias em que o coeficiente de expansão é máximo (a) positivo e (b) negativo.

Com o objetivo de observar o vigor das correntes descendentes, foi gerada a Figura 41 em que é plotado o valor mínimo de w de cada horário. Essa figura contém os movimentos descendentes a 535,6 m (nível próximo da base da nuvem, pois o NCL está em torno de $500 \mathrm{~m}$ ), simulados na grade mais refinada, sendo que a Figura 41a refere-se ao coeficiente máximo e 41b ao coeficiente mínimo para cada período do ano.

Analisando a Figura 41a, verifica-se que os movimentos verticais descendentes são mais intensos entre os horários das 15 e 20 UTC, e JAS e OND são os que apresentam as correntes descendentes mais fortes. Apenas o dia relativo a JFM possui dois picos claros de correntes descendentes, os quais encontram-se quase em fase com os picos de suas correntes ascendentes exibidas na Figura 40.

O dia referente a OND da Figura 41b apresenta as maiores correntes descendentes 
em comparação aos outros dias dessa figura e da Figura 41a. Na Figura 41b, as maiores correntes descendentes ocorrem entre as 15 e 19 UTC. Comparando-se as Figuras 41a e 41b, pode-se observar que os dias ligados aos acumulados de chuva acima da média possuem correntes descendentes mais intensas.

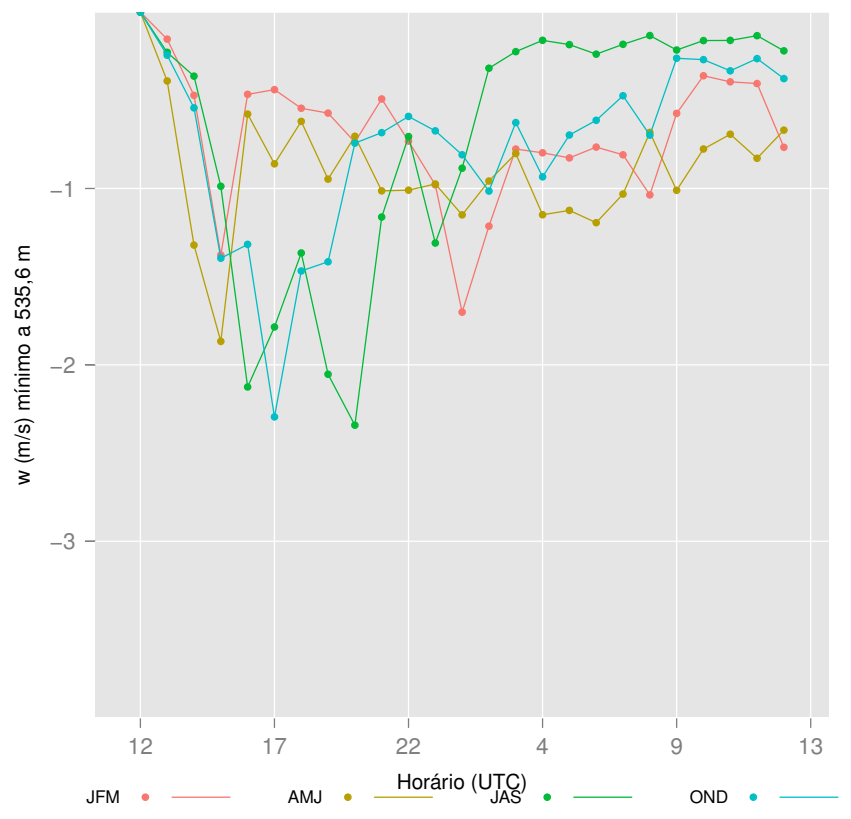

(a)

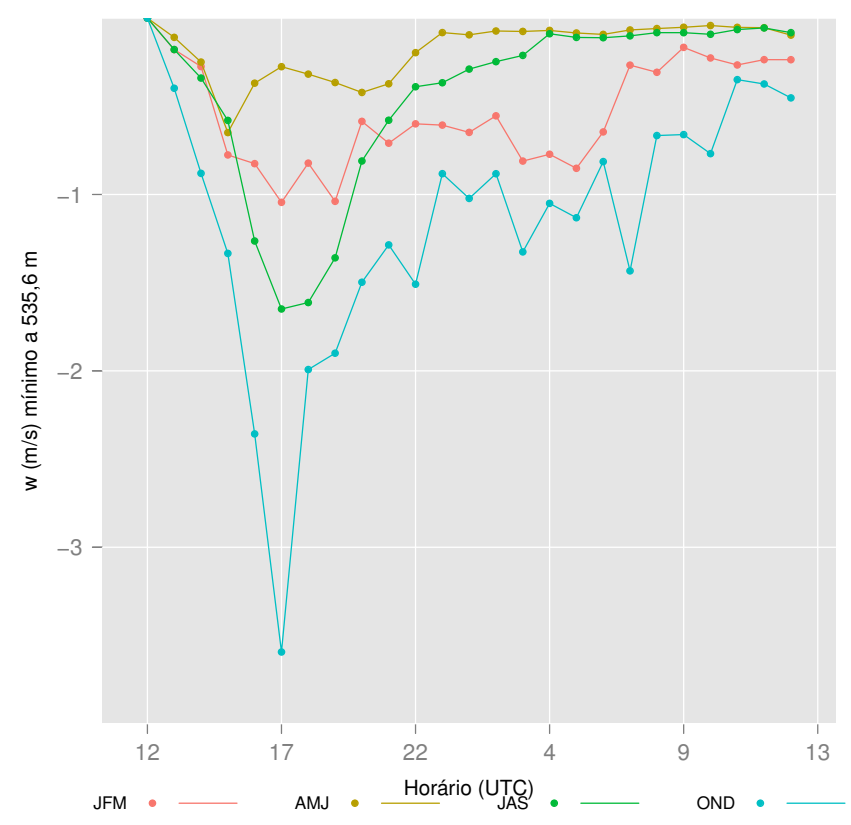

(b)

Figura 41: Velocidade vertical negativa máxima a 535,6 $\mathrm{m}$ da grade 4 para os dias em que o coeficiente de expansão é máximo (a) positivo e (b) negativo.

\subsubsection{Razão de mistura de água líquida e gelo de nuvem}

O somatório das razões de mistura de água líquida e gelo de nuvem totais da grade 4 para cada nível vertical e passo de tempo são mostrados na Figura 42 para os dias com os coeficientes de expansão de $e_{3}$ máximos. A convecção inicia mais cedo em (c) e (d), sendo mais vigorosa desde o seu início, estendendo-se durante as 24 horas de simulação. Percebe-se convecção profunda em (a), (c) e (d), nas quais a razão de mistura de água líquida e gelo existem até os níveis mais altos. A convecção começa a ser mais profunda a partir das 22 UTC para (a) e (c) e às 20 UTC em (d).

Em (c) e (d), nas quais o modelo gerou mais chuva, há valores altos de razão de mistura de água líquida e gelo desde o início da convecção. Esses máximos de razão de mistura deslocam-se para os níveis mais altos, evidenciando a presença dos movimentos ascendentes, ao passo que em níveis mais baixos surgem outros núcleos de nuvem a partir das 18 UTC, provavelmente gerados pelos os movimentos descendentes da nuvem. Os 
dias relativos a JAS e OND apresentam maior concentração de água de nuvem após as 18 UTC, sendo que em (b) a convecção exibida está associada a uma anomalia negativa de acpcp.

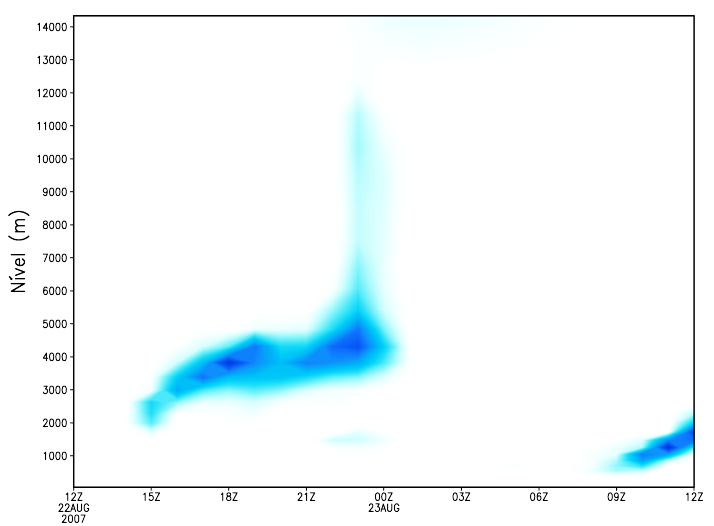

(a)

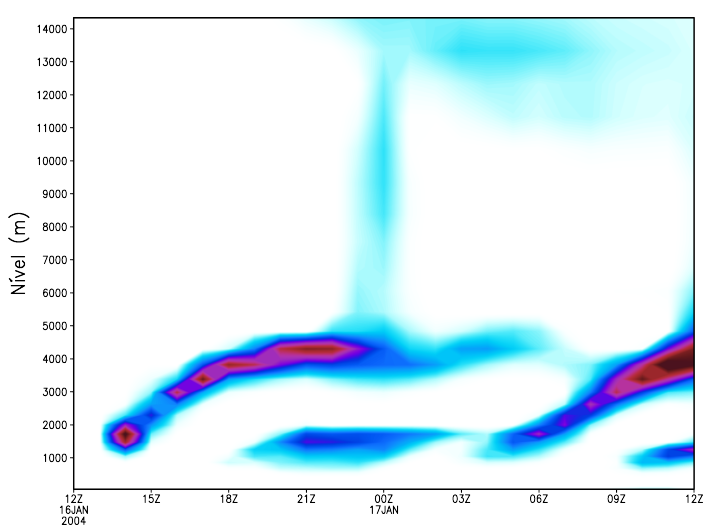

(c)

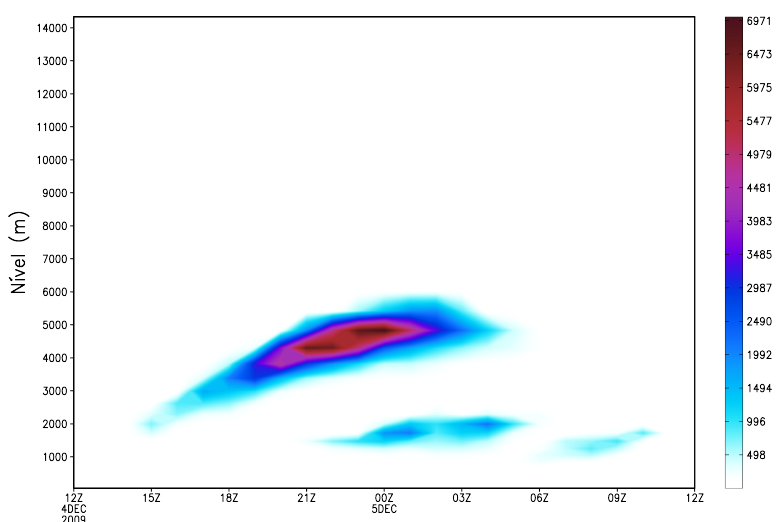

(b)

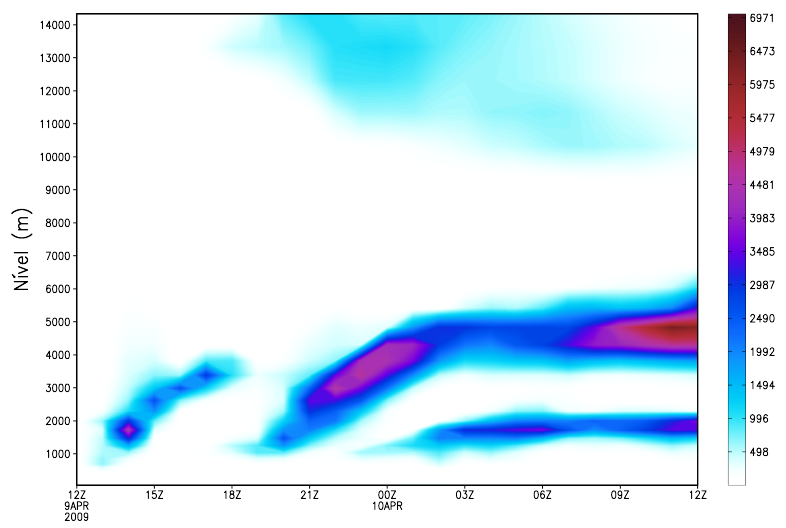

(d)

Figura 42: Somatório das razões de mistura de água líquida e gelo de nuvem totais da grade 4 em cada nível vertical e passo de tempo para os dias em que o coeficiente de expansão é máximo positivo em (a) JAS, (b) OND, (c) JFM e (d) AMJ.

Confeccionou-se a Figura 43 da mesma forma que o gráfico anterior, mas para os dias com o coeficiente de expansão mínimo. Como esperado, os resultados mostraram convecções menos vigorosas do que na Figura 42, exceto para o evento da OND que, neste caso, está relacionado a acumulados de chuva acima da média. Os eventos, como na figura anterior, iniciam-se entre o final da manhã e início da tarde. A Figura 43b apresenta um comportamento similar ao apresentado na Figura 42b, na qual os valores significativos de água de nuvem são registrados apenas no período noturno em torno de $5000 \mathrm{~m}$ de altura. 


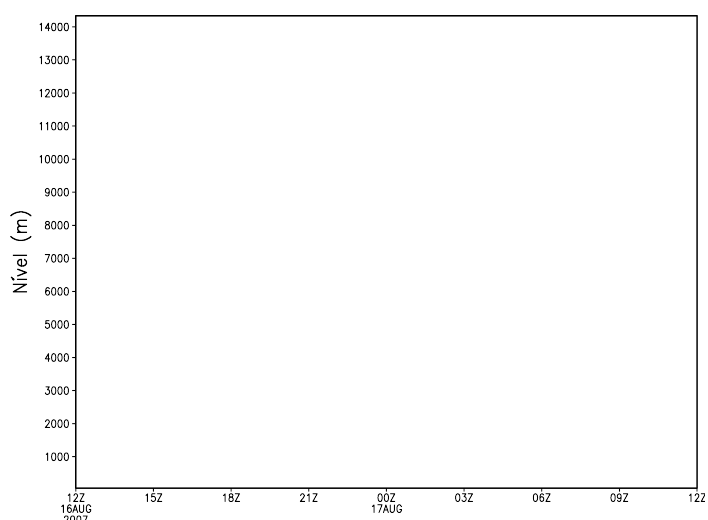

(a)

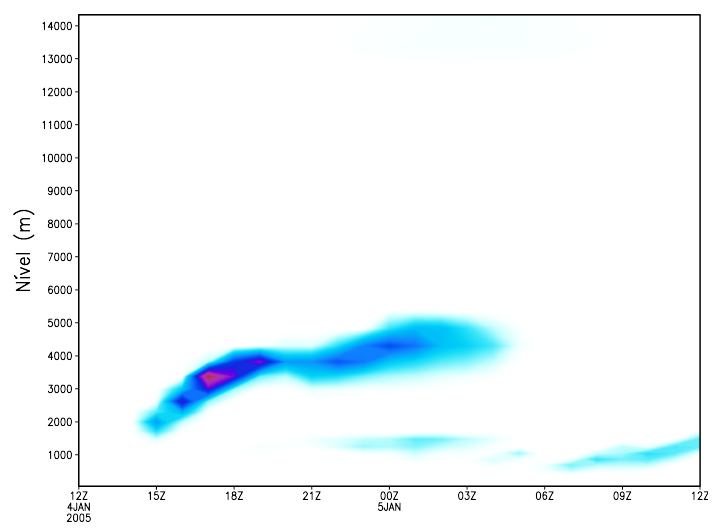

(c)

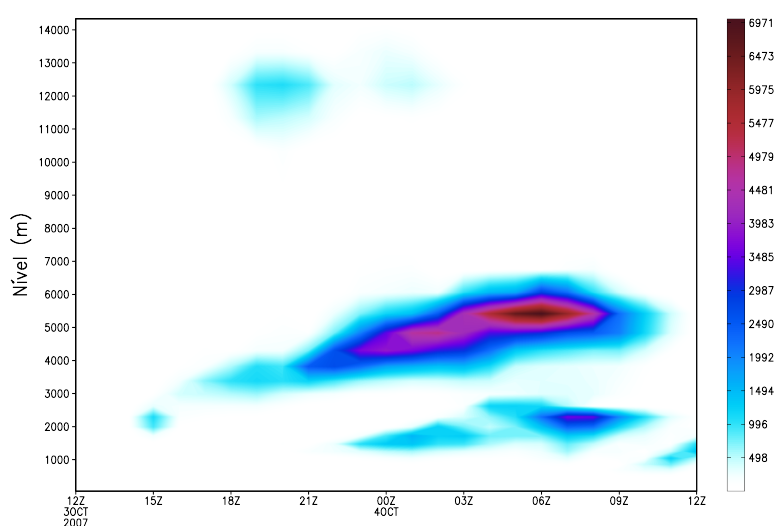

(b)

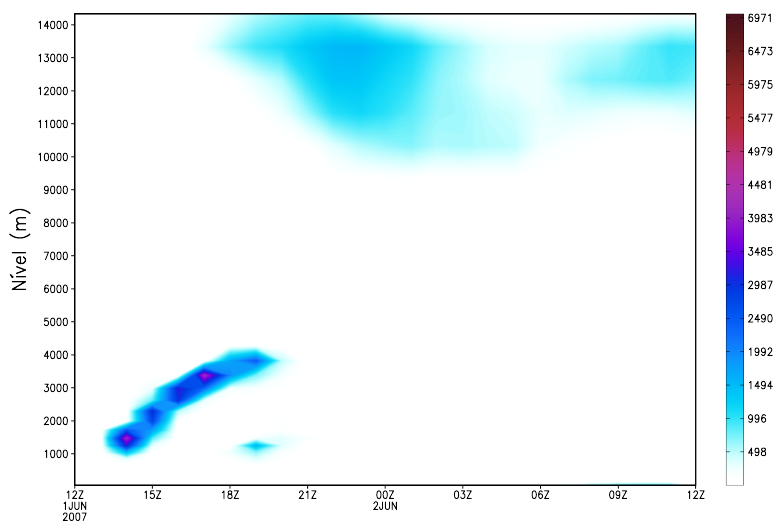

(d)

Figura 43: Somatório das razões de mistura de água líquida e gelo de nuvem totais da grade 4 em cada nível vertical e passo de tempo para os dias em que o coeficiente de expansão é máximo negativo em (a) JAS, (b) OND, (c) JFM e (d) AMJ. 


\section{SUMÁRIO E CONCLUSÕES}

Este trabalho enfocou os extremos de chuva diária em Belém em função da estrutura vertical local da atmosfera. Para isso foram usados os dados de radiossondagem e do TRMM-3B42 e a metodologia das EOF combinadas com intuito de identificar perfis verticais tipicamente associados a extremos de precipitação. Para verificar a relevância dos resultados com as EOF foram feitas uma série de simulações numéricas com o BRAMS enfocando brevemente o vigor da convecção nos casos extremos.

A variância explicada das EOF calculadas a partir das variáveis acpcp, $t, r_{v}, u$ e $v$ apresentou valores muito baixos quando comparada à variância explicada das EOF calculadas a partir de acpcp e $u$. Uma explicação para esse resultado seria de que a temperatura e a umidade não apresentam grandes variações no decorrer do ano, gerando assim anomalias muito próximas de zero. A variância explicada pelos autovetores obtidos através das variáveis acpcp, $u$ e $v$, embora melhor que $[X]$, não apresentaram um bom desempenho quando comparadas a variância explicada dos autovetores da matriz com aсpсp e $u$, provavelmente por $v$ representar uma pequena contribuição ao vento total (ACEITUNO, 1987; ALCÂNTARA et al., 2011).

A terceira EOF foi a que apresentou as maiores anomalias de acpcp em comparação as outras, identificando melhor os extremos chuvosos de cada período do ano. Esse autovetor identificou anomalias de vento muito fracas em todos os níveis calculados, ou seja, $e_{3}$ rastreou dias com ventos próximo à média da série de dados para cada período do ano, exceto para OND.

No período OND, $e_{3}$ revelou um comportamento diferenciado em relação aos outros períodos, na qual oscilou entre anomalias negativas em baixos níveis e altos níveis e positivas em médios níveis para os dias em que o coeficiente de expansão é positivo. Isso significa dizer ventos de leste mais intensos em baixos níveis acompanhados de ventos

de leste (oeste) mais fortes (fracos) em altos níveis e ventos de oeste (leste) mais fortes (fracos) em médios níveis. Essa análise inverte-se completamente para os dias em que a 
série temporal de $e_{3}$ é negativa.

Os padrões de vento encontrados por $e_{3}$ estão associados a anomalias positivas de chuva para os períodos de JFM, AMJ e JAS, para os quais os coeficientes de expansão são positivos e para OND, nos dias em que os coeficientes de expansão são negativos. Quanto maiores forem as anomalias positivas de chuva, maiores tendem a ser os acumulados diários de chuva e, consequentemente, maior é a capacidade da EOF de identificar os extremos chuvosos.

O primeiro e o segundo autovetor estão associados a anomalias de acumulado diário de chuva muito pequenas em comparação a $e_{3}$ e, consequentemente, não identificaram os extremos de chuva tão bem quanto $e_{3}$. Esses autovetores possuem anomalias mais significativas de vento que $e_{3}$, associadas à acumulados de chuva totais para os períodos de JFM, AMJ, JAS e OND menores que os acumulados de chuva totais de $e_{3}$ para anomalias positivas de acpcp. Esse resultado indica que dias com menores anomalias de vento são mais propícios a maiores anomalias de acumulado de chuva em Belém.

Com relação à análise sinótica, observou-se padrões favoráveis a convecção para os dias relativos a acumulados de chuva acima da média e menos favoráveis para os dias relativos a acumulados de chuva abaixo da média, o que era de se esperar. Os dias 16 de janeiro de 2004 e 9 de abril de 2009 foram os que apresentaram os maiores acumulados de chuva, 209,55 e 264,46 mm (acumulados extrapolados a partir dos dados de chuva registrados pelo TRMM), respectivamente. Em ambos os dias, foi verificada a presença da Alta da Bolívia e de um VCAN sobre o Oceano Atlântico, gerando uma região de divergência entre os sistemas, o que favoreceu o intenso desenvolvimento convectivo e a consequente chuva registrada em Belém.

Uma linha de instabilidade foi observada no dia 22 de agosto através das imagens de satélite sobre Belém, onde registrou-se um acumulado de chuva de 101,28 mm. Essa linha de instabilidade, inicialmente, desloca-se para noroeste onde funde-se com uma linha de Cumulonimbus que havia formado-se na costa do Amapá. Por volta das 23:45 UTC, esse sistema deslocou-se rumo a sudoeste devido a presença de um jato em baixos níveis. Esse resultado concorda com o artigo de Alcântara et al. (2011), o qual os autores verificam que na maior parte dos casos de LIA há um jatos em baixos níveis. Este é um caso complexo e exige uma análise mais aprofundada para maior entendimento com dados de radiossondagem de outras regiões afetadas pelo sistema.

Uma perturbação situada entre médios e altos níveis, oriunda de latitudes médias, contribuiu para o acumulado de chuva de 83,93 $\mathrm{mm}$ em Belém no dia 3 de outubro 
de 2007, pois por se tratar de um cavado, favorece os movimentos ascendentes à sua vanguarda. Essa configuração concorda com as anomalias do vento zonal em altos níveis de $e_{3}$ associadas a anomalias positivas de acpcp (coeficiente de expansão mínimo), pois esse sistema provocou uma aceleração do vento sobre a região de interesse.

O BRAMS conseguiu distinguir bem os dias que apresentaram acumulados de chuva acima da média dos dias com acumulados de chuva abaixo da média para o período de dados em questão. Quando comparado com os dados observados de precipitação para os casos identificados por $e_{3}$, o modelo apresentou anomalias de acpcp próximas das anomalias de acpcp do TRMM-3B42. Ou seja, estatisticamente, o modelo possui máximos e mínimos coincidentes com dados observados.

Os dias relativos às anomalias positivas de chuva apresentaram as correntes ascendentes mais fortes em relação aos dias com anomalias negativas de chuva, sendo que em JFM e AMJ houve dois picos de movimento ascendente ao passo que no JAS e OND apenas um pico. Os segundos picos das estações de JFM e AMJ ocorreram durante a noite evidenciando uma intensificação da convecção, contribuindo para o acumulado de chuva registrado.

Para casos associados às anomalias negativas de chuva, observou-se que os dias de JFM e AMJ apresentaram dois picos de correntes ascendentes, enquanto que os dias de JAS e OND apresentaram apenas um pico bem definido, todos associados a formação de células convectivas. Os picos de correntes ascendentes do dia de JFM foram os mais fracos, ao passo que o segundo pico de movimento ascendente foi o mais intenso dentre os quatro casos analisados.

Os picos de corrente ascendente estão relacionados ao desenvolvimento de novas células de tempestade. Essas células convectivas ocasionadas por esse máximo de movimento ascendente, foram as maiores responsáveis pelos acumulados de chuva observados.

Os dias associados a extremos de chuva apresentaram movimentos descendentes mais vigorosos do que os dias com baixos acumulados de chuva. Esses movimentos descendentes foram mais intensos entre 15 e 20 UTC.

Através das simulações numéricas, observou-se convecção profunda nos dias mais chuvosos dos quatro períodos do ano, identificada pelos campos de razão de mistura de água e gelo de nuvem totais. Os dias de JFM e AMJ referentes às anomalias positivas do acumulado de chuva apresentaram forte convecção e, portanto, altas concentrações de água de nuvem durante praticamente toda a simulação e de gelo a partir das 21 UTC. Esse 
resultado justifica a forte chuva registrada pelo TRMM, evidenciando o bom desempenho do BRAMS nas simulações para Belém.

Na sequência deste trabalho, pode-se sugerir que a mesma metodologia seja aplicada para outros locais do Brasil no intuito de identificar a capacidade de detecção de valores extremos de precipitação diária. O uso combinado das EOF para determinação do coeficiente de expansão num determinado dia e as simulações com o BRAMS podem melhorar a capacidade de previsão dos extremos chuvosos.

Uma outra sugestão, é um estudo mais aprofundado do caso de LIA ocorrido em Belém, Pará, no dia 22 de agosto de 2007. Este é um caso bem complexo e, como tal, necessita de mais dados e uma maior atenção para melhor entendimento do fenômeno atmosférico. 


\section{REFERÊNCIAS BIBLIOGRÁFICAS}

ACEITUNO, P. On the functioning of the South Oscillation in the South American Sector. Part I: Surface Climate. Monthly Weather Review, v. 116, p. 505-524, 1987.

AlCÂNTARA, C. R.; SIlva DIAS, M. A. F.; SOUZA, E. P.; COHEN, J. C. P. Verification of the role of the low level jets in Amazon squall lines. Atmospheric Research, v. 100, p. 36-44, 2011.

ALVES, J. M. B.; TEIXEIRA, R. F. B.; FERREIRA, A. G. Um intenso sistema convectivo de mesoescala no setor leste do Nordeste: O caso de 20 a 21 de maio de 1999. Revista Brasileira de Meteorologia, v. 16, p. 19-31, 1999.

BARBOSA, R. L. Interação das perturbações convectivas iniciadas na costa Norte do Brasil com distúrbios ondulatórios de leste. 81 p. Dissertação de Mestrado do Programa de Pós-Graduação em Meteorologia - Instituto Nacional de Pesquisas Espaciais, São José dos Campos, 2005.

CHEN, C.; COTTON, W. The physics of the marine stratocumulus-capped mixed layer. Journal of the Atmospheric Sciences, v. 44, n. 20, p. 2951-2977, 1987.

COHEN, C. A comparison of cumulus parameterizations in idealized sea-breeze simulations. Monthly Weather Review, v. 130, n. 11, p. 2554-2571, 2002.

COHEN, J. Um estudo observacional de linhas de instabilidade na Amazônia. 153 p. Dissertação de Mestrado do Programa de Pós-Graduação em Meteorologia Instituto Nacional de Pesquisas Espaciais, São José dos Campos, 1989.

COHEN, J. C. P.; SILVA DIAS, M. A. F.; NOBRE, A. N. Environmental conditions associated with amazonian squall lines: A case study. Monthly Weather Review, v. 123 , p. $3163-3174,1995$.

COTTON, W. R.; PIELKE, R. A.; WALKO, R. L.; LISTON, G. E.; TREMBACK, C. J.; JIANG, H.; MCANELLY, R. L.; HARRINGTON, J. Y.; NICHOLLS, M. E.; CARRIO, G. G.; MCFADDEN, J. P. RAMS 2001: Current status and future directions. Meteorology and Atmospheric Physics, v. 82, n. 1, p. 5-29, 2003.

COUTINHO, E. C.; FISCH, G. Distúrbios ondulatórios de leste na região do centro de lançamento de Alcântara-MA. Revista Brasileira de Meteorologia, v. 22, p. 193-203, 2007.

ESPINOZA, E. S. Distúrbios nos ventos de leste no atlântico tropical. 123 p. Dissertação de Mestrado do Programa de Pós-Graduação em Meteorologia — Instituto Nacional de Pesquisas Espaciais, São José dos Campos, 1996.

FREITAS, E. D.; ITIMURA, M. S.; GOUVÊA, M. L.; CABRAL, F. C.; BRANCO, F. V.; VENDRASCO, E. P.; MARTINS, L. D.; FREITAS, S. R.; SILVA DIAS, P. L.; 
PANETTA, J. Aplicações do modelo spm-brams a estudos de planejamento urbano e dipersão de poluentes. In: SOCIEDADE BRASILEIRA DE METEOROLOGIA, 2006, Florianópolis-SC, Brasil. Florianópolis-SC, Brasil: Anais do XIV Congresso Brasileiro de Meteorologia, 2006.

FREITAS, E. D.; MARTINS, L. D.; SILVA DIAS, P. L.; ANDRADE, M. F. A simple photochemical module implemented in rams for tropospheric ozone concentration forecast in the metropolitan area of sao paulo, brazil: Coupling and validation. Atmospheric Environment, v. 39, n. 34, p. 6352-6361, 2005.

FREITAS, S. R.; LONGO, K. M.; SILVA DIAS, M. A. F.; CHATIFIELD, R.; SILVA DIAS, P. L.; ARTAXO, P.; ANDREAE, M.; GRELL, G.; RODRIGUES, L. F.; FAZENDA, A. L.; PANETTA, J. The Coupled Aerosol and Tracer Transport model to the Brazilian developments on the Regional Atmospheric Modeling System (CATT-BRAMS). Part 1: Model description and evaluation. Atmospheric Chemistry and Physics (Online), v. 9, p. 2843-2861, 2009.

GARSTANG, M.; MASSIE, H. L.; HALVERSON, J.; GRECO, S.; SCALA, J. Amazon coastal squall lines. Part I: Structure and kinematics. Monthly Weather Review, v. 122, p. 608-622, 1994.

GRELL, G. A. Prognostic evaluation of assumptions used by cumulus parameterizations. Monthly Weather Review, v. 121, n. 3, p. 764-787, 1993.

HASTENRATH, S.; LAMB, P. Some aspects of circulation and climate over the eastern equatorial Atlantic. Monthly Weather Review, v. 105, p. 1019-1023, 1977.

KOREN, I.; MARTINS, J. V.; REMER, L. A.; AFARGAN, H. Smoke invigoration versus inhibition of clouds over the Amazon. Science, v. 321, n. 5891, p. 946-949, 2008.

KOUSKY, V. E. Diurnal rainfall variation in the northeast Brazil. Monthly Weather Review, v. 108, p. 488-498, 1980.

KOUSKY, V. E.; GAN, M. A. Upper tropospheric cyclonic vortices in the tropical South Atlantic. Tellus, v. 33, n. 6, p. 538-551, 1981.

KOUSKY, V. E.; KAGANO, M. T. A climatological study of the tropospheric circulation over the Amazon region. Acta Amazon, v. 11, n. 4, p. 743-753, 1981.

KOUSKY, V. E.; MOLION, L. C. B. Uma contribuição à climatologia da dinâmica da troposfera sobre a Amazônia. Acta Amazônica, v. 15, p. 311-320, 1985.

KREUELS, R.; FRAEDRICH, K.; RUPRECHT, E. An aerological climatology of South America. Meteorologische Rundschau, v. 28, p. 17-24, 1975.

KUO, H. Radiation fields in maritime stratocumulus. 91 p. Dissertação de mestrado - Department of Atmospheric Science - Colorado State University, Fort Collins, 1983.

LENTERS, J. D.; COOK, K. H. On the origin of the Bolivian high and related circulation features of the South American climate. Journal of the Atmospheric Sciences, v. 54, n. 5, p. 656-678, 1997. 
LONGO, K. M.; FREITAS, S. R.; SILVA DIAS, M. A. F.; SILVA DIAS, P. L. Numerical modelling of the biomass-burning aerosol direct radiative effects on the thermodynamics structure of the atmosphere and convective precipitation. International Conference on Southern Hemisphere Meteorology and Oceanography (ICSHMO), v. 8, p. 283-289, 2006.

MACHADO, L. A. T.; LAURENT, H.; DESSAY, N.; MIRANDA, I. Seasonal and diurnal variability of convection over the Amazonia: A comparison of different vegetation types and large scale forcing. Theoretical and applied climatology, v. 78, n. 1, p. 61-77, 2004.

MAHRER, Y.; PIELKE, R. A. A numerical study of the airflow over irregular terrain. Beiträge zur Physik der Atmosphäre, v. 50, n. 1, p. 98-113, 1977.

MARCELINO, B. C. Análise das oscilações da troposfera na região sudeste do Brasil. 150 p. Dissertação de Mestrado do Programa de Pós-Graduação em Meteorologia - Universidade de São Paulo, São Paulo, 1985.

MARTINS, J. A.; SILVA DIAS, M. A. F.; GONÇALVES, F. L. T. Impact of biomass burning aerosols on precipitation in the Amazon: A modeling case study. Journal of Geophysical Research, v. 114, p. Journal of Geophysical Research, 2009.

MISHRA, S. K.; RAO, V. B.; FRANCHITO, S. H. Genesis of the northeast Brazil upper-tropospheric cyclonic vortex: A primitive equation barotropic instability study. Journal of the Atmospheric Sciences, v. 64, n. 4, p. 1379-1392, 2007.

MOLION, L. C. B. Climatologia Dinâmica da região Amazônica: mecanismos de precipitação. Revista Brasileira de Meteorologia, v. 2, n. 1, p. 107-117, 1987.

NAEGELIN, C. C.; MCCRONE, P. J. The mesoscale forecasting problem: applying the next generation mesoscale forecast. 2006. AFWA/TN-06/001. Disponível em: <http://rammb.cira.colostate.edu/visit/blog/wpcontent/uploads/2008/04$/$ mesoscale_forecast_process.pdf $>$.

PIELKE, R. A.; COTTON, W. R.; WALKO, R. L.; TREMBACK, C. J.; LYONS, W. A.; GRASSO, L. D.; NICHOLLS, M. E.; MORAN, M. D.; WESLEY, D. A.; LEE, T. J.; COPELAND, J. H. A comprehensive meteorological modeling system-RAMS. Meteorology and Atmospheric Physics, v. 49, n. 1, p. 69-91, 1992.

RAMÍREZ, M. C. V.; KAYANO, M. T.; FERREIRA, N. J. Statistical analysis of upper tropospheric vortices in the vicinity of northeast Brazil during the 1980-1989.

Atmósfera, v. 12, n. 2, 1999.

RANDALL, D.; KHAIROUTDINOV, M.; ARAKAWA, A.; GRABOWSKY, W. Breaking the cloud parameterization deadlock. Bulletin of the American Meteorological Society, v. 84, p. 1547-1564, 2003.

REED, R. J.; HOLLINGSWORTH, A.; HECKLEY, W. A.; DELSOL, F. An evaluation of the performance of the ECMWF operational system in analyzing and forecasting easterly wave disturbances over Africa and the tropical Atlantic. Monthly weather review, v. 116, p. 824-865, 1988. 
ROTUNNO, R.; KLEMP, J. B. The influence of the shear-induced pressure gradient on thunderstorm motion. Monthly Weather Review, v. 110, n. 2, p. 136-151, 1982.

SILVA DIAS, P. L.; SHUBERT, W. H.; DEMARIA, M. Large-scale response of tropical atmosphere to transient convection. Journal of the Atmospheric Sciences, v. 40, p. 2689-2707, 1983.

SOUZA, E. P. Estudo teórico e numérico da relação entre convecção e superfícies heterogêneas na região amazônica. 121 p. Tese de Doutorado do Programa de Pós-Graduação em Meteorologia — Universidade de São Paulo, São Paulo, 1999.

SOUZA, E. P.; SILVA, E. M. Impacto da implementação de uma parametrização de convecção rasa em um modelo de mesoescala: Descrição e testes de sensibilidade do esquema. Revista Brasileira de Meteorologia, v. 18, n. 1, p. 33-42, 2003.

SOUZA, P.; CAVALCANTI, I. F. A. Atmospheric centers of action associated with the Atlantic ITCZ position. International Journal of Climatology, v. 29, p. 2091-2195, 2009.

TREMBACK, C. J. Numerical simulation of a mesoscale convective complex: Model development and numerical results. 247 p. Tese de Doutorado - Department of Atmospheric Science — Colorado State University, Fort Collins, 1990.

TRIPOLI, G. J.; COTTON, W. R. The Colorado State University three-dimensional cloud mesoscale model - 1982. Part I: General theoretical framework and sensitivity. Journal de Recherches Atmospheriques, v. 16, p. 185-220, 1982.

UVO, C. B.; NOBRE, C. A. A Zona de Convergência Intertropical (ZCIT) e a precipitação no norte do Nordeste do Brasil. Parte I: A posição da ZCIT no Atlântico equatorial. Climanálise, São José dos Campos, v. 4, n. 7, p. 34-42, 1989.

VIRJI, H. A preliminary study of summertime tropospheric circulation patterns over South America estimated from cloud winds. Monthly Weather Review, v. 109, p. 599-610, 1981.

WALKO, R. L.; BAND, L. E.; BARON, J.; KITTEL, T. G. F.; LAMMERS, R.; LEE, T. J.; OJIMA, D.; PIELKE, R. A.; TAYLOR, C.; TAGUE, C.; TREMBACK, C. J.; VIDALE, P. L. Coupled atmosphere-biophysics-hydrology models for environmental modeling. Journal of Applied Meteorology, v. 39, n. 6, p. 931-944, 2000.

WALKO, R. L.; TREMBACK, C. J. Modifications for the Transition From LEAF-2 to LEAF-3. ATMET technical note (disponível em www.atmet.com), 2005.

WILKS, D. S. Statistical methods in the atmospheric sciences. Second. Burlington: Academic press, Elsevier, 2006. 610 p.

XAVIER, T. M. B. S.; SILVA, J. F.; REBELlO, E. R. G. A Técnica dos Quantis e suas Aplicações em Meteorologia, Climatologia e Hidrologia, com ênfase para as Regiões Brasileiras. First. Brasília: Thesaurus, 2002. 140 p. 